August $2000 \quad$ • NREL/SR-500-28473

\title{
NREL Advanced Research Turbine (ART) Aerodynamic Design of ART-2B Rotor Blades
}

Dayton A. Griffin

Global Energy Concepts, LLC

Kirkland, Washington

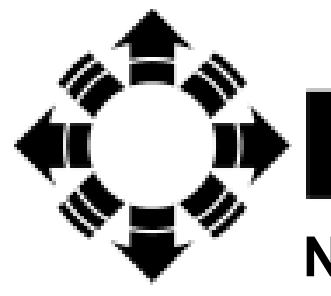

National Renewable Energy Laboratory

1617 Cole Boulevard

Golden, Colorado 80401-3393

NREL is a U.S. Department of Energy Laboratory

Operated by Midwest Research Institute • Battelle • Bechtel

Contract No. DE-AC36-99-G010337 


August $2000 \quad \cdots \quad$ NREL/SR-500-28473

NREL Advanced Research
Turbine (ART) Aerodynamic
Design of ART-2B Rotor Blades

Dayton A. Griffin

Global Energy Concepts, LLC

Kirkland, Washington

NREL Technical Monitor: Alan Laxson

Prepared under Subcontract No. VAM-8-18208-01

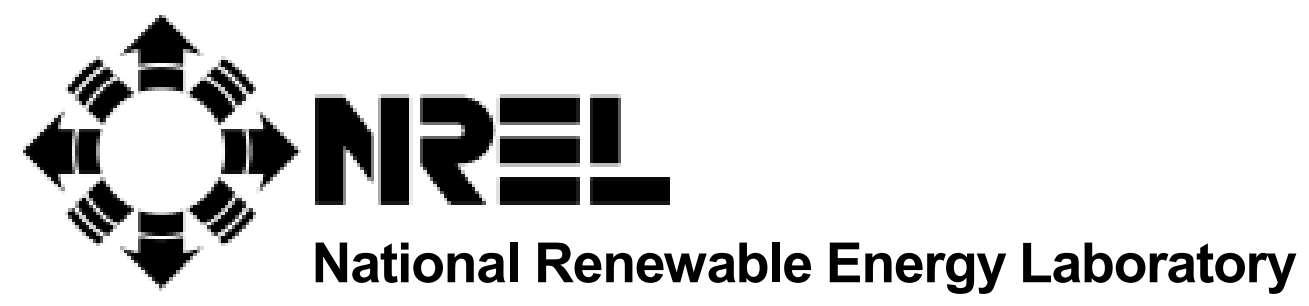

1617 Cole Boulevard

Golden, Colorado 80401-3393

NREL is a U.S. Department of Energy Laboratory

Operated by Midwest Research Institute $\bullet$ Battelle $\bullet$ Bechtel

Contract No. DE-AC36-99-G010337 


\section{NOTICE}

This report was prepared as an account of work sponsored by an agency of the United States government. Neither the United States government nor any agency thereof, nor any of their employees, makes any warranty, express or implied, or assumes any legal liability or responsibility for the accuracy, completeness, or usefulness of any information, apparatus, product, or process disclosed, or represents that its use would not infringe privately owned rights. Reference herein to any specific commercial product, process, or service by trade name, trademark, manufacturer, or otherwise does not necessarily constitute or imply its endorsement, recommendation, or favoring by the United States government or any agency thereof. The views and opinions of authors expressed herein do not necessarily state or reflect those of the United States government or any agency thereof.

Available electronically at http://www.doe.gov/bridge

Available for a processing fee to U.S. Department of Energy

and its contractors, in paper, from:

U.S. Department of Energy

Office of Scientific and Technical Information

P.O. Box 62

Oak Ridge, TN 37831-0062

phone: 865.576.8401

fax: 865.576.5728

email: reports@adonis.osti.gov

Available for sale to the public, in paper, from:

U.S. Department of Commerce

National Technical Information Service

5285 Port Royal Road

Springfield, VA 22161

phone: 800.553.6847

fax: 703.605.6900

email: orders@ntis.fedworld.gov

online ordering: http://www.ntis.gov/ordering.htm

Printed on paper containing at least $50 \%$ wastepaper, including $20 \%$ postconsumer waste 


\section{Table of Contents}

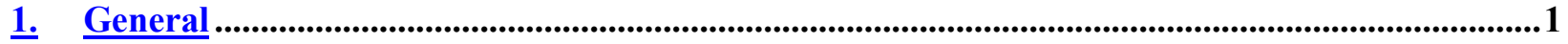

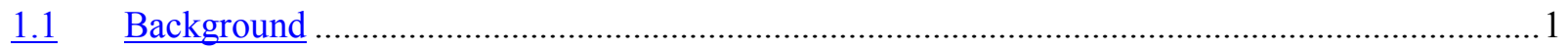

1.2 Purpose

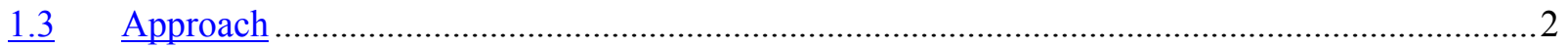

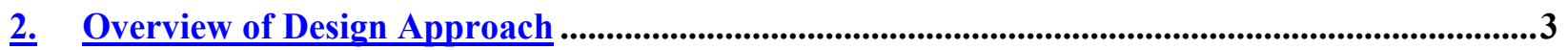

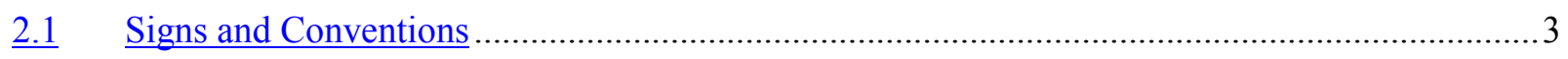

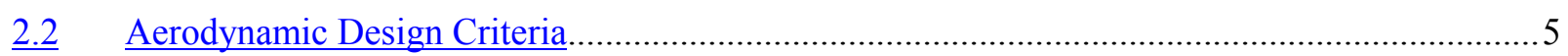

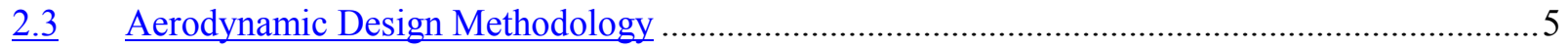

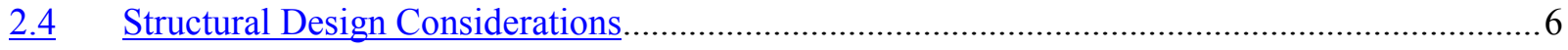

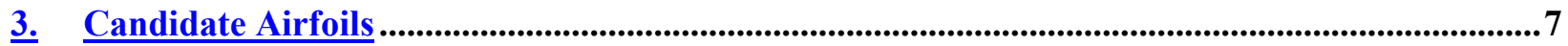

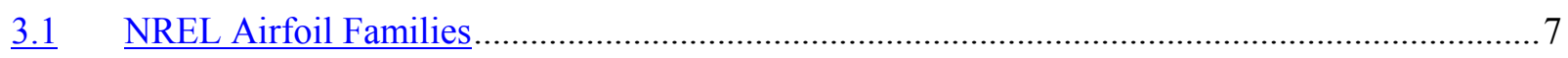

3.2 Eppler Calculations of Airfoil Properties .............................................................................. 7

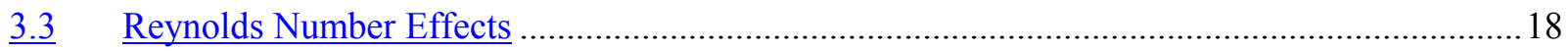

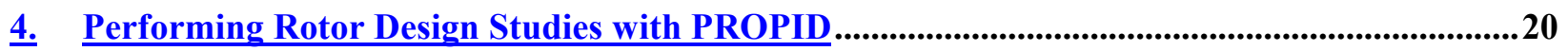

4.1 Design Process for Near-Optimal Variable-Speed Performance ...............................................20

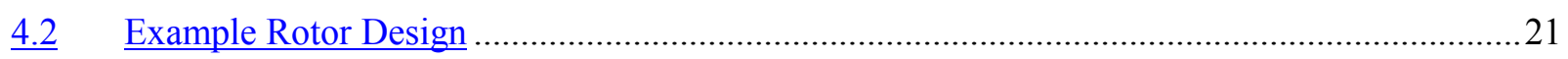

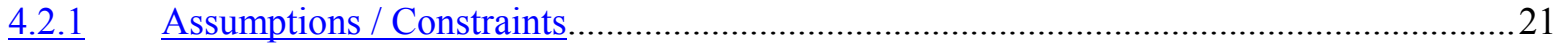

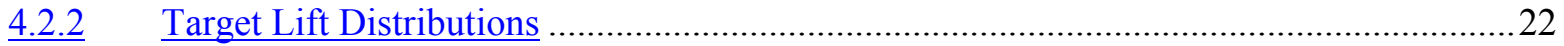

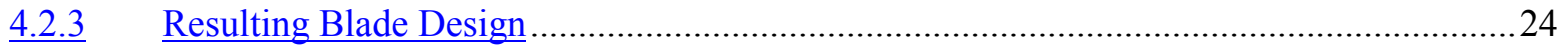

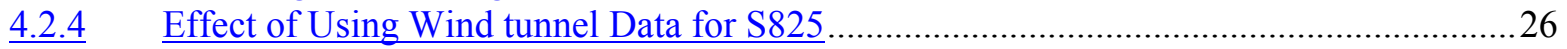

5. Evaluation of Candidate Airfoil Families .......................................................................................................28

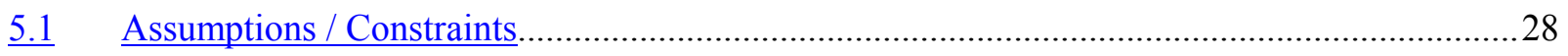

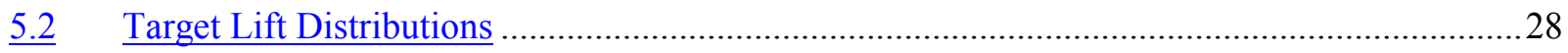

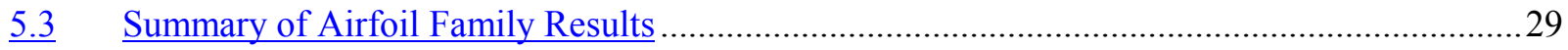

6. Sweep of Design TSR for Blade Using S818/825/826 Airfoils ......................................................33

7. Detailed Aerodynamic Design .....................................................................................................................36

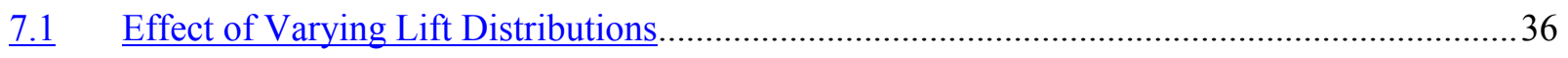

7.2 Performance Losses Due to Imposed Design Details .............................................................37

7.3 Comparison of Power Performance with ART-1 and ART-2A Rotors ….................................39

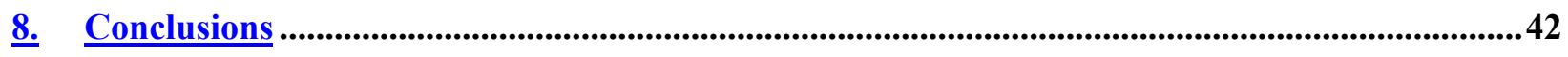

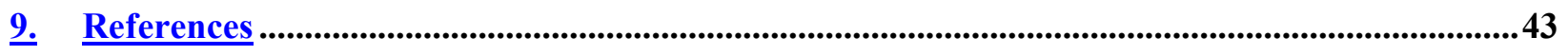

Appendix A Summary of Archived Electronic Files ............................................................................ A-1

Appendix B Example PROPID Input File for Rotor Design and Analysis .................................... B-1 


\section{List of Figures}

Figure 1. Blade planform viewed facing downwind ...........................................................................

Figure 2. Relationship between global and local blade coordinates (viewed from root to tip) ..................4

Figure 3. Blade airfoil section in local coordinates (viewed from root-to-tip) ........................................ 4

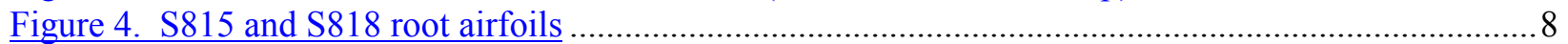

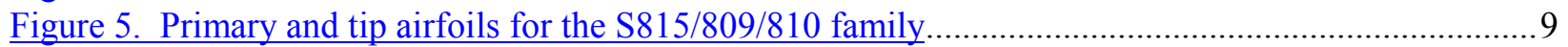

Figure 6. Primary and tip airfoils for the $\mathrm{S} 818 / 825 / 826$ family...................................................... 10

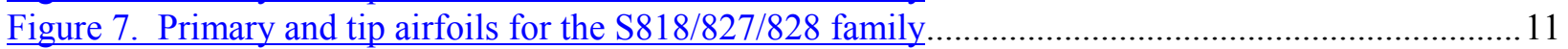

Figure 8. Aerodynamic curves for the S815/809/810 airfoil family ...................................................... 12

Figure 9. Aerodynamic curves for the S818/825/826 airfoil family ............................................... 13

Figure 10. Aerodynamic curves for the S818/827/828 airfoil family................................................... 14

Figure 11. Comparison of Eppler calculations with Delft wind tunnel data for S809............................16

Figure 12. Comparison of Eppler calculations with LTPT wind tunnel data for S825 ….....................17

Figure 13. Blade Reynolds number for ART-2A (variable-speed ART-1) ............................................ 18

Figure 14. Reynolds number effects for S818/825/826 airfoil family ...................................................19

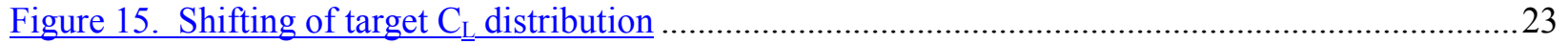

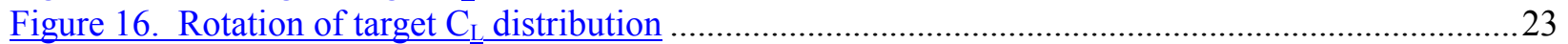

Figure 17. Variation of $\mathrm{C}_{\mathrm{Pmax}}$ because of shifting of target $\mathrm{C}_{\mathrm{L}}$ distribution .........................................24

Figure 18. PROPID planform for near-optimal rotor (S818/825/826 at design TSR $=8$ ).....................25

Figure 19. PROPID twist distribution for near-optimal rotor $(\mathrm{S} 818 / 825 / 826$ at design TSR $=8) \ldots \ldots \ldots \ldots . .25$

Figure 20. PROPID planforms for S818/825/826 blade, measured versus Eppler S285 data ..................27

Figure 21. PROPID twist distributions for S818/825/826 blade, measured versus Eppler S285 data ......27

Figure 22. PROPID near-optimal planforms for candidate airfoil families.......................................... 30

Figure 23. Calculated thrust versus power for candidate airfoil families ................................................ 31

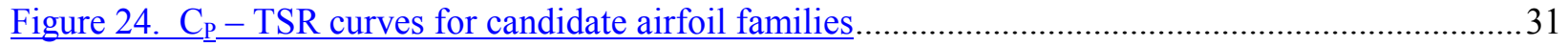

Figure 25. Thrust versus power for S818/825/826 blades at varying design TSR .................................34

Figure 26. RPM Schedule for optimal VS operation at varying design TSR .........................................34

Figure 27. $\mathrm{C}_{\mathrm{P}}$-TSR curves for near-optimal S818/825/826 blades ….................................................35

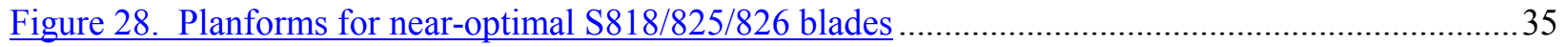

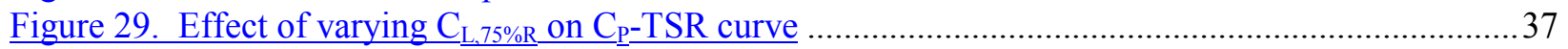

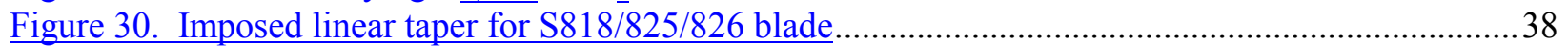

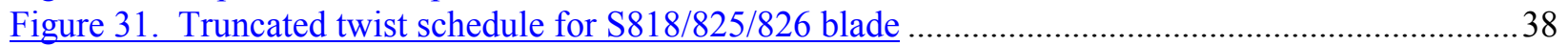

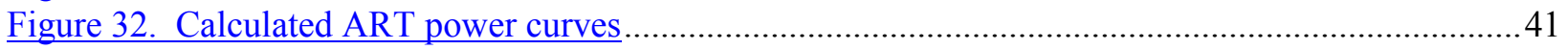

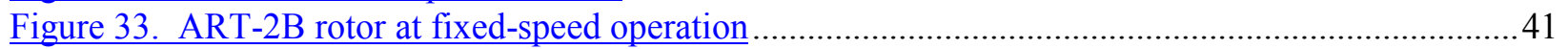

\section{List of Tables}

Table 1. Summary of Design Parameters for NREL S-Series Airfoils ................................................. 15

Table 2. Baseline Target $\mathrm{C}_{\underline{L}}$ Distribution for S818/825/826 Airfoil Family .........................................22

Table 3. Baseline Target $C_{L}$ Distribution for S818/825/826 Airfoils using Measured S825 Data............26

Table 4. Baseline Target $C_{L}$ Distribution for S818/827/828 Airfoil Family .........................................28

Table 5. Baseline Target $C_{L}$ Distribution for S815/809/810 Airfoil Family ..........................................28

Table 6. Near-Optimal Rotor Designs for Candidate Airfoil Families....................................................29

Table 7. Summary of Rotor Designs for Candidate Airfoil Families .......................................................32

Table 8. Summary Results for Study of Design TSR, S818/825/826 Blades ..........................................33

Table 9. Summary Effects of Varying $\mathrm{C}_{\mathrm{L}, 75 \% \mathrm{R}}$ for S818/825/826 Blade at Design TSR $=8$....................36

Table 10. Effect of Design Details on S818/825/826 Blade ................................................................39

Table 11. Blade Geometry for S818/825/826 with Aerodynamic Design Details....................................39

Table 12. AEP Calculations for ART Rotor Power Curves......................................................................40 


\section{General}

\subsection{Background}

As a part of its Advanced Research Program, the National Renewable Energy Laboratory (NREL) installed two new Advanced Research Turbines (ART). The ART turbines are being used by NREL as full-scale test beds for ongoing research efforts, including three-dimensional blade aerodynamics and the effects of various control methods on turbine loads and performance. The Westinghouse WWG-0600 was selected as a baseline configuration for the ART turbines because of its scale, robust design, and well-known operational history.

The Westinghouse WWG-0600 is a 600-kilowatt (kW), two-bladed upwind turbine with a teetering hub and full-span blade pitch control. The first turbine NREL installed, designated ART-1, at the National Wind Technology Center (NWTC) near Boulder, Colorado, is currently operational and has been used to collect a baseline set of performance and loads data.

A second turbine, designated ART-2A, was installed on a neighboring site at the NWTC. The ART-2A turbine is also a WWG-0600 but incorporates several major modifications:

1. A new hub was installed with independent electromechanical blade pitch systems replacing the original hydraulic pitch system.

2. An induction generator with a variable-speed drive replaced the synchronous generator and fluid coupling.

3. The original controller was replaced by a PC-based integrated control and data acquisition system.

This second turbine may be upgraded further to a configuration designated ART-2B. Possible features of the ART-2B turbine include a multi-degree of freedom hub and newly designed rotor blades.

Global Energy Concepts, L.L.C. (GEC, formerly Kamzin Technology, Inc.) provided engineering support to NREL in designing the components for the ART-2B turbine. The current document provides a summary of work performed by GEC on the aerodynamic design of ART-2B rotor blades.

\subsection{Purpose}

The purpose of this report is to summarize the aerodynamic design work performed for the ART-2B rotor and to formally document both the process used and the results obtained. 


\subsection{Approach}

The ART-2B turbine is intended to support the ongoing research efforts of NREL's Advanced Research Program. The ART-2B blade design is, therefore, not intended to be commercially competitive but rather to reflect state-of-the-art aerodynamic performance. As such, the aerodynamic design objectives were given first priority in this process, and structural design aspects were considered secondary.

The aerodynamic design of the ART-2B rotor blades was optimized for variable-speed, variable-pitch operation, with peak rotor power coefficients $\left(\mathrm{C}_{\mathrm{P}}\right)$ as high as possible. Design studies were performed to investigate various airfoil families, design tip-speed ratios(TSR), and other design considerations. Specifically, the design studies included:

- An evaluation of three NREL S-series airfoil families

- S818/825/826

- S818/827/828

- S815/809/810.

- For the S818/825/826 airfoil family, a sweep of design TSR was conducted.

- For the S818/825/826 airfoil family at design TSR =8, the detailed aerodynamic design was considered, including an evaluation of performance losses because of imposed design details.

For each airfoil design considered, a near-optimal blade geometry was determined, with calculated annual energy production (AEP) used as the primary figure of merit. Structural efficiency (strength, cost, and weight) were addressed qualitatively through consideration of the resulting blade dimensions. For selected cases, the effects of design variations on operating rotor thrust and peak ( 50 -year) blade bending loads were evaluated. 


\section{Overview of Design Approach}

\subsection{Signs and Conventions}

Some basic blade terminology, signs, and conventions are defined in Figures 1 through 3. A generator line (z-axis) is defined that is perpendicular to the plane of the blade root. A global blade coordinate system is defined with $\mathrm{x}$ and $\mathrm{y}$ axes lying in the plane of the blade root.

The blade shape is then described as a series of airfoil sections along the blade span. At each spanwise station, local coordinates $\left(\mathrm{x}^{\prime}-\mathrm{y}^{\prime}\right)$ are introduced as indicated in Figure 2. The local coordinate system is related to the global blade coordinates by a translation in the $x-y$ plane followed by a rotation equal to the local blade twist angle. Each blade section is then defined by its $x^{\prime}-y^{\prime}$ coordinates, with the leading edge at the local origin, and the local section chord coincident with the $y^{\prime}$-axis.

In the present work, each blade aerodynamic design is described and analyzed in terms of its spanwise schedule of airfoil shapes, chord lengths and twist angles. The aerodynamic designs will frequently be presented and discussed in non-dimensional combinations of the dimensions and parameters shown in Figures 1 through 3 (i.e., $r / R, c / R, x^{\prime} / c, y^{\prime} / c$ ).

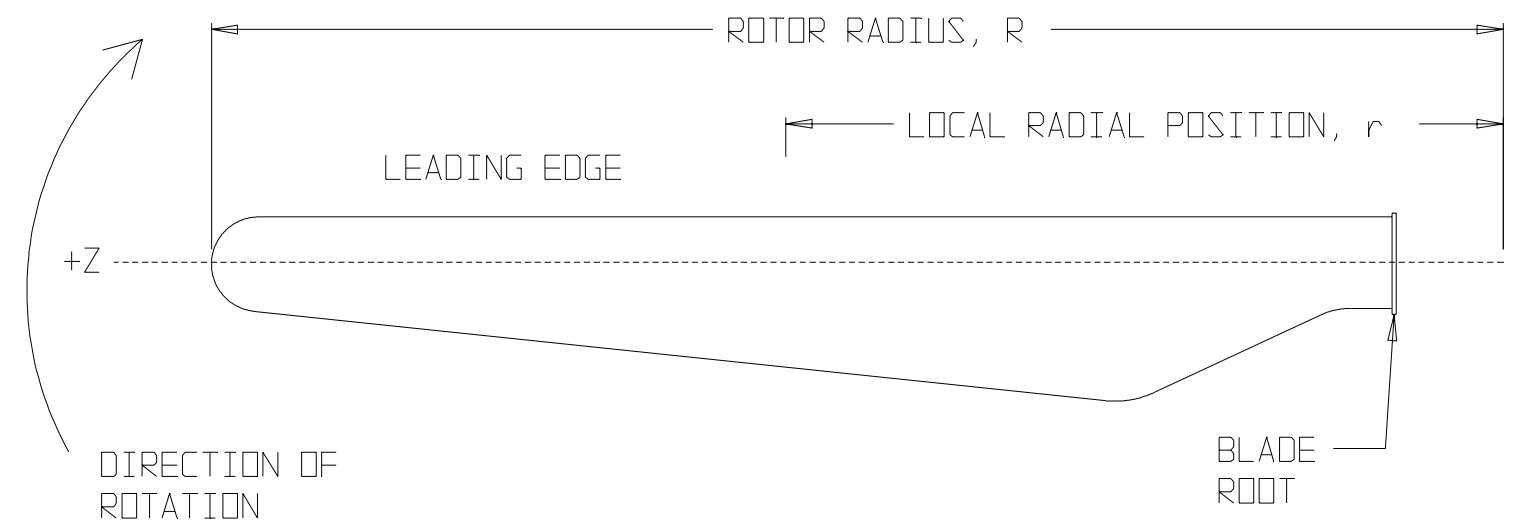

Figure 1. Blade planform viewed facing downwind 


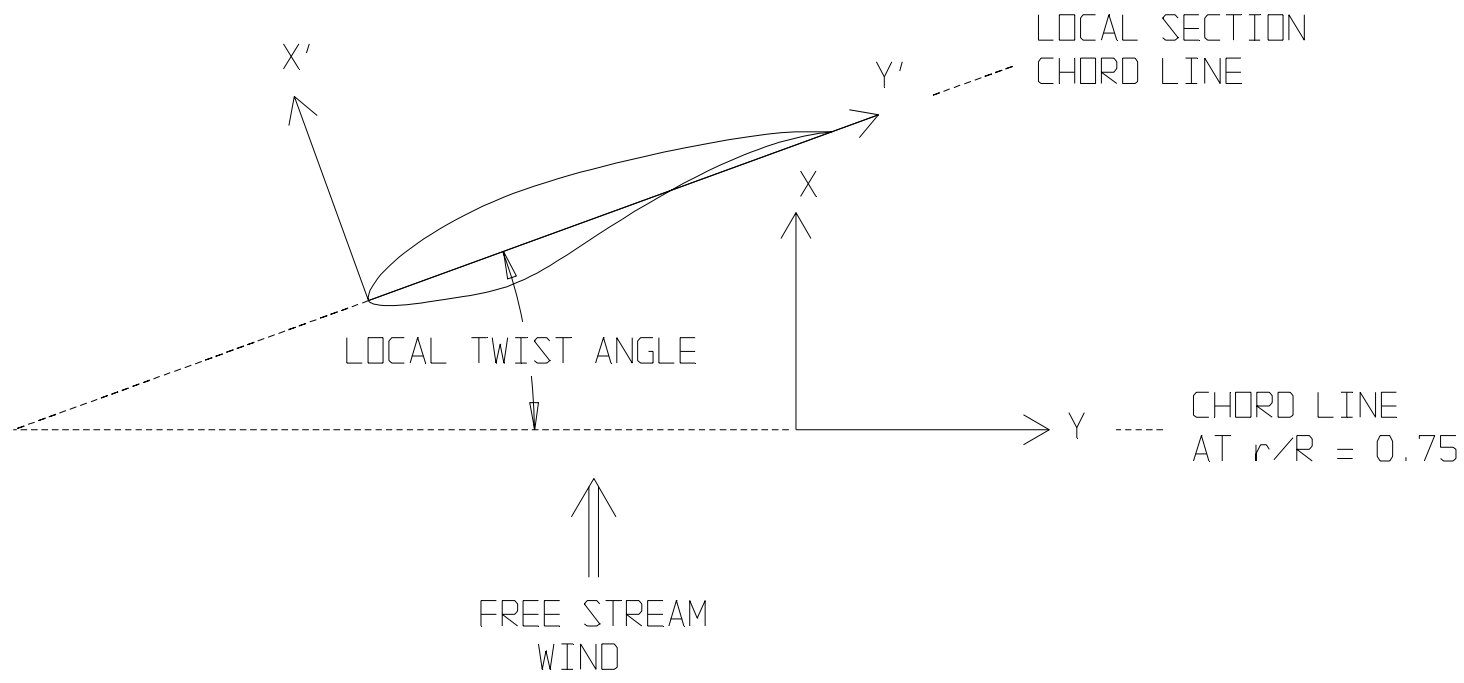

Figure 2. Relationship between global and local blade coordinates (viewed from root to tip)

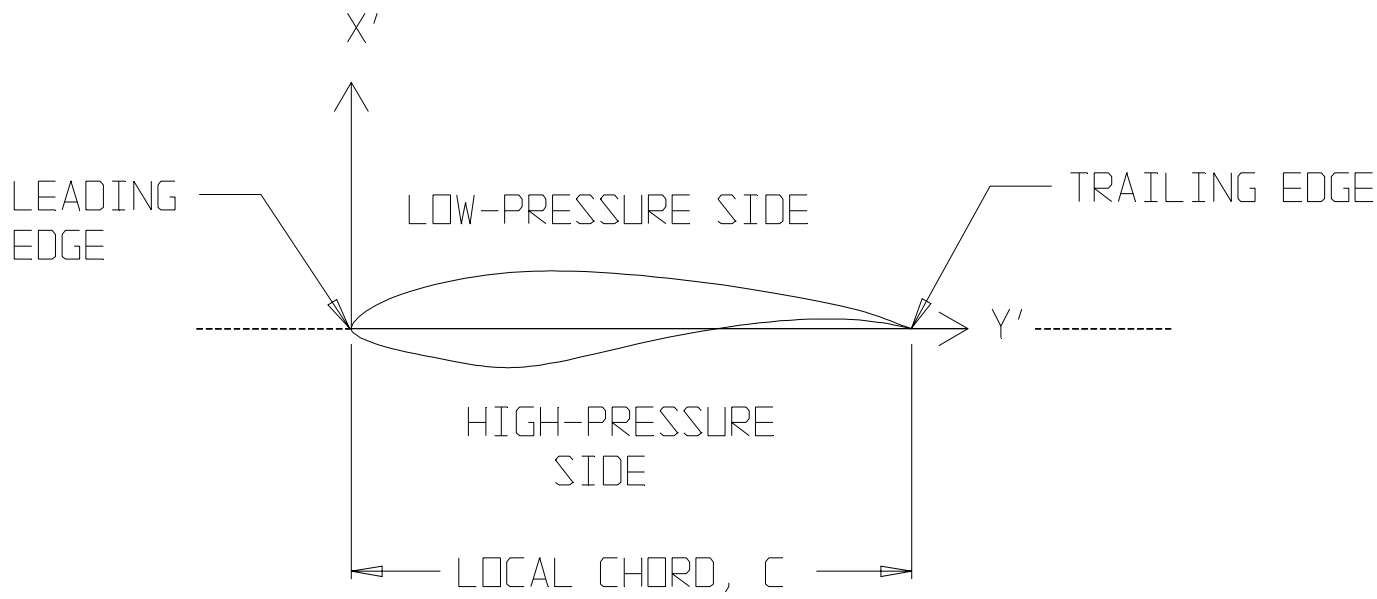

Figure 3. Blade airfoil section in local coordinates (viewed from root-to-tip) 


\subsection{Aerodynamic Design Criteria}

The aerodynamic designs for the ART-2B rotors were developed to optimize power performance for variable-speed, variable-pitch operation. This implies that each rotor is designed to maximize peak rotor power coefficients $\left(\mathrm{C}_{\mathrm{Pmax}}\right)$. In making AEP calculations, the rotors were assumed to maintain peak $\mathrm{C}_{\mathrm{P}}$ for all wind speeds up to rated power. The designs were subject to the following constraints:

- $\quad$ Rated power $=600 \mathrm{~kW}$, independent of air density

- $\quad$ Rotor radius $=21.34$ meters $(\mathrm{m}),[70$ feet $(\mathrm{ft})]$

- Hub radius (to blade root) $=1.38 \mathrm{~m},[54.4$ inches (in.) $]$

- $\quad$ Root chord $=1.14 \mathrm{~m}$ (45 in.)

- Rotor speed range (low speed shaft) $=$ zero to 45 revolutions per minute $(\mathrm{rpm})$

- Number of blades $=2$

- $\quad$ Rotation $=$ clockwise when viewed facing downwind

\subsection{Aerodynamic Design Methodology}

The ART-2B blade design was conducted using the NREL S-series of airfoils [Ref. 1]. In particular, the design and analysis focused on three families of airfoils that were designed for high Reynolds number $(\mathrm{Re})$. Note that throughout this report, the full designation will be used when referencing a single airfoil (i.e., the S825 airfoil), however for brevity only the first "S" will be used when discussing complete airfoil families (i.e., the S818/825/826 family).

The aerodynamic properties of the candidate airfoils (lift and drag curves) were calculated using the Eppler Airfoil Design and Analysis Code [Ref. 2], with the calculations validated using wind tunnel data as available [Refs. 3 and 4]. Once the aerodynamic properties were developed, several design studies were performed, including:

- An evaluation of the three NREL S-series airfoil families

- S818/825/826

- $\mathrm{S} 818 / 827 / 828$

- S815/809/810.

- For the S818/825/826 airfoil family, a sweep of design TSR was conducted.

- For the S818/825/826 airfoil family at design TSR $=8$, the detailed aerodynamic design was considered, including an evaluation of performance losses due to imposed design details.

For each airfoil design considered, a near-optimal blade geometry was determined. With airfoils and design tip-speed selected, and the blade radius constrained, the primary design variables remaining are distributions of local chord and twist. The blade designs were performed using the PROPID computer code [Ref. 5].

The primary figure of merit for aerodynamic performance was the calculated annual energy production. The AEP calculations were performed within PROPID according to the methods presented in Reference 6 . The calculations were based on generator power versus wind-speed curves, assuming a constant drivetrain efficiency of $90 \%$, no soiling or array losses, and $100 \%$ availability. The AEP calculations used a Weibull wind distribution with shape factor $k=1.7$, annual average wind speed of 7.5 meters per second $(\mathrm{m} / \mathrm{s})$ at hub-height, and an air density of 1.03 kilograms per meter cubed $\left(\mathrm{kg} / \mathrm{m}^{3}\right)$. Because all of 
the designs resulting from this study reached rated power at or before $12 \mathrm{~m} / \mathrm{s}$ wind speed, the majority of the comparative AEP calculations in this report have been performed excluding wind speeds above $12 \mathrm{~m} / \mathrm{s}$.

\subsection{Structural Design Considerations}

As discussed earlier, the aerodynamic design objectives were given first priority in this process, with structural design aspects considered as secondary. Although no rigorous studies were conducted to tradeoff aerodynamic performance against blade cost and weight, structural efficiency has been addressed qualitatively through consideration of blade dimensions.

For selected cases, the effect of design variations on operating rotor thrust and peak (50-year) blade bending loads has been evaluated. All bending loads are reported in kilo Newton-meters $(\mathrm{kN}-\mathrm{m})$. For peak bending loads, a 50 -year extreme gust of $70 \mathrm{~m} / \mathrm{s}$ was used according to a Class I wind regime per the International Electrotechnical Commission 61400-1 standard [Ref. 7]. Air density of $1.03 \mathrm{~kg} / \mathrm{m}^{3}$ was used for all aerodynamic calculations, including the peak bending loads. A drag coefficient of 1.8 was used for making the bending load calculations, and the full planform was assumed to be loaded (i.e., blades in full power-production position with no reduction in loaded area due to twist and pitch). Although these assumptions are somewhat conservative, the calculations are only presented for comparative purposes. Finally, it should be noted that no load partial safety factors have been applied to either the thrust or peak bending loads presented herein. 


\section{Candidate Airfoils}

\subsection{NREL Airfoil Families}

The ART-2B blade design was conducted using the NREL S-series of airfoils. In particular, the process focused on the following three families of airfoils that were designed for high Reynolds number:

- $\mathrm{S} 818 / 825 / 826$

- $\mathrm{S} 818 / 827 / 828$

- $\mathrm{S} 815 / 809 / 810$

The root airfoils for these families (S815 and 818) are depicted in Figure 4. The primary (75\% span) and tip (95\% span) airfoils for each family are presented in Figures 5-7. In all cases the airfoil coordinates and maximum thickness are shown as normalized to the airfoil chord $\left(\mathrm{x}^{\prime} / \mathrm{c}, \mathrm{y}^{\prime} / \mathrm{c}\right.$ and $\mathrm{t} / \mathrm{c}$, expressed as a percentage). As seen in the figures, the S818/825/826 family is the thinnest and most highly cambered.

\subsection{Eppler Calculations of Airfoil Properties}

The aerodynamic properties of the candidate airfoils (lift and drag curves) were calculated using the Eppler Airfoil Design and Analysis Code, with the calculations validated using wind tunnel data as available. The lift and drag data are presented in coefficient form $\left(\mathrm{C}_{\mathrm{L}}\right.$ and $\left.\mathrm{C}_{\mathrm{D}}\right)$. In preparing the Eppler data for input into the PROPID code, the lift curves for all airfoils were flat-lined for all angles of attack (AOA) above maximum lift coefficient $\left(\mathrm{C}_{\mathrm{Lmax}}\right)$. This was done for convenience, and allowed the PROPID inverse design process to run more robustly. As will be illustrated in the following discussions, the aerodynamic data above $C_{\text {Lmax }}$ is of no consequence to the aerodynamic design of variable-speed rotors with active power control.

Figure 8 shows the calculated aerodynamic properties for the S815/809/810 family. Note that the root airfoil (S815) shows markedly different lift characteristics than the primary and tip airfoils (S809 and $\mathrm{S} 810$ ). The outboard airfoils were designed for low $\mathrm{C}_{\mathrm{Lmax}}$, whereas no attempt was made to restrain $\mathrm{C}_{\mathrm{Lmax}}$ for the root airfoil. Inspection of the airfoil shapes (Figures 4 and 5) shows that the S815 also has significantly more camber than the S809 and S810 airfoils, and this distinction is evident by the offset in zero-lift angles between the root and the outboard airfoils. Figure 8 also shows the lift/drag (L/D) curve for the S815/809/810 family. Comparison with the lift curve shows that maximum lift $/ \mathrm{drag}\left(\mathrm{L} / \mathrm{D}_{\max }\right)$ occurs at an earlier angle of attack than $\mathrm{C}_{\mathrm{Lmax}}$, which holds true for all airfoils considered.

Figure 9 shows the aerodynamic properties for the S818/825/826 family. All three airfoils have been designed for high $\mathrm{C}_{\mathrm{Lmax}}$, and the lift curves for the airfoils are similar in both zero lift angle and magnitude of $C_{L \text { max }}$. The $L / D$ curves show a well-behaved trend of increasing $L / D_{\max }$ with decreasing airfoil thickness. Due to the wider drag bucket of the S818, the angle of attack for $\mathrm{L} / \mathrm{D}_{\max }$ is several degrees higher than for the outboard airfoils.

Figure 10 shows the calculated aerodynamic properties for the S818/827/828 family. For this family, the primary and tip airfoils have been designed for low $\mathrm{C}_{\mathrm{Lmax}}$, so the corresponding lift curves are markedly different that that of the S818. Note that the S827 and S828 airfoils have also been designed for very low drag, and as a result, have the highest $\mathrm{L} / \mathrm{D}_{\max }$ values of the candidate airfoils considered. 

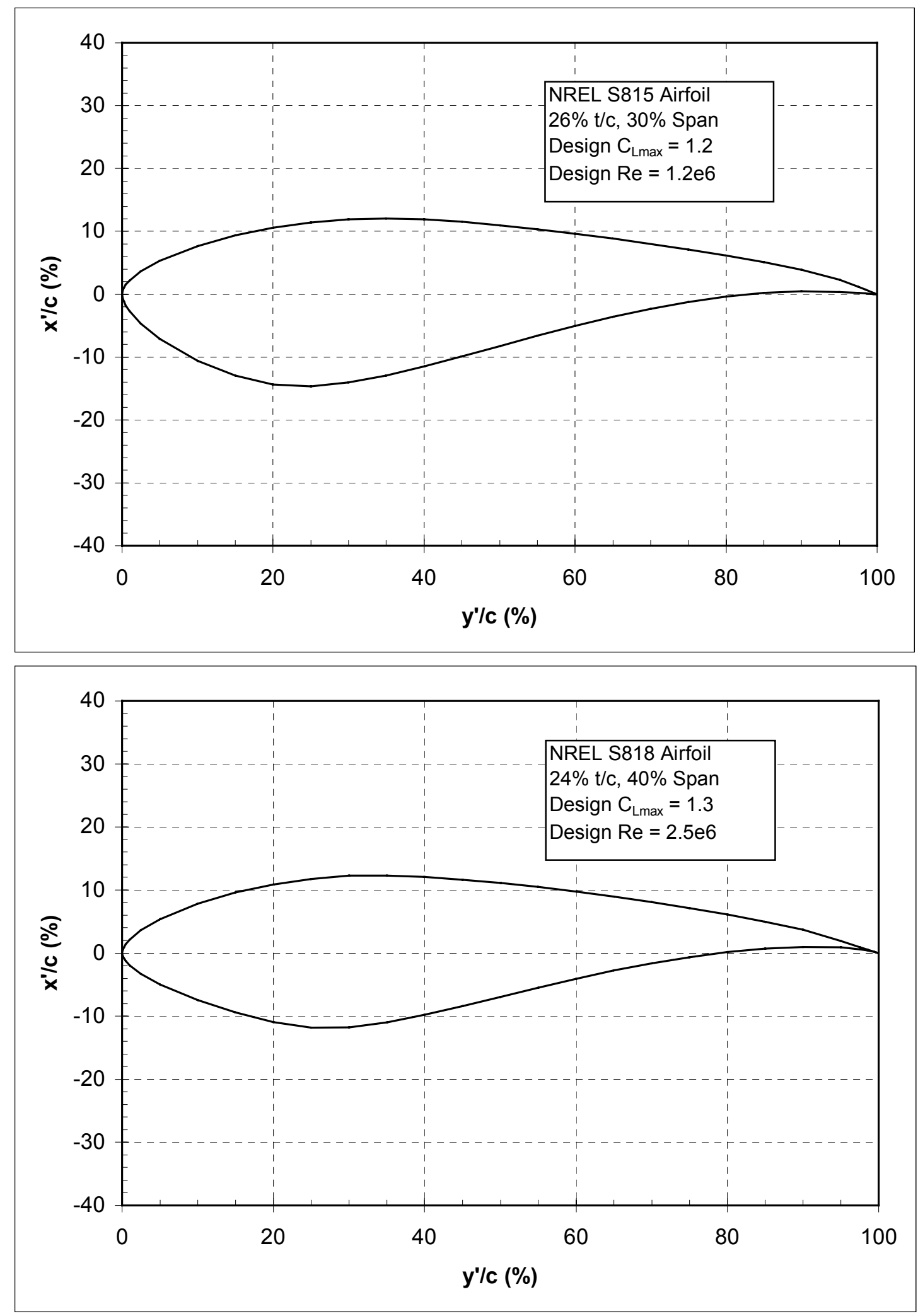

Figure 4. S815 and S818 root airfoils 

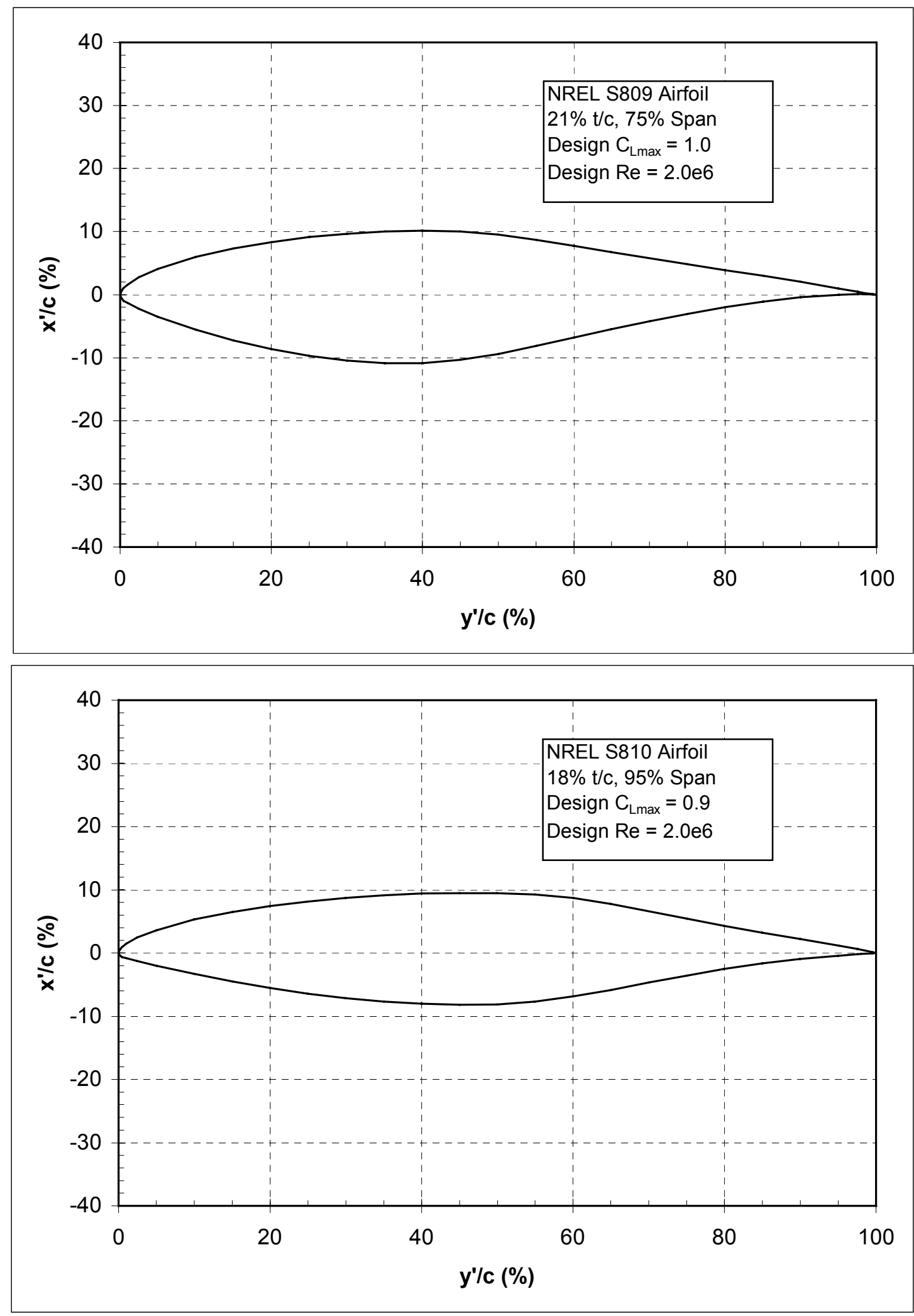

Figure 5. Primary and tip airfoils for the $\$ 815 / 809 / 810$ family 

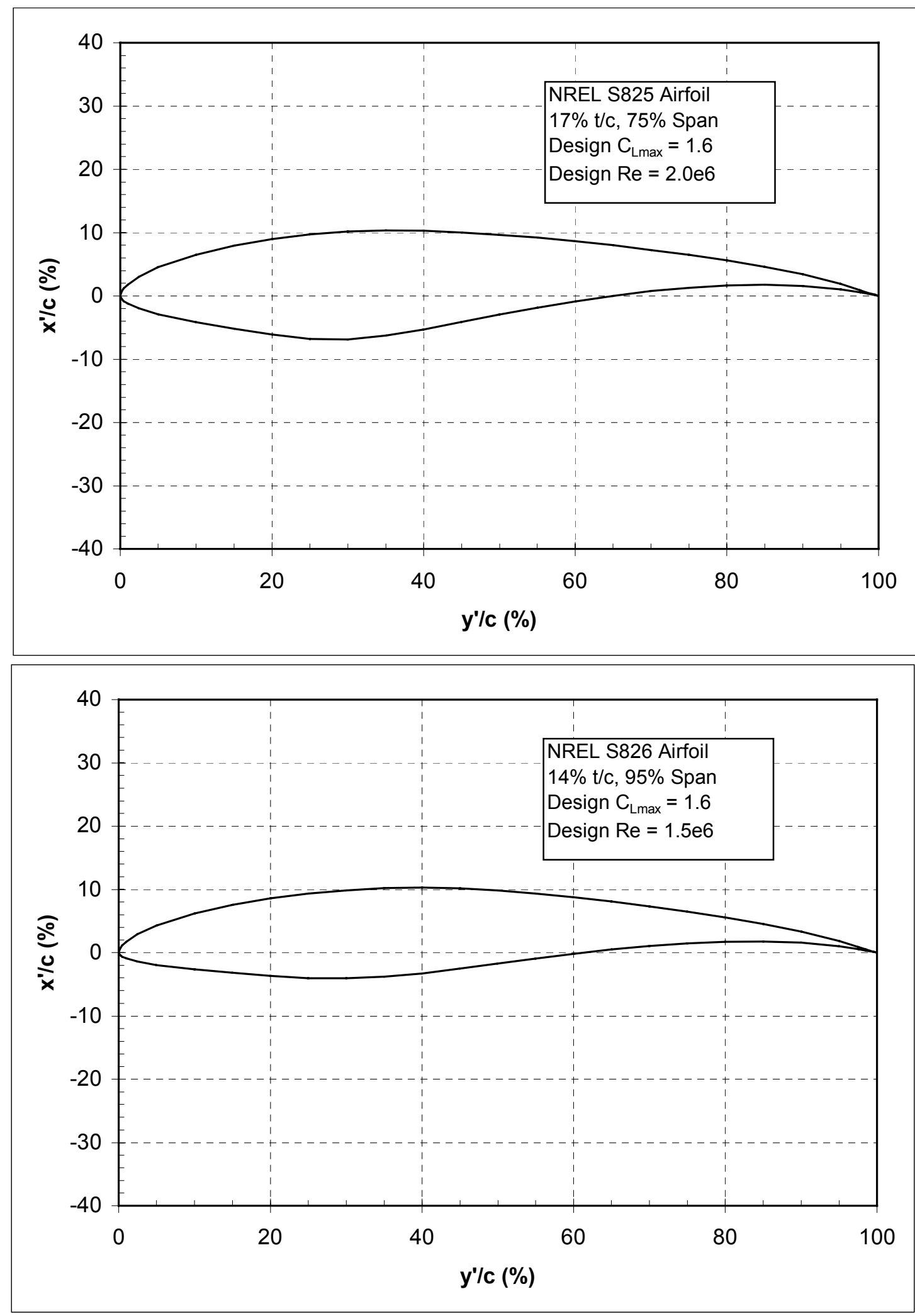

Figure 6. Primary and tip airfoils for the $\$ 818 / 825 / 826$ family 

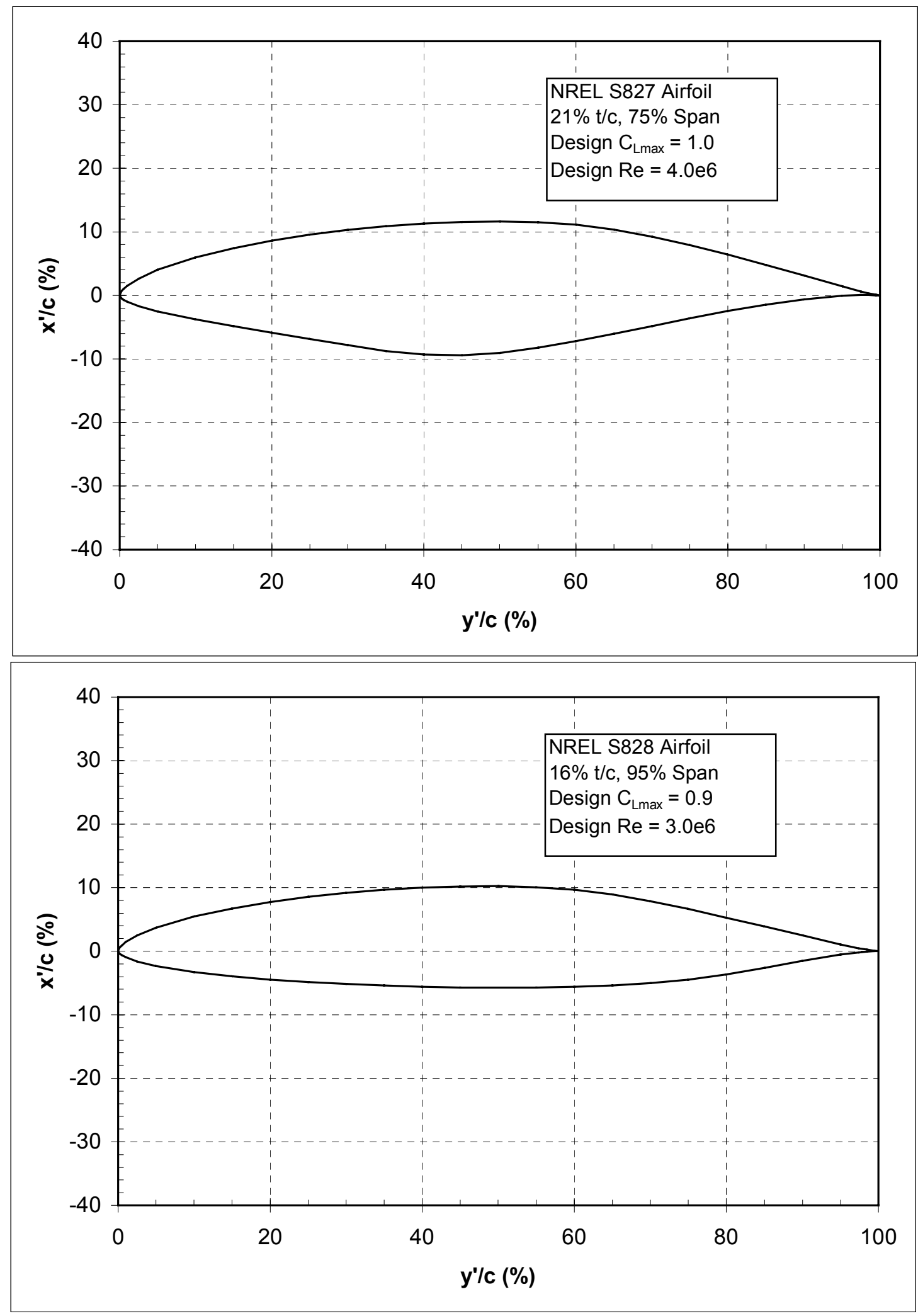

Figure 7. Primary and tip airfoils for the $\$ 818 / 827 / 828$ family 

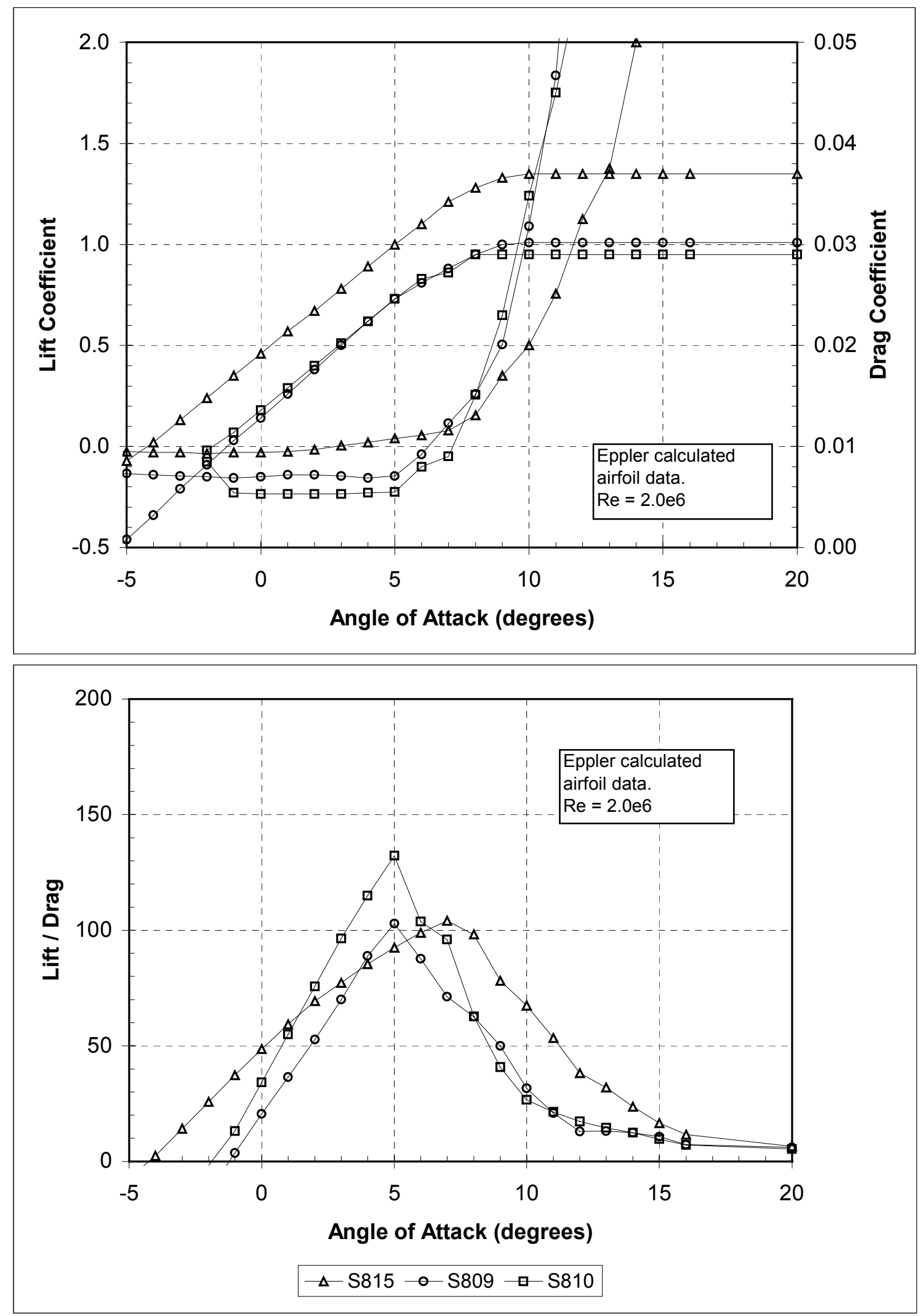

Figure 8. Aerodynamic curves for the $\$ 815 / 809 / 810$ airfoil family 

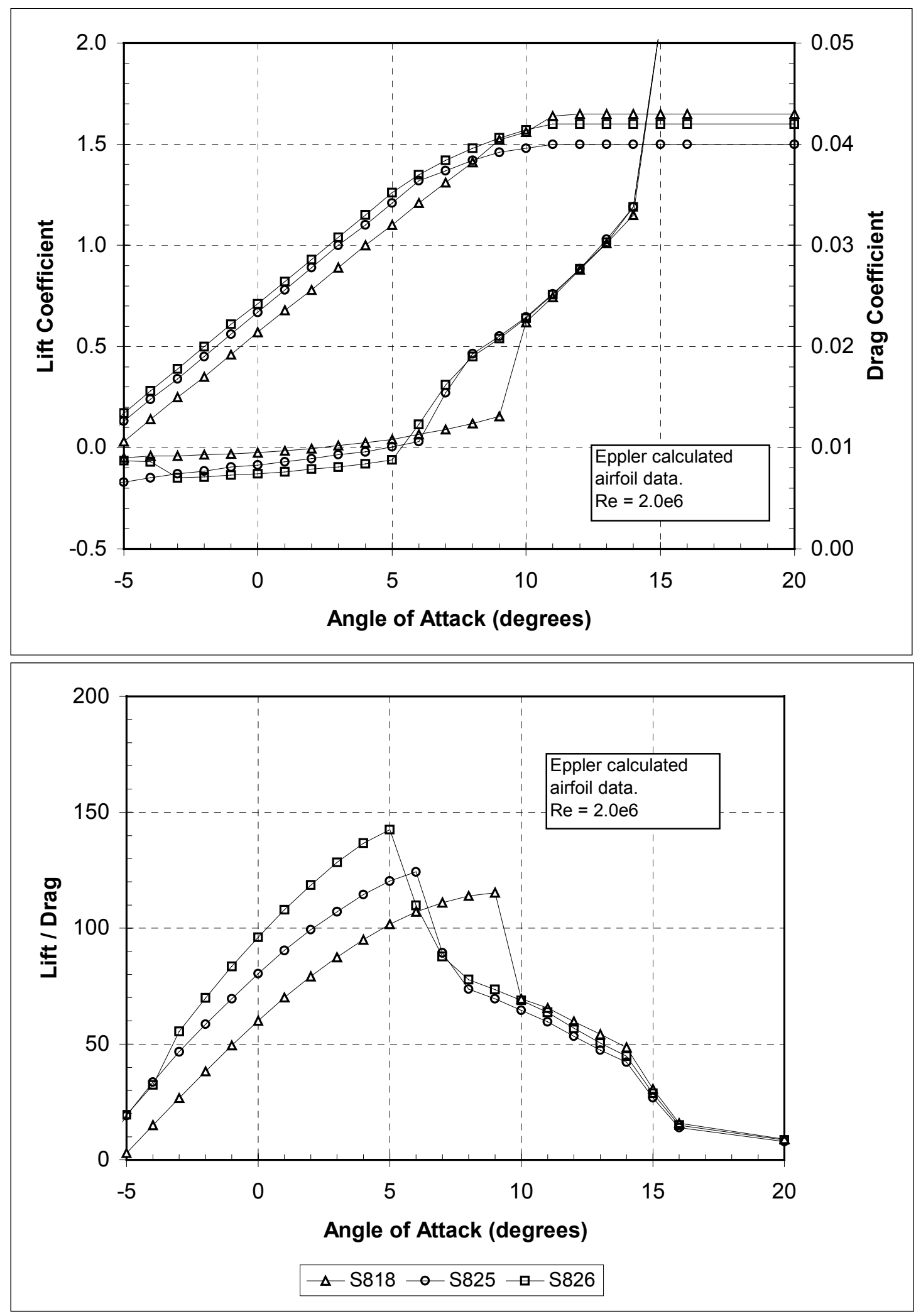

Figure 9. Aerodynamic curves for the $\$ 818 / 825 / 826$ airfoil family 

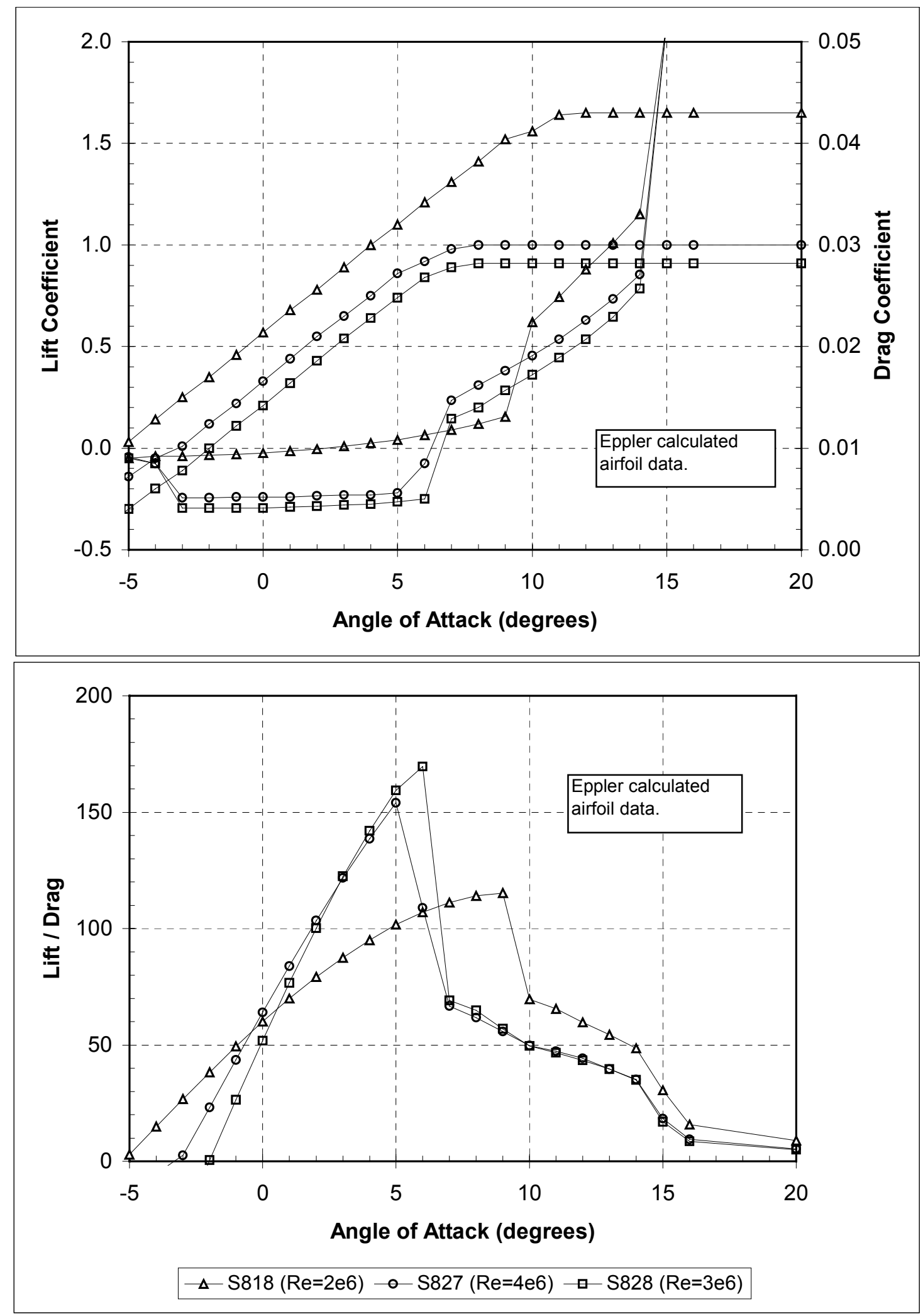

Figure 10. Aerodynamic curves for the $\$ 818 / 827 / 828$ airfoil family 
Wind tunnel testing was conducted at Delft University to verify the aerodynamic properties of the S809 airfoil [Ref. 3]. Figure 11 shows a comparison of these measured Delft data with the Eppler calculations used in the present work. The experimental lift curve shows a very subtle stall between $9^{\circ}$ and $11^{\circ} \mathrm{AOA}$, with a "secondary" $\mathrm{C}_{\mathrm{Lmax}}$ and stall around $15^{\circ}$. The Eppler calculations do not show this secondary $\mathrm{C}_{\mathrm{Lmax}}$, but otherwise are near-perfect in their prediction of the measured data. Similarly good agreement with Eppler predictions was found from testing of the S814 airfoil at Delft [Ref. 8].

The S825 and S827 airfoils were tested in 1999 at the National Aeronautic and Space Administration Langley Low-Turbulence Pressure Tunnel (LTPT) [Ref. 4]. Figure 12 shows the comparison of the measured aerodynamic properties with Eppler calculations. As seen in the figure, there is an offset between the predicted and measured lift curves, and the drag data do not agree as well as was observed for the S809. The error in predicted lift and drag combine to result in the discrepancies seen in the L/D curves. Most important to the aerodynamic design of blades is not that the measured $L / D_{\max }$ is lower than predicted, but that it occurs at a lower value of $\mathrm{C}_{\mathrm{L}}$ and $2^{\circ}$ earlier AOA. The significance of this discrepancy to aerodynamic blade design will be evaluated in Section 4.2.4.

The LTPT-measured data for the S827 also deviated substantially from the Eppler predictions, but with different trends than seen for the S825. (Note that the tabular data for S827 measurements were not made available to GEC, but the graphical data can be found in Reference 4). Specifically, the S827 showed $\mathrm{C}_{\mathrm{Lmax}}$ values significantly higher than the design target. This characteristic is contrary to the originally intended application of the S827 (benign stall-regulated operation). However, the higher value of $\mathrm{C}_{\mathrm{Lmax}}$ would be of no consequence to a rotor designed for variable speed operation with active power control so long as the power control was pitch-to-feather.

The majority of work performed on the ART-2B rotor blade design occurred before the LTPT test results for the S825 and S827 were available. The scaling studies presented herein are based entirely on Epplercalculated aerodynamic properties, with the exception of the example calculations in Section 4.2.4.

Table 1 provides a summary of the key design parameters for the candidate NREL airfoils. Note that for the S825, both the calculated and measured parameters are given.

Table 1. Summary of Design Parameters for NREL S-Series Airfoils

\begin{tabular}{|c|c|c|c|c|c|c|c|c|}
\hline $\begin{array}{c}\text { Airfoi } \\
l\end{array}$ & $\begin{array}{c}\text { Location } \\
(\% \\
\text { Radius) } \\
\end{array}$ & $\begin{array}{c}\text { Thicknes } \\
\text { s } \\
\left(t / c_{\max }\right) \\
\end{array}$ & $\begin{array}{l}\text { Design Re } \\
\text { (millions) }\end{array}$ & $C_{\text {Lmax }}$ & $\begin{array}{c}\text { Alpha } \\
\text { at } C_{\text {Lmax }}\end{array}$ & $\mathbf{L} / \mathbf{D}_{\max }$ & $\begin{array}{c}C_{L} \text { at } \\
L / D_{\max }\end{array}$ & $\begin{array}{c}\text { Alpha } \\
\text { at } L / D_{\max }\end{array}$ \\
\hline S815 & 0.30 & 0.26 & 1.2 & 1.35 & $10.0^{\circ}$ & 104 & 1.21 & $7.0^{\circ}$ \\
\hline S818 & 0.40 & 0.24 & 2.5 & 1.60 & $11.0^{\circ}$ & 115 & 1.52 & $9.0^{\circ}$ \\
\hline S809 & 0.75 & 0.21 & 2.0 & 1.00 & $10.0^{\circ}$ & 103 & 0.73 & $5.0^{\circ}$ \\
\hline S810 & 0.95 & 0.18 & 2.0 & 0.95 & $8.0^{\circ}$ & 132 & 0.73 & $5.0^{\circ}$ \\
\hline S825 & 0.75 & 0.17 & 2.0 & 1.50 & $11.0^{\circ}$ & 125 & 1.32 & $6.0^{\circ}$ \\
\hline S825* & 0.75 & 0.17 & 2.0 & 1.56 & $13.0^{\circ}$ & 115 & 1.01 & $4.0^{\circ}$ \\
\hline S826 & 0.95 & 0.14 & 1.5 & 1.60 & $11.0^{\circ}$ & 142 & 1.26 & $5.0^{\circ}$ \\
\hline S827 & 0.75 & 0.21 & 4.0 & 1.00 & $8.0^{\circ}$ & 154 & 0.86 & $5.0^{\circ}$ \\
\hline S828 & 0.95 & 0.16 & 3.0 & 0.91 & $8.0^{\circ}$ & 170 & 0.84 & $6.0^{\circ}$ \\
\hline
\end{tabular}

*Properties as measured for S825 at LTPT wind tunnel tests 

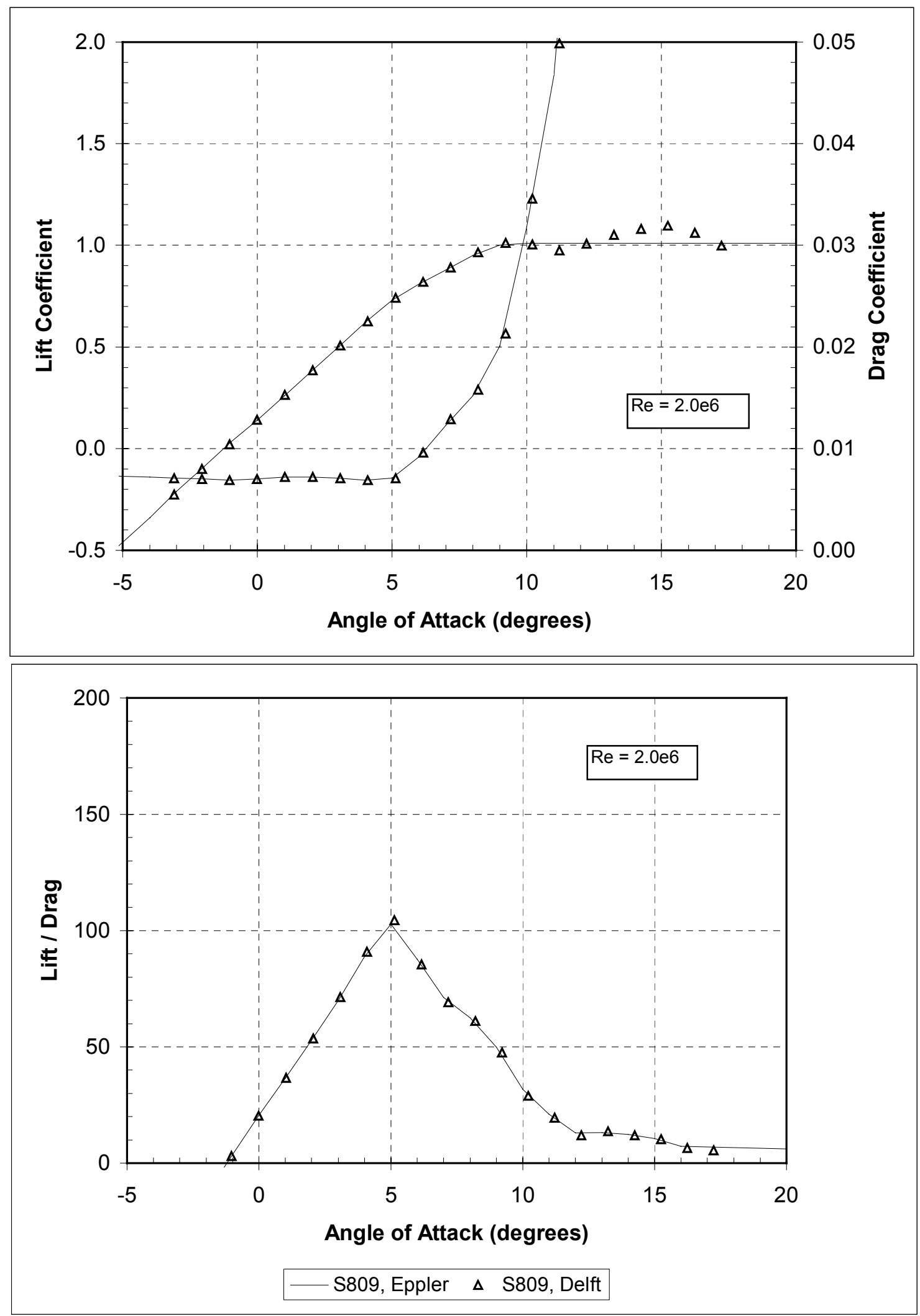

Figure 11. Comparison of Eppler calculations with Delft wind tunnel data for $\mathbf{S 8 0 9}$ 

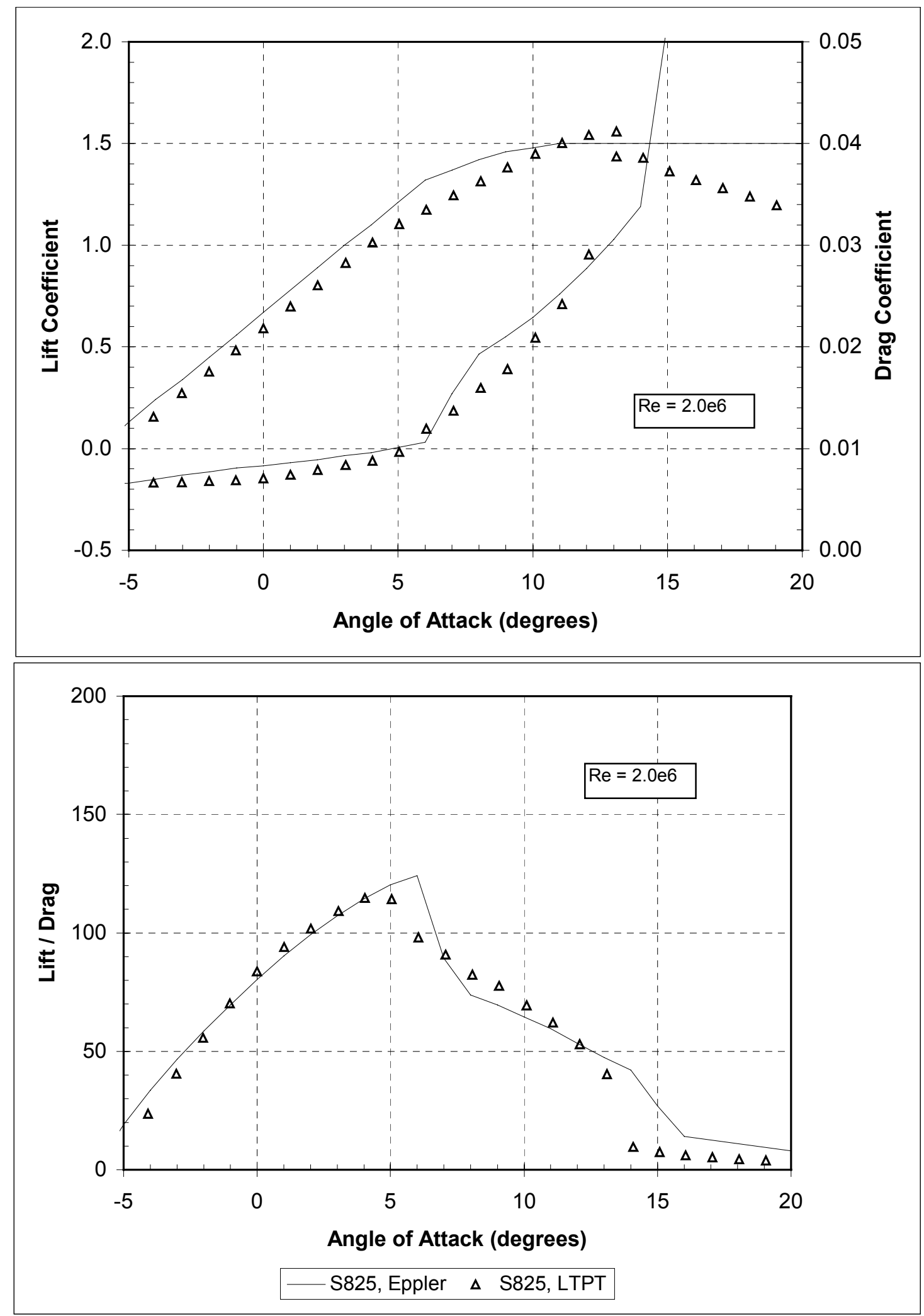

Figure 12. Comparison of Eppler calculations with LTPT wind tunnel data for S825 


\subsection{Reynolds Number Effects}

The PROPID calculations used in this study include Reynolds number effects. Figure 13 shows the spanwise Re distribution calculated for ART-1 rotor blade at a schedule of discrete rotational speeds (42 rpm represents the baseline fixed-speed operation of the ART-1). Although the actual Re distribution for ART-2B blades will vary with each rotor design, Figure 13 provides a useful estimate of both the range of typical magnitudes and the effect of rotor speed on Re.

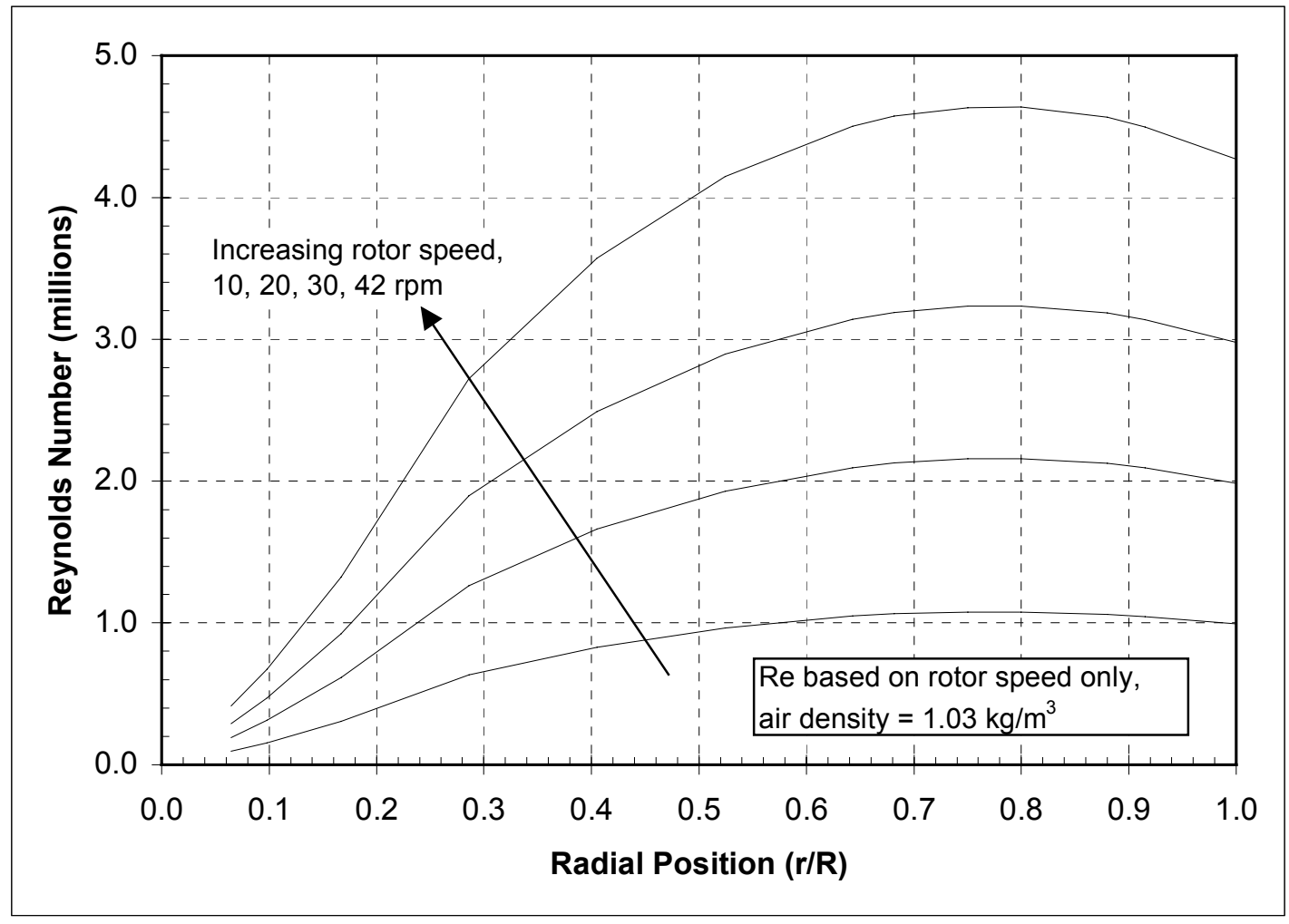

Figure 13. Blade Reynolds number for ART-2A (variable-speed ART-1)

In terms of airfoil aerodynamic properties, two effects may be expected with increasing Re-a decrease in drag values throughout the drag bucket and an increase in $\mathrm{C}_{\mathrm{Lmax}}$. The increments in minimum drag and $\mathrm{C}_{\mathrm{Lmax}}$ are most pronounced at the lower range of Re (i.e., from $1 \mathrm{e} 6$ to $2 \mathrm{e} 6$ ) and diminish at higher Re (i.e., from $3 \mathrm{e} 6$ to $4 \mathrm{e} 6)$.

Figure 14 shows the aerodynamic properties used in the present scaling study for the S825 at varying Reynolds numbers. Note that although the Eppler calculations for the S825 predicted an increase in $\mathrm{C}_{\mathrm{Lmax}}$ with increasing $\mathrm{Re}$, that trend would have no effect on the design of optimal variable speed rotors and as such has not been included in the input data files. However, the decrease in minimum drag with increasing Re is evident in the drag curve and is responsible for the corresponding increases in $L / D_{\max }$. This Re trend will effect the blade optimizations and is incorporated in the PROPID calculations. 

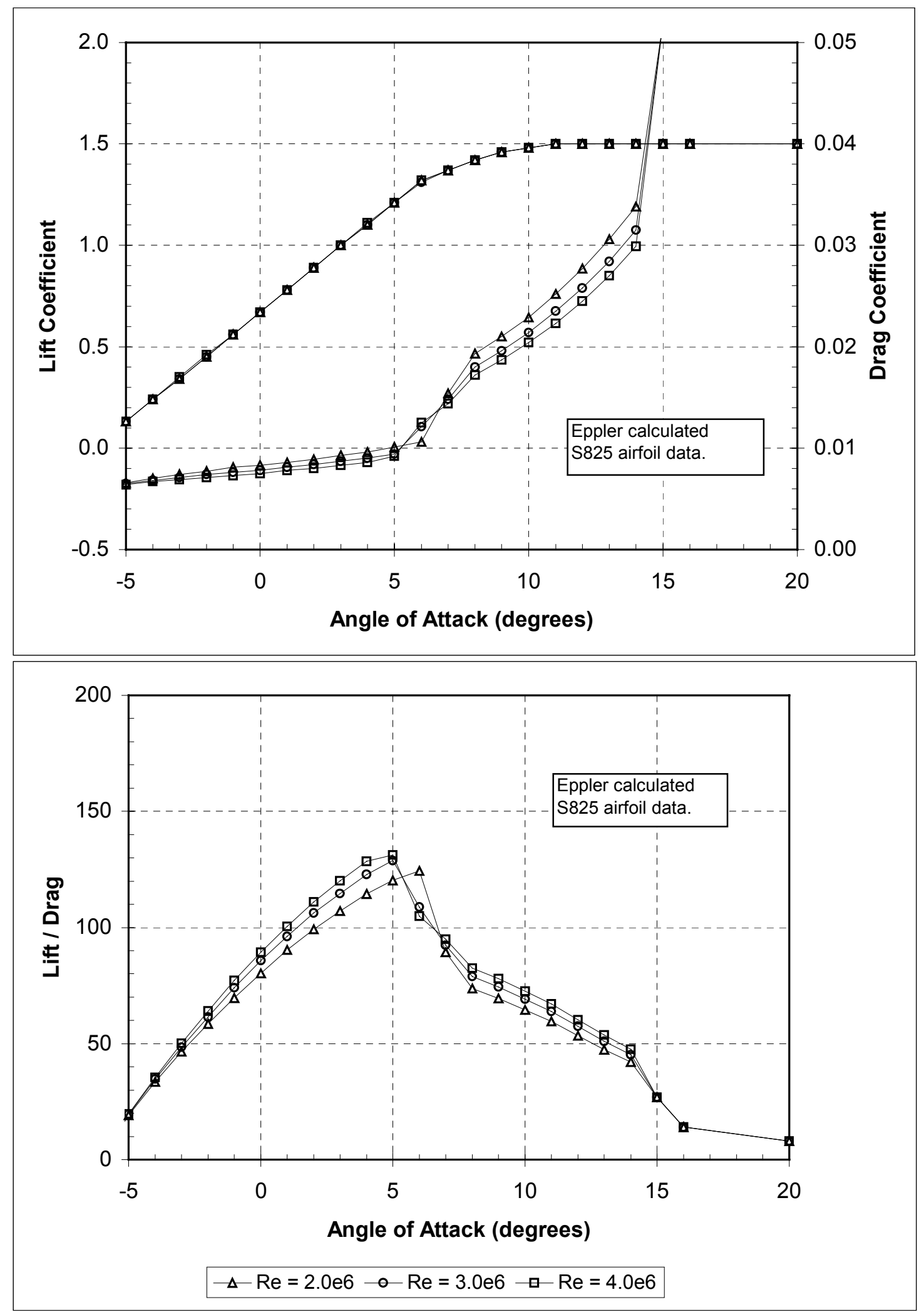

Figure 14. Reynolds number effects for $\$ 818 / 825 / 826$ airfoil family 


\section{Performing Rotor Design Studies with PROPID}

The original ART-2B blade scaling studies were performed and presented to NWTC personnel in November 1998. In subsequent work and in the course of preparing this report, additional cases were run and updates were made to the original design study calculations. As a result, all of the design studies presented in the current report are based on calculations using the PROPID code version "PROPID34" [Ref. 9]. All of the archived input and output files for these studies are documented in Appendix A.

\subsection{Design Process for Near-Optimal Variable-Speed Performance}

PROPID does not optimize, but rather will perform a multi-point inverse design of a rotor blade to meet any number of specified criteria. The development of a near-optimal blade design therefore requires some pre-knowledge of rotor design trends and the use of judgment in developing input files. No rigorous optimization methodology has been used in the current work, and the resulting designs must, therefore, be considered "near-optimal." However, it will be seen in the following sections that the nearoptimal design space can become very flat and that the performance increment between these nearoptima and a true optimum design is very small.

PROPID will iterate to search for a blade design to satisfy any number of designer-specified criteria, but the code can converge on a solution only if the specified combination is physically realizable. For each design criterion specified, the designer must give up one degree of freedom. For instance, for each blade segment where the local lift coefficient is specified, PROPID must have one variable on which it can iterate to satisfy the criterion. In the case of specified $\mathrm{C}_{\mathrm{L}}$, the blade twist is the logical choice of a free variable. Similarly, the local blade chords can be used as free design variables to achieve a desired distribution of axial induction factors.

For any combination of design objectives (i.e., $\mathrm{C}_{\mathrm{L}}$ and axial induction factors), a "design point" must be specified at which the rotor will satisfy the objectives. In general, each design point includes specification of wind speed, rotor speed, and blade pitch angle. Note that these design point parameters may also be included as either design objectives or allowed as degrees of freedom in the iteration, but only so long as a one-to-one correspondence is maintained between the design criteria and free variables.

For the ART-2B rotor design studies, a design point wind speed of $7.15 \mathrm{~m} / \mathrm{s}$ was used for all cases. That is, the rotor designs will achieve their near-optimal $C_{P}$ conditions at a wind speed of $7.15 \mathrm{~m} / \mathrm{s}$. This selection of design point wind speed is somewhat arbitrary. Because the rotors are designed for variablespeed operation, the rotor will track the optimum $C_{P}$ condition over a wide range of the power curve (wind speeds) below rated power. For each blade design, the rotor speed was set to achieve the desired design TSR, and the blade pitch angle was given up as a degree of freedom.

The following steps outline the process used to design blades for near-optimal variable-speed power performance:

1. Specify an airfoil family and the spanwise location of each airfoil on the blade.

2. Specify a $C_{L}$ distribution along the blade that is close to $L / D_{\max }$.

3. Specify a constant axial induction factor of 0.33 at all blade stations (near-optimal value from bladeelement momentum theory). 
4. Select a design point (TSR and wind speed) at which to satisfy the design objectives.

5. Allow PROPID to iterate on blade twist, chord, and pitch to achieve specifications.

6. Evaluate each design on the basis of calculated AEP and maximum rotor $\mathrm{C}_{\mathrm{P}}$.

7. Shift specified $\mathrm{C}_{\mathrm{L}}$ distribution and repeat steps 3 through 6 .

8. Identify near-optimum based on highest $\mathrm{AEP}$ and/or best $\mathrm{C}_{\text {Pmax }}$.

The above steps will result in blades that are close enough to optimal designs so that the process can be used for comparative evaluation of airfoil families, design tip speed ratios, rotor scaling, and other such trade-off studies. However, if a full, detailed design is desired, the process can be refined through:

9. Subtle perturbation of the $\mathrm{C}_{\mathrm{L}}$ and axial induction distribution specifications and evaluation of results.

10. Smoothing of design output and/or imposition of constraints on chord, twist, and thickness distribution (for reduced cost, weight, and ease-of-manufacture). Evaluation of resulting designs and iteration as desired.

Note that steps 1 through 9 above result in the near-optimization of the blade in terms of power performance. The items described in step 10 will result in reductions of power performance from the theoretical optimum. It is at this point that such AEP compromises must evaluated and weighed against the benefits of lower cost, weight, ease of manufacture, and other considerations.

All of the design processes outlined above were completed during the ART-2B blade design work and will be presented herein. The following section provides an example rotor design that illustrates steps 1 through 8 above.

\subsection{Example Rotor Design}

The current example is for near-optimal performance using the $\mathrm{S} 818 / 825 / 826$ airfoil family at a design $\mathrm{TSR}=8$. The complete PROPID input file for this design, "18_25_26_01.in," is provided in Appendix B. Note that "18_25_26_01.in" also contains lines for performing the optimization at other design TSRs, but that those lines are commented out. This same input file was used to complete the design TSR sweep presented in Section 6.0 by adding and deleting comment characters to systematically change which TSR lines were included in the file.

\subsubsection{Assumptions / Constraints}

In addition to the constraints given in Section 2.2, the present design example assumes:

- $\quad$ S818 airfoil shape continues all the way to the root.

- No restrictions are imposed on allowable chord and twist distributions.

- $\quad$ Design $\mathrm{TSR}=8$.

The selection of design TSR $=8$ is somewhat arbitrary. The effect of varying deign TSR will be investigated in Section 6.0. 


\subsubsection{Target Lift Distributions}

Table 2 shows the baseline target $C_{L}$ distribution to achieve maximum $\mathrm{L} / \mathrm{D}$ at all blade stations. Note that the left-hand side of the table shows only four stations, at which the airfoils and airfoil properties are directly specified in the input file. If the designer specifies intermediate blade stations in the design and analysis (typical approach), then PROPID will automatically interpolate between the input airfoil properties to develop the aerodynamic curves for the intermediate stations. However, it is up to the designer to specify the target conditions at all stations where inverse design is desired. The right-hand side of Table 2, has, therefore, been derived for all 10 blade stations via a linear interpolation of the four input stations. The far-right column shows target $C_{L}$ with respect to the value of $C_{L}$ at $75 \%$ span $\left(C_{L}\right.$ w.r.t. $75 \%$ R). This data format has been calculated for ease-of-use within the PROPID input file structure, and it is these relative $C_{L}$ values that appear in the file "18_25_26_01.in."

Table 2. Baseline Target $C_{L}$ Distribution for S818/825/826 Airfoil Family

\begin{tabular}{|c|c|c|c|c|c|c|c|}
\hline \multicolumn{4}{|c|}{ Airfoil Family $C_{L}$ Distribution } & \multicolumn{4}{|c|}{ Target $C_{\mathrm{L}}$ Distribution } \\
\hline Station \# & Airfoil & $r / R$ & $\mathrm{C}_{\mathrm{L}}$ at $\mathrm{L} / \mathrm{D}_{\max }$ & Station \# & $r / R$ & $\mathrm{C}_{\mathrm{L}}$ at $\mathrm{L} / \mathrm{D}_{\max }$ & $\mathrm{C}_{\mathrm{L}}$ w.r.t. $75 \% \mathrm{R}$ \\
\hline 1 & S818 & 0.05 & 1.52 & 1 & 0.05 & 1.52 & 0.20 \\
\hline 4 & S818 & 0.35 & 1.52 & 2 & 0.15 & 1.52 & 0.20 \\
\hline 8 & S825 & 0.75 & 1.32 & 3 & 0.25 & 1.52 & 0.20 \\
\hline 10 & S826 & 0.95 & 1.26 & 4 & 0.35 & 1.52 & 0.20 \\
\hline & & & & 5 & 0.45 & 1.47 & 0.15 \\
\hline & & & & 6 & 0.55 & 1.42 & 0.10 \\
\hline & & & & 7 & 0.65 & 1.37 & 0.05 \\
\hline & & & & 8 & 0.75 & 1.32 & 0.00 \\
\hline & & & & 9 & 0.85 & 1.29 & -0.03 \\
\hline & & & & 10 & 0.95 & 1.26 & -0.06 \\
\hline
\end{tabular}

The process of shifting and perturbing the target $C_{L}$ distribution is illustrated graphically in Figures 15 and 16. As outlined in Section 4.1, the first step in the design process is to perform the $C_{L}$ shifts (as in Figure 15) and evaluate the resulting designs. Once a near-optimum is found, then subtle $C_{L}$ perturbations can be performed (as in Figure 16) and the effect of perturbations on the axial induction factor can be investigated.

For the present example, Figure 17 shows the variation of maximum rotor power coefficient due to shifting of the target $C_{L}$ distribution. The highest $C_{P \max }$ occurs with the $C_{L}$ at $75 \%$ radius $\left(C_{L, 75 \% R}\right)$ equal to 1.15. However, the optimum with respect to this parameter is very flat. Although the $\mathrm{C}_{\mathrm{Pmax}}$ appears to fall off sharply as $C_{L, 75 \% R}$ exceeds 1.20 , the entire range of $C_{P \max }$ values in Figure 17 varies by less than $1 \%$.

Subsequent to locating the highest $\mathrm{C}_{\mathrm{Pmax}}$ via shifting of the lift distribution, the target $\mathrm{C}_{\mathrm{L}}$ distribution was rotated about $\mathrm{C}_{\mathrm{L}, 75 \% \mathrm{R}}=1.15$ (as depicted in Figure 16). The target axial induction distribution was also perturbed slightly (from the constant value of 0.33 ) through both shifts and rotations. For this design case, these rotations and perturbations resulted in either no change or a slight decrease in $\mathrm{C}_{\mathrm{Pmax}}$. It was, therefore, concluded that for this case the design achieved purely by shifting the target $\mathrm{C}_{\mathrm{L}}$ distribution is very near the true optimum. 


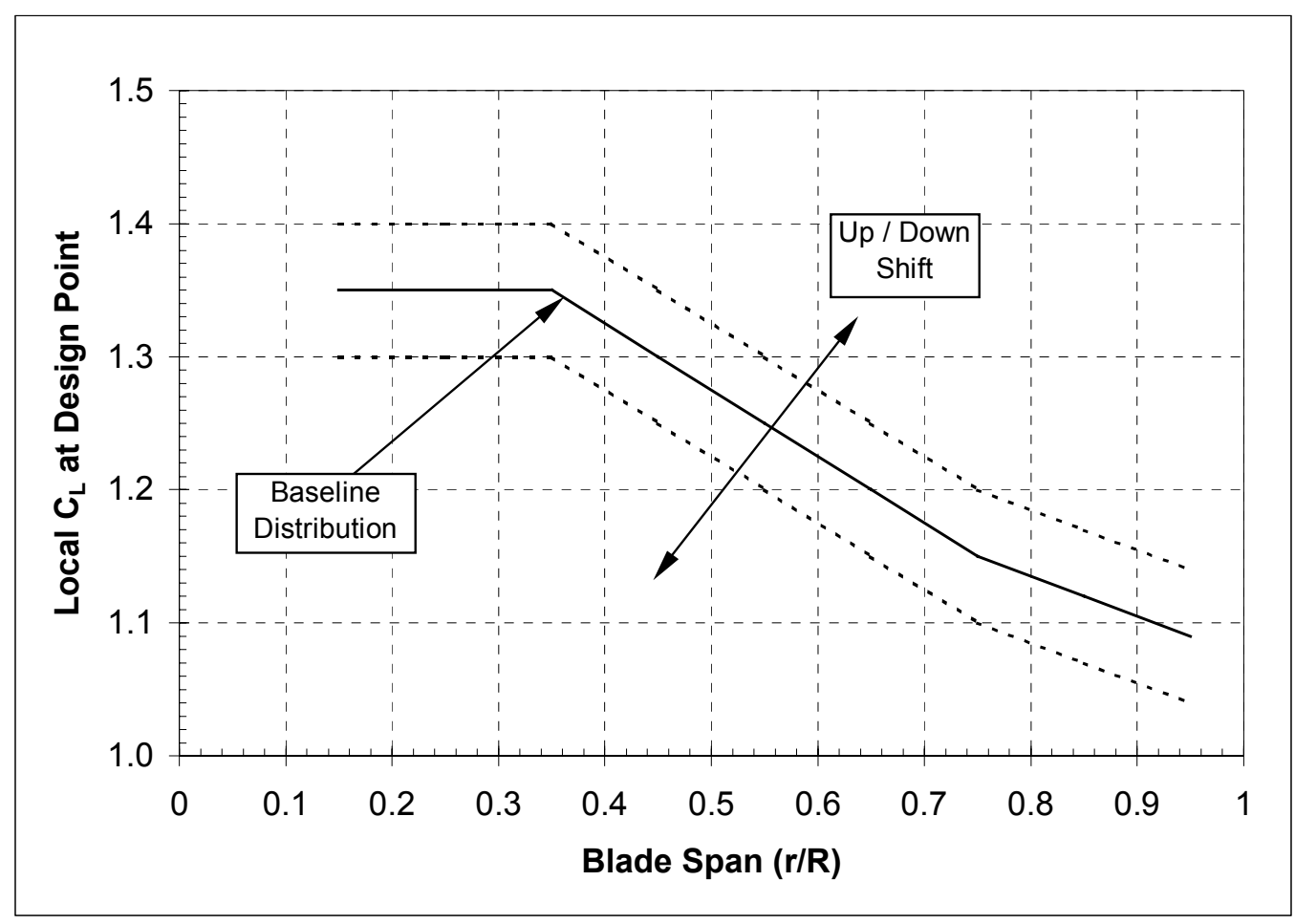

Figure 15. Shifting of target $C_{L}$ distribution

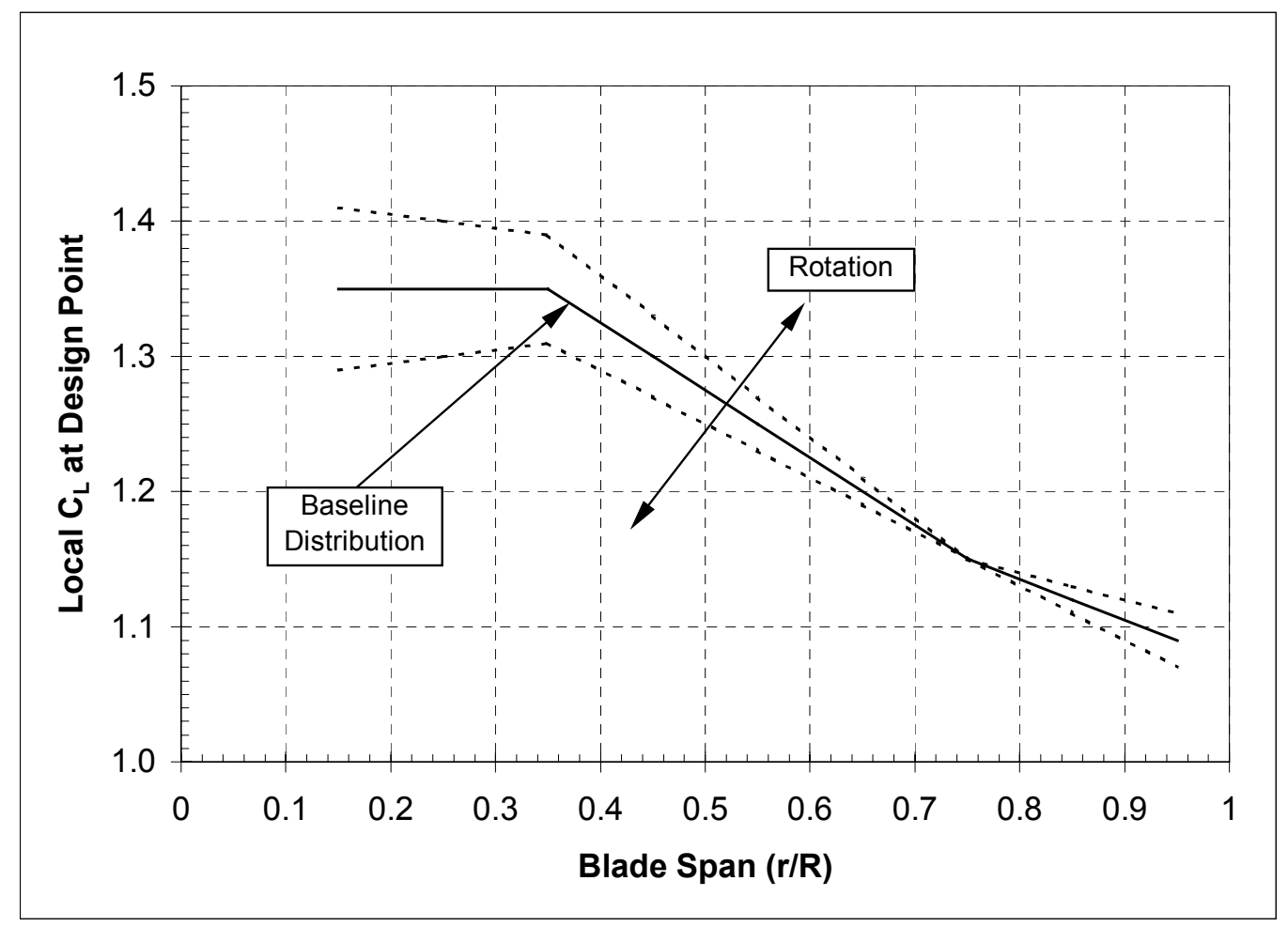

Figure 16. Rotation of target $C_{L}$ distribution 


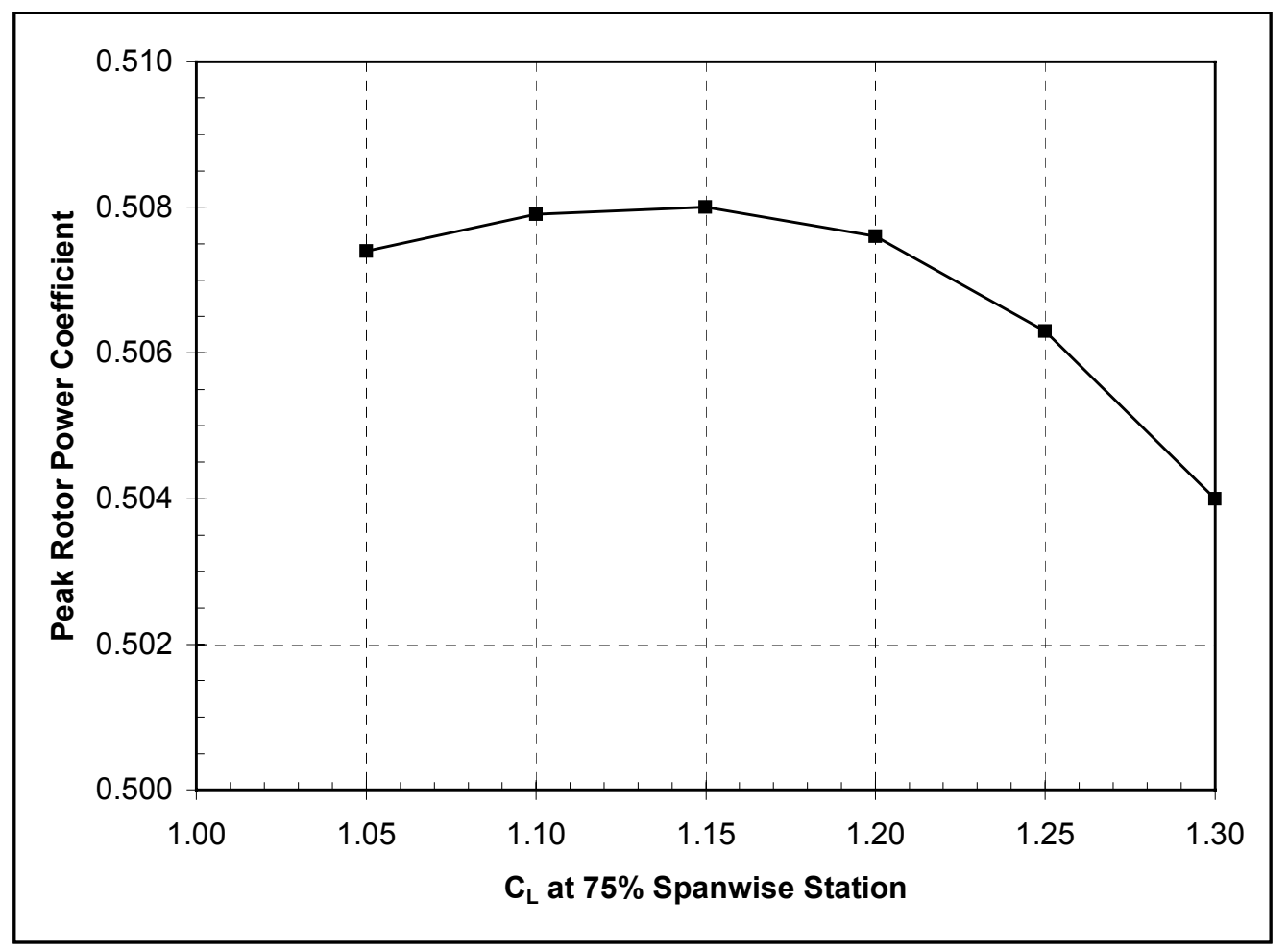

Figure 17. Variation of $C_{P \max }$ because of shifting of target $C_{L}$ distribution

Comparing the results of Figure 17 with the data in Table 2, it is seen that the best peak $\mathrm{C}_{\mathrm{P}}$ was obtained with a $C_{L}$ distribution significantly lower than the distribution that follows $L / D_{\max }$ (best $C_{P_{\max }}$ is at $\mathrm{C}_{\mathrm{L}, 75 \% \mathrm{R}}=1.15$, whereas the $\mathrm{L} / \mathrm{D}_{\max }$ condition occurred for $\mathrm{C}_{\mathrm{L}, 75 \% \mathrm{R}}=1.32$ ). This trend persisted throughout the ART-2B trade studies; peak power performance was consistently found with lift distributions lower than those for maximum L/D. This phenomenon has also been observed and interpreted by Dr. Selig [Ref. 10].

For all of the primary design studies presented in this report, the blade geometry corresponding to the highest $\mathrm{C}_{\mathrm{Pmax}}$ has been used $\left(\mathrm{C}_{\mathrm{L}, 75 \% \mathrm{R}}=1.15\right.$ in the case of the $\left.\mathrm{S} 818 / 825 / 826\right)$. However, as the power performance optima are very flat, the implications of designing for $\mathrm{C}_{\mathrm{L}, 75 \% \mathrm{R}}$ either below or above peak $\mathrm{C}_{\mathrm{Pmax}}$ are investigated in Section 7.1.

\subsubsection{Resulting Blade Design}

Figures 18 and 19 show the planform and twist distribution corresponding to the PROPID near-optimum blade design for the $\mathrm{S} 818 / 825 / 826$ airfoil family at design TSR $=8$. As indicated by Figure 17, the peak rotor $\mathrm{C}_{\mathrm{P}}$ for this design is equal to 0.5080 . The calculated system AEP for this design (all wind speeds below $12 \mathrm{~m} / \mathrm{s})$ is 966 megawatt-hours per year $(\mathrm{MWh} / \mathrm{y})$.

Note that the chord and twist values at 5\% radial location have not been calculated by PROPID, but remained as the "first guess" in the input file. This is because the ART rotor hub extends to $6.5 \%$ R, and the blade at $5 \% \mathrm{R}$ is, therefore, not properly included in the blade design. The chord dimension shown in Figure 18 is the actual dimension of the ART hub flange. The twist value shown in Figure 19 is a semiarbitrary guess and has a negligible effect on the PROPID calculations. 


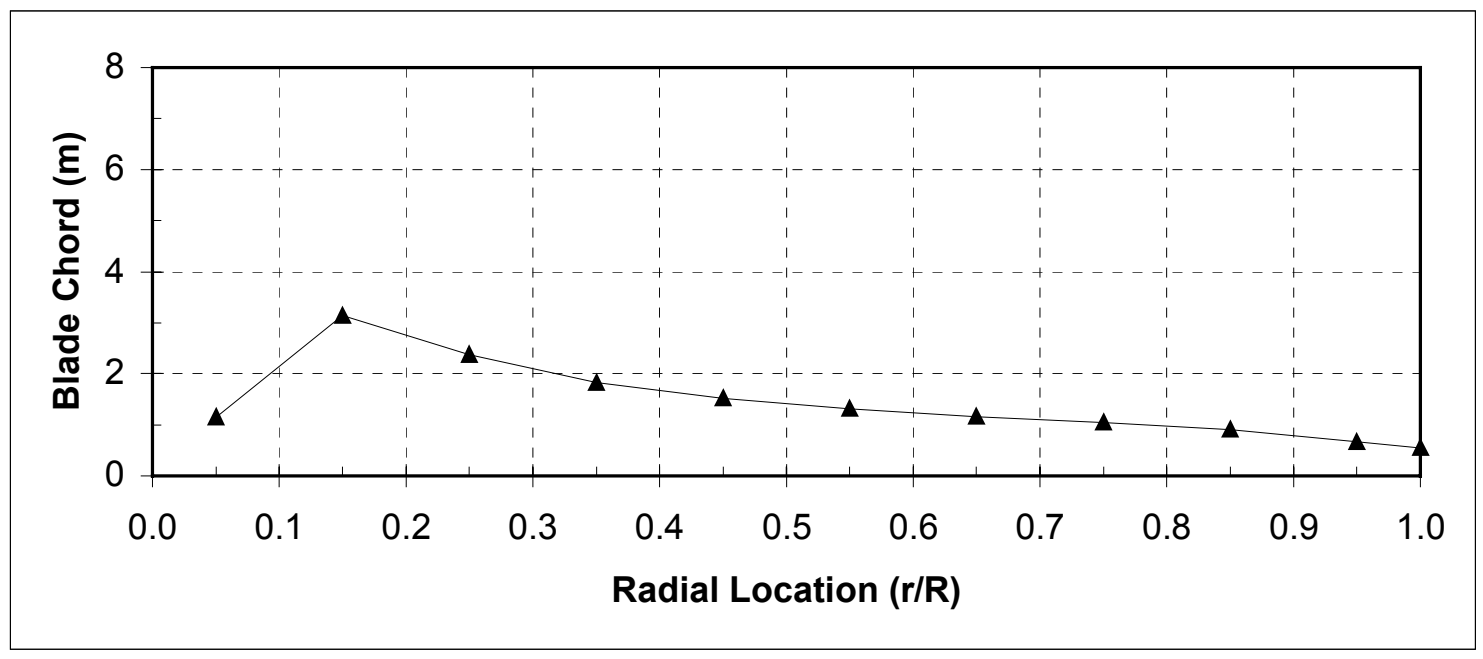

Figure 18. PROPID planform for near-optimal rotor $(S 818 / 825 / 826$ at design $T S R=8)$

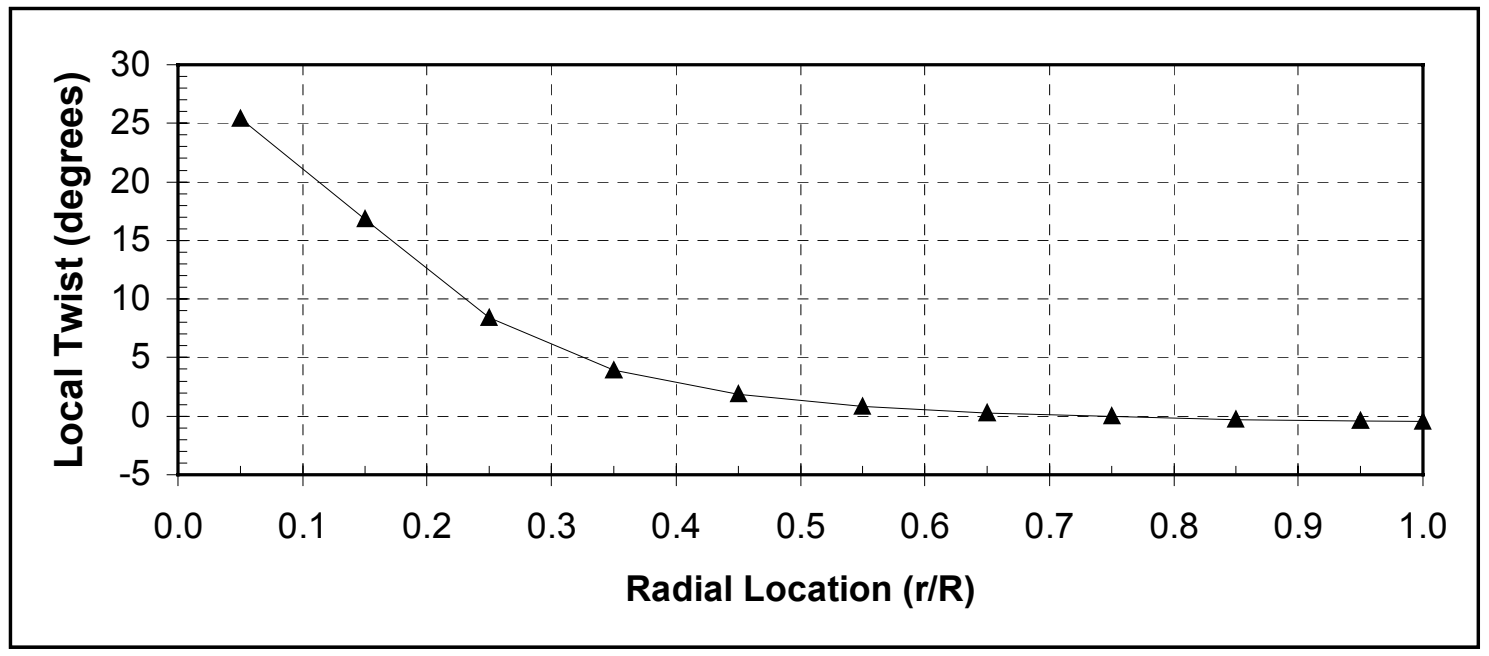

Figure 19. PROPID twist distribution for near-optimal rotor $(\mathbf{S 8 1 8 / 8 2 5 / 8 2 6}$ at design $T S R=8)$

Figure 18 has been scaled to be nearly proportional (the blade span is approximately $21 \mathrm{~m}$ ). Careful inspection of the figure shows that the outboard blade planform is almost, but not quite, linear. Also, for the inboard blade sections, the chord lengths become quite long and the twist angles are high. Although this geometry is the result of seeking maximum power performance, it is natural to wonder what power performance penalty would be paid for modifying these design details. That question is addressed in Section 7.2 of this report. 


\subsubsection{Effect of Using Wind tunnel Data for S825}

The design for the S818/285/826 blade was used to evaluate the effect of using the recently available wind tunnel data for the S825 airfoil. Two questions were addressed:

1. What design would result from using the measured $\mathrm{S} 825$ aerodynamic properties (along with the Eppler properties for the S818 and S826) as PROPID input?

2. What performance is realized if the Eppler aerodynamic properties are used for all three airfoils in determining the design, and then the measured S825 aerodynamic properties are used in the analysis?

To answer the first question, an input file was developed using the measured S825 data in conjunction with the Eppler S818 and S826 properties. The baseline target $C_{L}$ distribution was developed as described in Section 4.2.2 and is shown in Table 3. This target $\mathrm{C}_{\mathrm{L}}$ distribution was then used to perform the design, shifting the distribution (as indicated in Figure 15 and discussed earlier) and evaluating the results. Using this approach the near-optimal performance was determined to be at $\mathrm{C}_{\mathrm{L}, 75 \% \mathrm{R}}=0.85$ with $\mathrm{C}_{\mathrm{Pmax}}=0.5082$.

This power performance is essentially equal to that found for the blade design using the Eppler data as input for all three airfoils. However, as indicated in Figures 20 and 21, the resulting geometries are very unusual. The planform has a pronounced local bulge at $75 \%$ span, and the twist distribution shows an inflection in that region as well. This can be explained by a review of Section 3.2, which shows that the measured S825 not only had a lower $\mathrm{L} / \mathrm{D}_{\max }$ than was predicted by the Eppler calculations, but that it occurred at a lower value of $\mathrm{C}_{\mathrm{L}}$ and a $2^{\circ}$ lower AOA.

Therefore, the measured data for the S825 are "mismatched" to the Eppler data for the S826 tip section, and combining the data sets during the design process can result in a blade with theoretically good power performance but undesirable physical attributes. Once this mismatch has been recognized, the designer could still use these data sets and work to derive $C_{L}$ distributions that remain close to tracking $L / D_{\max }$ while avoiding the undesirable inflections in planform and twist distribution.

To answer the second question above, an analysis was performed of the blade shown in Figures 18 and 19 (designed by using the Eppler aerodynamic properties for all three airfoils) using the measured S825 aerodynamic properties during the analysis. At TSR $=8$ (original design value) the $C_{P}$ was 0.5056 , or slightly less than $0.5 \%$ lower than the near-optimal blade designs. However, the analysis also showed that the highest $C_{P}$ was 0.5072 , occurring at $T S R=9$.

Table 3. Baseline Target $C_{L}$ Distribution for S818/825/826 Airfoils using Measured S825 Data

\begin{tabular}{|c|c|c|c|c|c|c|c|}
\hline \multicolumn{4}{|c|}{ Airfoil Family $C_{L}$ Distribution } & \multicolumn{4}{|c|}{ Target $C_{L}$ Distribution } \\
\hline Station \# & Airfoil & $r / R$ & $\mathrm{C}_{\mathrm{L}}$ at $\mathrm{L} / \mathrm{D}_{\max }$ & Station \# & $r / R$ & $\mathrm{C}_{\mathrm{L}}$ at $\mathrm{L} / \mathrm{D}_{\max }$ & $\mathrm{C}_{\mathrm{L}}$ w.r.t. $75 \% \mathrm{R}$ \\
\hline 1 & S818 & 0.05 & 1.52 & 1 & 0.05 & 1.52 & 0.52 \\
\hline 4 & S818 & 0.35 & 1.52 & 2 & 0.15 & 1.52 & 0.52 \\
\hline 8 & S825* & 0.75 & 1.00 & 3 & 0.25 & 1.52 & 0.52 \\
\hline 10 & S826 & 0.95 & 1.26 & 4 & 0.35 & 1.52 & 0.52 \\
\hline & & & & 5 & 0.45 & 1.39 & 0.39 \\
\hline & & & & 6 & 0.55 & 1.26 & 0.26 \\
\hline & & & & 7 & 0.65 & 1.13 & 0.13 \\
\hline & & & & 8 & 0.75 & 1.00 & 0.00 \\
\hline & & & & 9 & 0.85 & 1.13 & 0.13 \\
\hline & & & & 10 & 0.95 & 1.26 & 0.26 \\
\hline
\end{tabular}




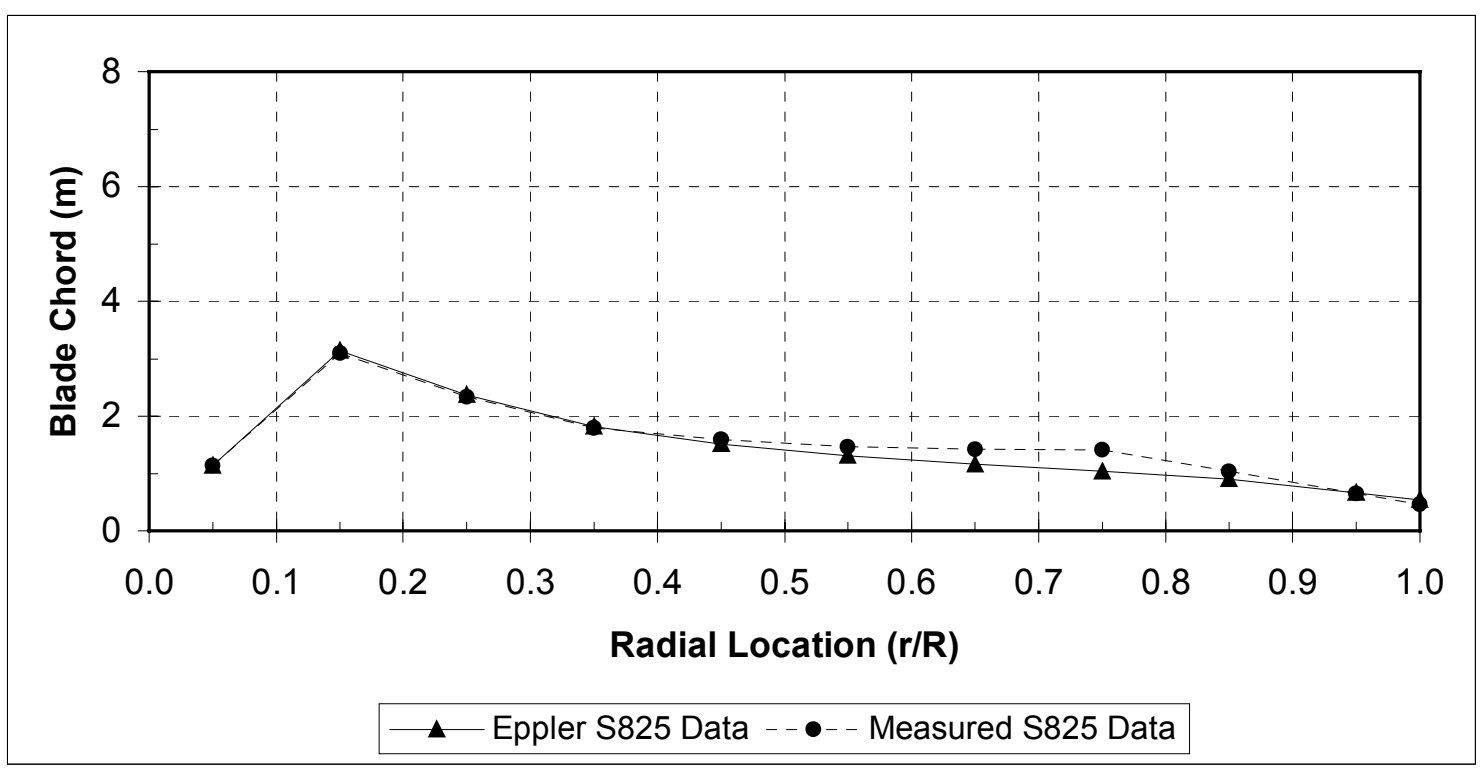

Figure 20. PROPID planforms for $\mathbf{S 8 1 8 / 8 2 5 / 8 2 6}$ blade, measured versus Eppler S285 data

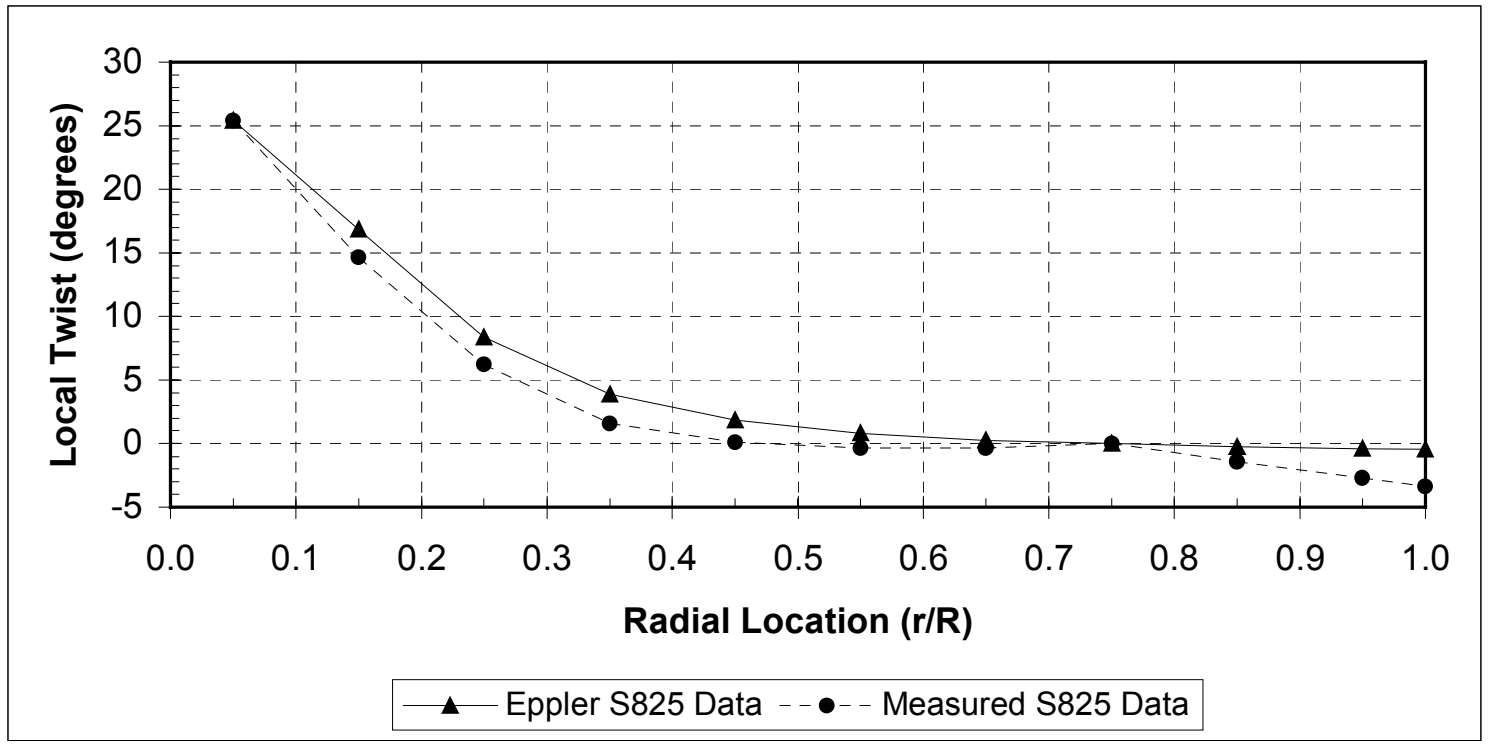

Figure 21. PROPID twist distributions for $\mathbf{S 8 1 8 / 8 2 5 / 8 2 6}$ blade, measured versus Eppler S285 data 


\section{Evaluation of Candidate Airfoil Families}

In this section, a comparison is made between near-optimal designs for the candidate airfoil families. The design for the $\mathrm{S} 818 / 825 / 826$ blade was described in detail in Section 4.2. A similar process was followed for the S818/827/828 and S815/809/810 families, with the input data and results summarized below.

\subsection{Assumptions / Constraints}

In addition to the constraints given in Section 2.2, the evaluation of candidate airfoil families assumes:

- The $35 \% \mathrm{R}$ airfoil shapes continue all the way to the root.

- No restrictions are imposed on allowable chord and twist distributions.

- $\quad$ Design TSR $=8$.

\subsection{Target Lift Distributions}

The target lift distributions for the S818/827/828 and S815/809/810 families are shown in Tables 4 and 5, respectively. Near-optimal rotor designs were obtained with PROPID, shifting these distributions as described in Section 4.2.2 and evaluating the resulting designs for power performance and $\mathrm{C}_{\mathrm{Pmax}}$.

Table 4. Baseline Target $C_{L}$ Distribution for $\mathbf{S 8 1 8 / 8 2 7 / 8 2 8}$ Airfoil Family

\begin{tabular}{|c|c|c|c|c|c|c|c|}
\hline \multicolumn{4}{|c|}{ Airfoil Family $C_{L}$ Distribution } & \multicolumn{4}{|c|}{ Target $C_{L}$ Distribution } \\
\hline Station \# & Airfoil & $r / R$ & $\mathrm{C}_{\mathrm{L}}$ at $\mathrm{L} / \mathrm{D}_{\max }$ & Station \# & $r / R$ & $\mathrm{C}_{\mathrm{L}}$ at $\mathrm{L} / \mathrm{D}_{\max }$ & $\mathrm{C}_{\mathrm{L}}$ w.r.t. $75 \% R$ \\
\hline 1 & S818 & 0.05 & 1.52 & 1 & 0.05 & 1.52 & 0.66 \\
\hline 4 & S818 & 0.35 & 1.52 & 2 & 0.15 & 1.52 & 0.66 \\
\hline 8 & S827 & 0.75 & 0.86 & 3 & 0.25 & 1.52 & 0.66 \\
\hline 10 & S828 & 0.95 & 0.84 & 4 & 0.35 & 1.52 & 0.66 \\
\hline & & & & 5 & 0.45 & 1.36 & 0.50 \\
\hline & & & & 6 & 0.55 & 1.19 & 0.33 \\
\hline & & & & 7 & 0.65 & 1.03 & 0.17 \\
\hline & & & & 8 & 0.75 & 0.86 & 0.00 \\
\hline & & & & 9 & 0.85 & 0.85 & -0.01 \\
\hline & & & & 10 & 0.95 & 0.84 & -0.02 \\
\hline
\end{tabular}

Table 5. Baseline Target $C_{L}$ Distribution for $\$ 815 / 809 / 810$ Airfoil Family

\begin{tabular}{|c|c|c|c|c|c|c|c|}
\hline \multicolumn{4}{|c|}{ Airfoil Family $C_{L}$ Distribution } & \multicolumn{4}{|c|}{ Target $C_{L}$ Distribution } \\
\hline Station \# & Airfoil & $r / R$ & $\mathrm{C}_{\mathrm{L}}$ at $\mathrm{L} / \mathrm{D}_{\max }$ & Station \# & $r / R$ & $\mathrm{C}_{\mathrm{L}}$ at $\mathrm{L} / \mathrm{D}_{\max }$ & $\mathrm{C}_{\mathrm{L}}$ w.r.t. $75 \% R$ \\
\hline 1 & $S 815$ & 0.05 & 1.21 & 1 & 0.05 & 1.21 & 0.48 \\
\hline 4 & S815 & 0.35 & 1.21 & 2 & 0.15 & 1.21 & 0.48 \\
\hline 8 & $S 809$ & 0.75 & 0.73 & 3 & 0.25 & 1.21 & 0.48 \\
\hline 10 & $\mathrm{~S} 810$ & 0.95 & 0.73 & 4 & 0.35 & 1.21 & 0.48 \\
\hline & & & & 5 & 0.45 & 1.09 & 0.36 \\
\hline & & & & 6 & 0.55 & 0.97 & 0.24 \\
\hline & & & & 7 & 0.65 & 0.85 & 0.12 \\
\hline & & & & 8 & 0.75 & 0.73 & 0.00 \\
\hline & & & & 9 & 0.85 & 0.73 & 0.00 \\
\hline & & & & 10 & 0.95 & 0.73 & 0.00 \\
\hline
\end{tabular}




\subsection{Summary of Airfoil Family Results}

Table 6 provides a summary of the PROPID results for the candidate airfoil families. For completeness, the design Reynolds number, $L / D_{\max }$, and thickness of each airfoil is also given. The values of $C_{L, 75 \% R}$ that correspond to the maximum power performance designs are also indicated. Comparison with the baseline $\mathrm{C}_{\mathrm{L}}$ distributions of Tables 4 and 5 show that the $\mathrm{C}_{\mathrm{L}, 75 \% \mathrm{R}}$ values for optimal performance are lower than $\mathrm{L} / \mathrm{D}_{\max }$.

Table 6. Near-Optimal Rotor Designs for Candidate Airfoil Families

\begin{tabular}{|c|c|c|c|c|c|c|c|}
\hline $\begin{array}{c}\text { Airfoil } \\
\text { Family }\end{array}$ & $\begin{array}{c}\text { Design Re } \\
\text { (millions) }\end{array}$ & $\begin{array}{c}\text { Maximum } \\
\mathbf{L} / \mathbf{D}\end{array}$ & $\begin{array}{c}\text { Thickness } \\
\mathbf{t} / \mathbf{c}_{\max }(\%)\end{array}$ & $\begin{array}{c}\mathbf{C}_{\mathbf{L}, 75 \%} \\
\mathbf{R}\end{array}$ & $\begin{array}{c}\mathbf{A E P} \mathbf{M}^{*} \\
\mathbf{M W h} / \\
\mathbf{y})\end{array}$ & $\mathbf{C}_{\mathbf{P m a x}}$ & $\begin{array}{c}\mathbf{R F B}_{\max } \\
(\mathbf{k N}-\mathbf{m})\end{array}$ \\
\hline $\mathrm{S} 818 / 825 / 826$ & $\begin{array}{c}2.5 / 2.0 / \\
1.5\end{array}$ & $\begin{array}{c}115 / 125 / \\
142\end{array}$ & $24 / 17 / 14$ & 1.15 & 966 & 0.5080 & 1,260 \\
\hline $\mathrm{S} 818 / 827 / 828$ & $\begin{array}{c}2.5 / 4.0 / \\
3.0\end{array}$ & $\begin{array}{c}115 / 154 / \\
170\end{array}$ & $24 / 21 / 16$ & 0.75 & 967 & 0.5106 & 1,550 \\
\hline $\mathrm{S} 815 / 809 / 810$ & $\begin{array}{c}1.2 / 2.0 / \\
2.0\end{array}$ & $\begin{array}{c}104 / 103 / \\
132\end{array}$ & $26 / 21 / 18$ & 0.65 & 954 & 0.5023 & 1,840 \\
\hline
\end{tabular}

*System AEP calculated for wind speeds $\leq 12 \mathrm{~m} / \mathrm{s}$

The S818/827/827 blade has the best power performance, with the S818/825/826 and S815/809/810 blades achieving peak $\mathrm{C}_{\mathrm{P}}$ values that are $0.5 \%$ and $1.6 \%$ lower, respectively. This trend would be expected by inspection of the $\mathrm{L} / \mathrm{D}_{\max }$ values for each family. Table 6 also lists the maximum root-flap bending $\left(\mathrm{RFB}_{\max }\right)$ for each blade design. These have been calculated for a 50 -year gust using the method and assumptions described in Section 2.4. The table shows that the RFB $\mathrm{max}_{\text {for }}$ fhe $\mathrm{S} 818 / 827 / 828$ and S $815 / 809 / 810$ blades are $23 \%$ and $43 \%$ higher, respectively than the $S 818 / 825 / 826$ blade.

Figure 22 shows the planforms corresponding to the near-optimal design for each airfoil family. Both of the families with low $C_{L}$ have significantly longer chords than the S818/825/826 blade, accounting for the higher values of calculated $\mathrm{RFB}_{\max }$. Also, these blades show a more pronounced non-linear bulging of the planform near $75 \%$ span than the S818/825/826 blade, and would likely require more smoothing (and associated performance losses) prior to developing a final design.

Before proceeding, it should be noted that the comparisons of $\mathrm{RFB}_{\max }$ contained in this report are based on the assumption that the maximum flap bending occurs as the result of a drag-based load case (i.e., extreme wind with blade pitched to the full power production position). However, the actual peak flap bending load is dependent on many factors, including the turbine architecture, control system and assumed fault cases. For instance, for a rotor with full-span pitch control, the blades may be assumed to be in fully-feathered position during a 50-year gust. In that case, the peak flap bending would be dominated by aerodynamic lift, and for the blade designs under consideration there would be offsetting effects between increased planform and the corresponding lower values of lift. 


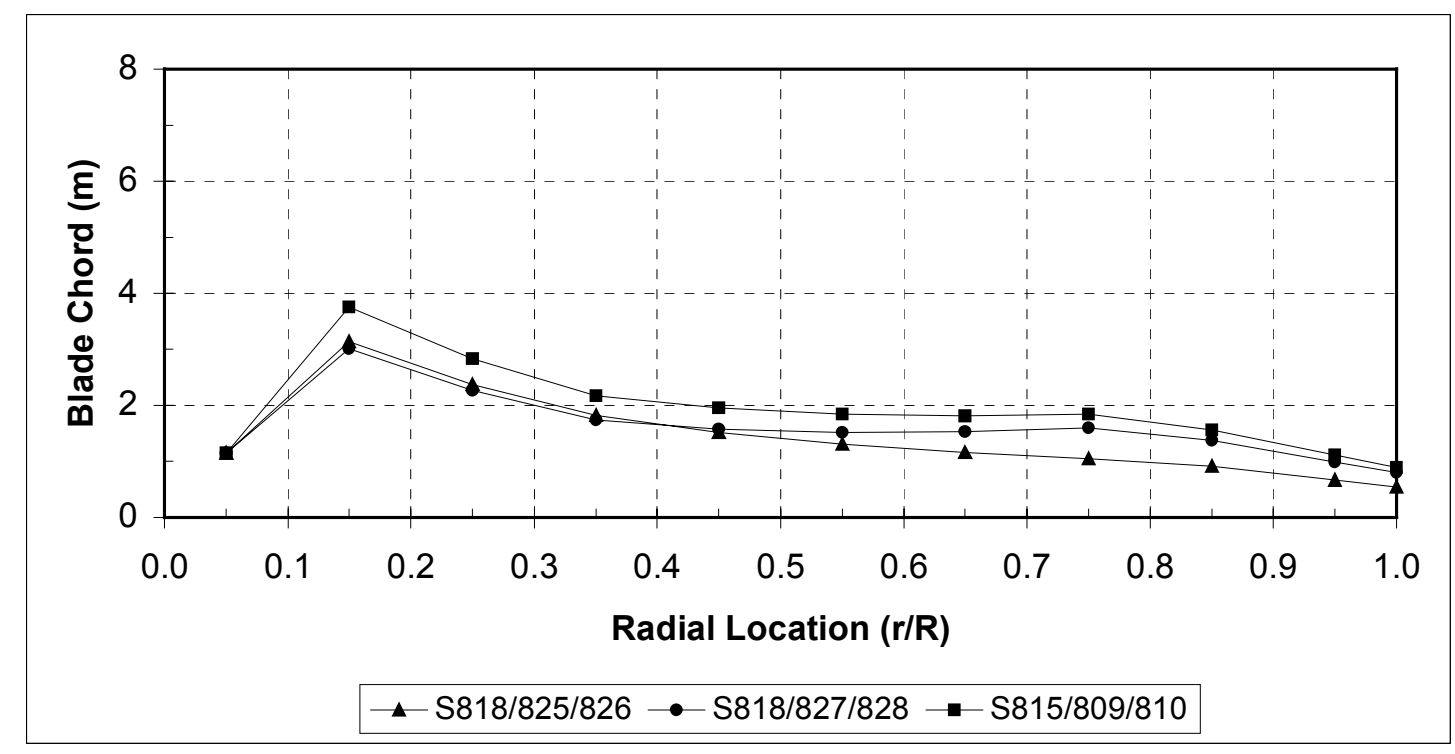

Figure 22. PROPID near-optimal planforms for candidate airfoil families

Figure 23 shows the calculated thrust versus power for each of the candidate airfoil families, which shows virtually no variation. This is because the blades with larger chords dimensions are operating at lower $\mathrm{C}_{\mathrm{L}}$, and the net resultant forces are nearly the same for each design. Based on this result it is expected that the steady aerodynamic component of the operating root-flap-bending moment would also be the same for each design, although the inertial and dynamic components would vary according to the differing blade structures.

Figure 24 shows the $\mathrm{C}_{\mathrm{P}}$-TSR curves for each airfoil family. It is evident that the peak $\mathrm{C}_{\mathrm{P}}$ occurs at the design TSR of 8, and that all three blade designs are relatively insensitive to off-design operation in the range of TSR $=7-9$. The S818/825/826 performance falls off more rapidly than the other two families at very high tip-speed ratios. As fixed-speed operation involves high tip speeds at low-to-moderate wind speeds, the S818/825/826 blade would have the poorest fixed-speed performance of the three designs considered. 


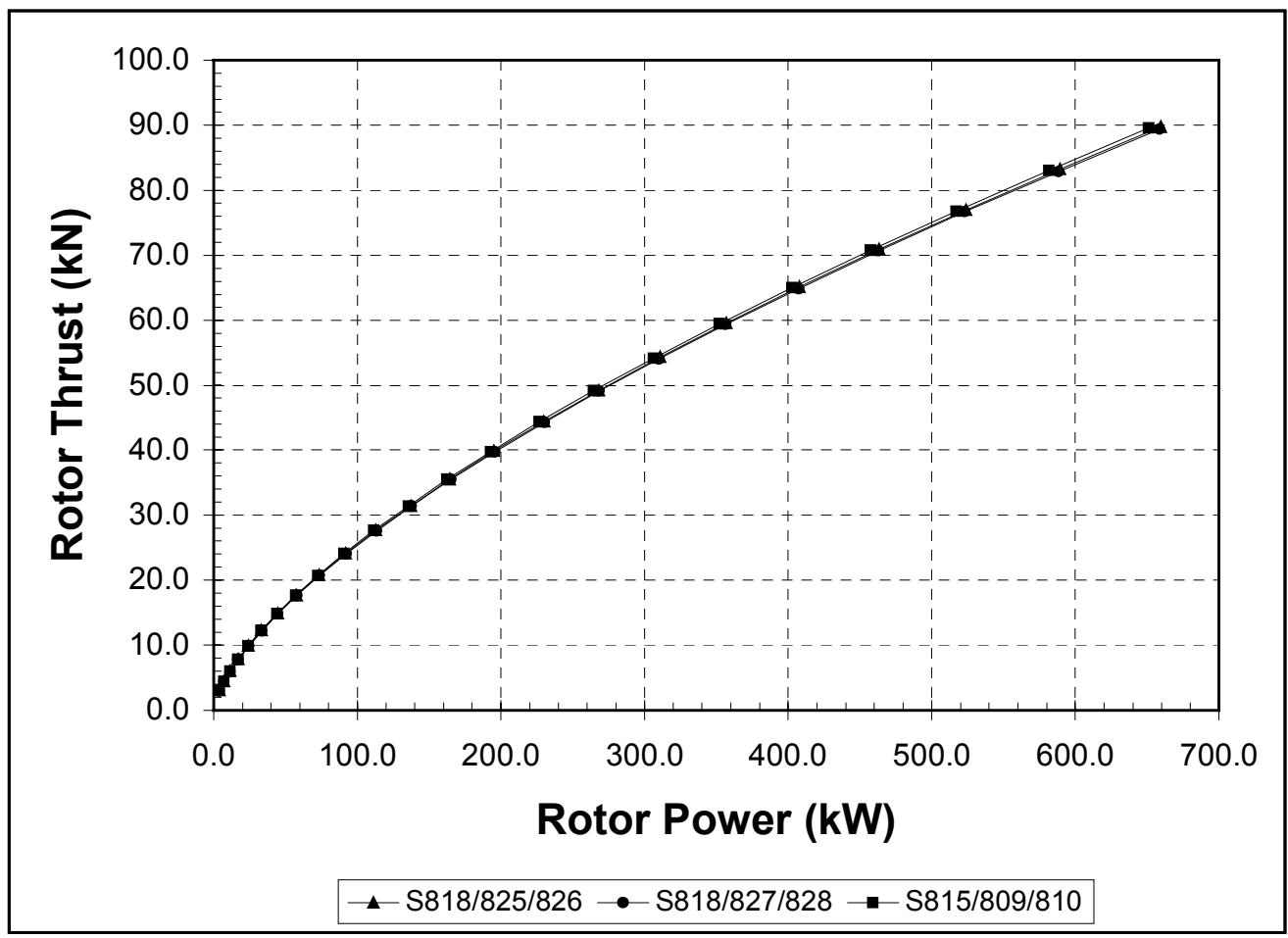

Figure 23. Calculated thrust versus power for candidate airfoil families

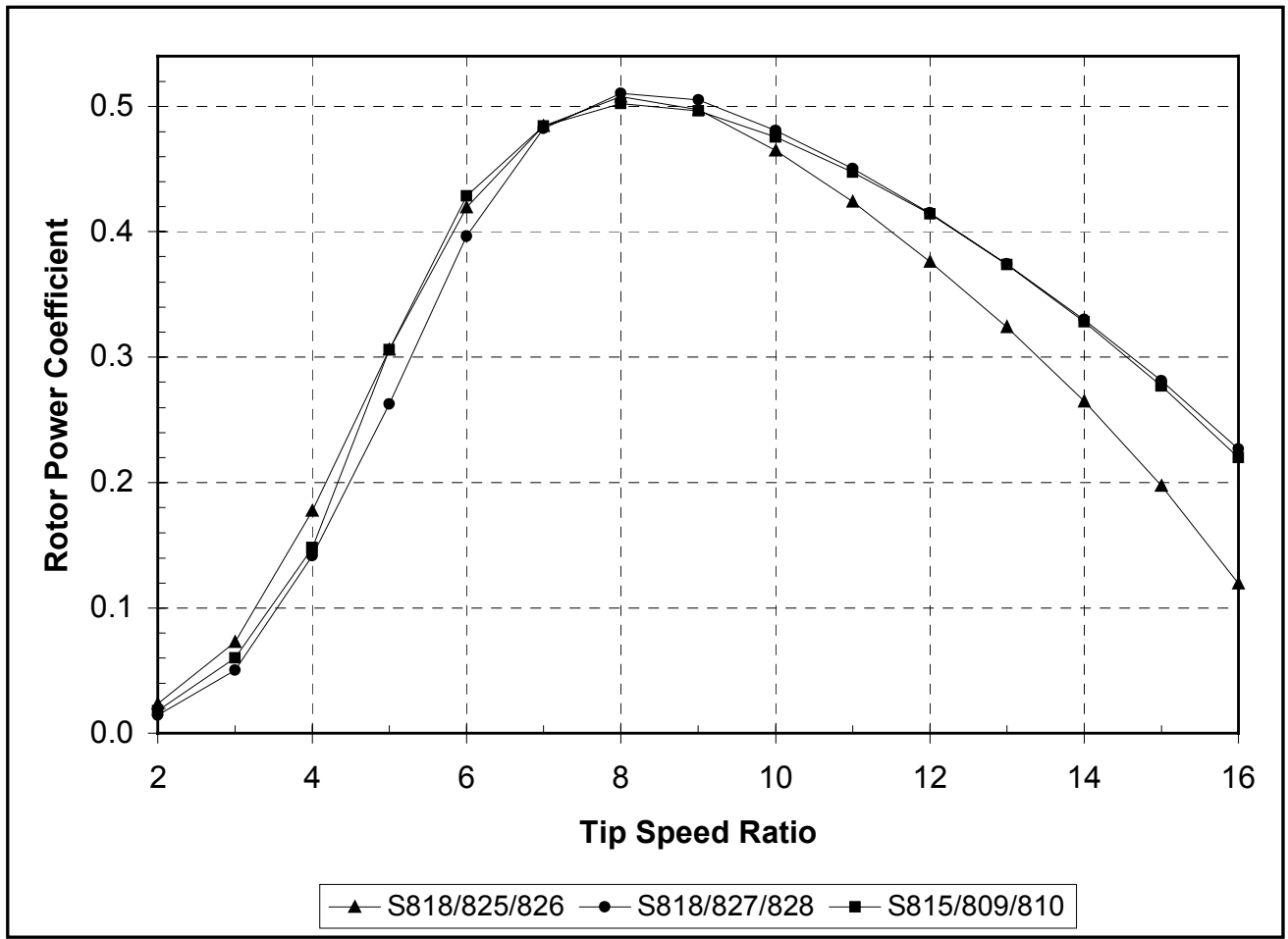

Figure 24. $C_{P}-$ TSR curves for candidate airfoil families 
Table 7 summarizes the advantages and disadvantages for each of the candidate airfoil families. For the purposes of the remaining ART-2B blade design studies, the S818/825/826 airfoil family was selected.

Table 7. Summary of Rotor Designs for Candidate Airfoil Families

\begin{tabular}{|c|c|c|}
\hline $\begin{array}{l}\text { Airfoil } \\
\text { Family }\end{array}$ & Advantages & Disadvantages \\
\hline S818/825/826 & $\begin{array}{l}\text { - } \text { Good peak } \mathrm{C}_{\mathrm{P}} \\
\text { - } \mathrm{S} 825 \text { tested at LTPT to high } \\
\text { confidence } \\
\text { - } \text { Smallest chord dimensions } \\
\text { - } \text { Planform nearest to linear; would } \\
\text { require the least smoothing } \\
\end{array}$ & $\begin{array}{l}\text { - Relatively thin sections would pose } \\
\text { structural challenges } \\
\text { - Lower energy capture for fixed-speed } \\
\text { operation } \\
\text { - High } C_{\text {Lmax }} \text { tip section not suitable for } \\
\text { pitch-to-stall power control }\end{array}$ \\
\hline S818/827/828 & $\begin{array}{l}\text { - } \text { Best peak } C_{P} \\
\text { - } \text { S827 tested at LTPT to high } \\
\text { confidence } \\
\text { - Good fixed-speed energy capture } \\
\text { - } \text { Good structural shapes }\end{array}$ & $\begin{array}{l}\text { - Could be "too laminar;" LTPT data } \\
\text { showed high soiling losses } \\
\text { - Variable-speed operation would be } \\
\text { below design Re at low wind speeds } \\
\text { - Large chord / peak bending loads } \\
\text { - Optimal planform has substantial non- } \\
\text { linear bulge; would require significant } \\
\text { smoothing } \\
\text { - LTPT data showed high } \mathrm{C}_{\text {Lmax }} \text {; not } \\
\text { suitable for pitch-to-stall power control }\end{array}$ \\
\hline S815/809/810 & $\begin{array}{l}\text { - Likely benign for stall power control } \\
\text { - Good fixed-speed energy capture } \\
\text { - Primary airfoil (S809) tested at Delft; } \\
\text { other airfoils tested in multiple } \\
\text { tunnels } \\
\text { - Best structural shapes }\end{array}$ & $\begin{array}{l}\text { - Lowest peak } \mathrm{C}_{\mathrm{P}} \\
\text { - Largest chord / peak bending loads } \\
\text { - Optimal planform has substantial non- } \\
\text { linear bulge; would require significant } \\
\text { smoothing }\end{array}$ \\
\hline
\end{tabular}




\section{Sweep of Design TSR for Blade Using S818/825/826 Airfoils}

A sweep of design tip-speed ratios was performed for blades using the S818/825/826 airfoil family. As with the previous design studies, no restriction was placed on the allowable chord and twist distributions, and the inboard airfoil (S818) shape was assumed to continue all the way to the root. It was determined that $\mathrm{C}_{\mathrm{L}, 75 \% \mathrm{R}}=1.15$ resulted in the highest $\mathrm{C}_{\mathrm{Pmax}}$ for all design TSRs considered, so that value was used for the designs shown.

Table 8 shows the summary results for the TSR sweep. The peak power performance is found at a design $\mathrm{TSR}=9$, with the peak $\mathrm{C}_{\mathrm{P}}$ about $0.3 \%$ higher than at design TSR $=8$ and a slow decline in power performance for TSR above 9 . The power performance falls off more rapidly at lower design TSRs. Table 8 also shows the chord length at $75 \%$ span and the calculated peak (50-year) root flap bending for each near-optimal design. As expected, the blades become more slender and $\mathrm{RFB}_{\max }$ decreases as design TSR is increased. This trend is more pronounced below TSR $=8$, and the incremental changes diminish at high design TSR.

Table 8. Summary Results for Study of Design TSR, S818/825/826 Blades

\begin{tabular}{|c|c|c|c|c|c|c|c|}
\hline $\begin{array}{c}\text { Design } \\
\text { TSR }\end{array}$ & $\begin{array}{c}\text { AEP* } \\
(\mathbf{M W h} / \mathbf{y})\end{array}$ & $\begin{array}{l}\Delta \text { AEP w.r.t. } \\
\text { TSR }=8(\%)\end{array}$ & $\mathbf{C}_{\text {Pmax }}$ & $\begin{array}{c}\Delta C_{\text {Pmax }} \text { w.r.t. } \\
\text { TSR=8 (\%) }\end{array}$ & $\begin{array}{c}\text { Chord at } 75 \% \\
\text { R (cm) } \\
\end{array}$ & $\begin{array}{c}\mathrm{RFB}_{\text {max }} \\
(\mathrm{kN}-\mathrm{m})\end{array}$ & $\begin{array}{c}\mathrm{RFB}_{\max } \text { w.r.t. } \\
\mathrm{TSR}=\mathbf{8}(\%)\end{array}$ \\
\hline 6 & 947 & -1.97 & 0.4988 & -1.81 & 179.2 & 2,095 & +65 \\
\hline 7 & 959 & -0.73 & 0.5048 & -0.62 & 134.4 & 1,609 & +27 \\
\hline 8 & 966 & - & 0.5080 & - & 104.2 & 1,270 & - \\
\hline 9 & 970 & +0.41 & 0.5094 & +0.28 & 83.2 & 1,029 & -19 \\
\hline 10 & 970 & +0.41 & 0.5093 & +0.26 & 67.7 & 850 & -33 \\
\hline 11 & 968 & +0.21 & 0.5081 & +0.02 & 56.1 & 715 & -44 \\
\hline
\end{tabular}

System AEP calculated for wind speeds $\leq 12 \mathrm{~m} / \mathrm{s}$

Figure 26 shows the operating rotor thrust versus power for the range of tip-speed ratios considered. The thrust versus power curves show very little variation with design TSR, with the increase in blade speed at high TSR designs being nearly offset by the corresponding decrease in rotor solidity. Again, it should be noted that the result of Figure 25 is for the steady aerodynamic component of thrust, and that non-steady thrust variations due to blade-turbine dynamic interaction and response to turbulent inflow could show a stronger dependence on the blade designs considered.

Figure 26 shows the variable-speed rpm schedule required to track peak $\mathrm{C}_{\mathrm{P}}$ for each TSR. Each curve assumes that peak $C_{P}$ is tracked up to rated power and that active (pitch) power control is implemented for all wind speeds above rated. The figure shows that for design TSR $\geq 8$, tracking peak $\mathrm{C}_{\mathrm{P}}$ up to rated implies exceedance of the baseline ART-1 rotor speed (42 rpm). Alternately, rotors with design TSR $\geq 8$ could be controlled to track peak $\mathrm{C}_{\mathrm{P}}$ up to a selected maximum rotor speed and operate at less than peak $\mathrm{C}_{\mathrm{P}}$ between that point and rated power. Inspection of Figure 26 shows that the power performance penalty for limiting rotor speed to $42 \mathrm{rpm}$ would be minimal for design TSR $=8$ and increase for higher design tip-speed ratios. 


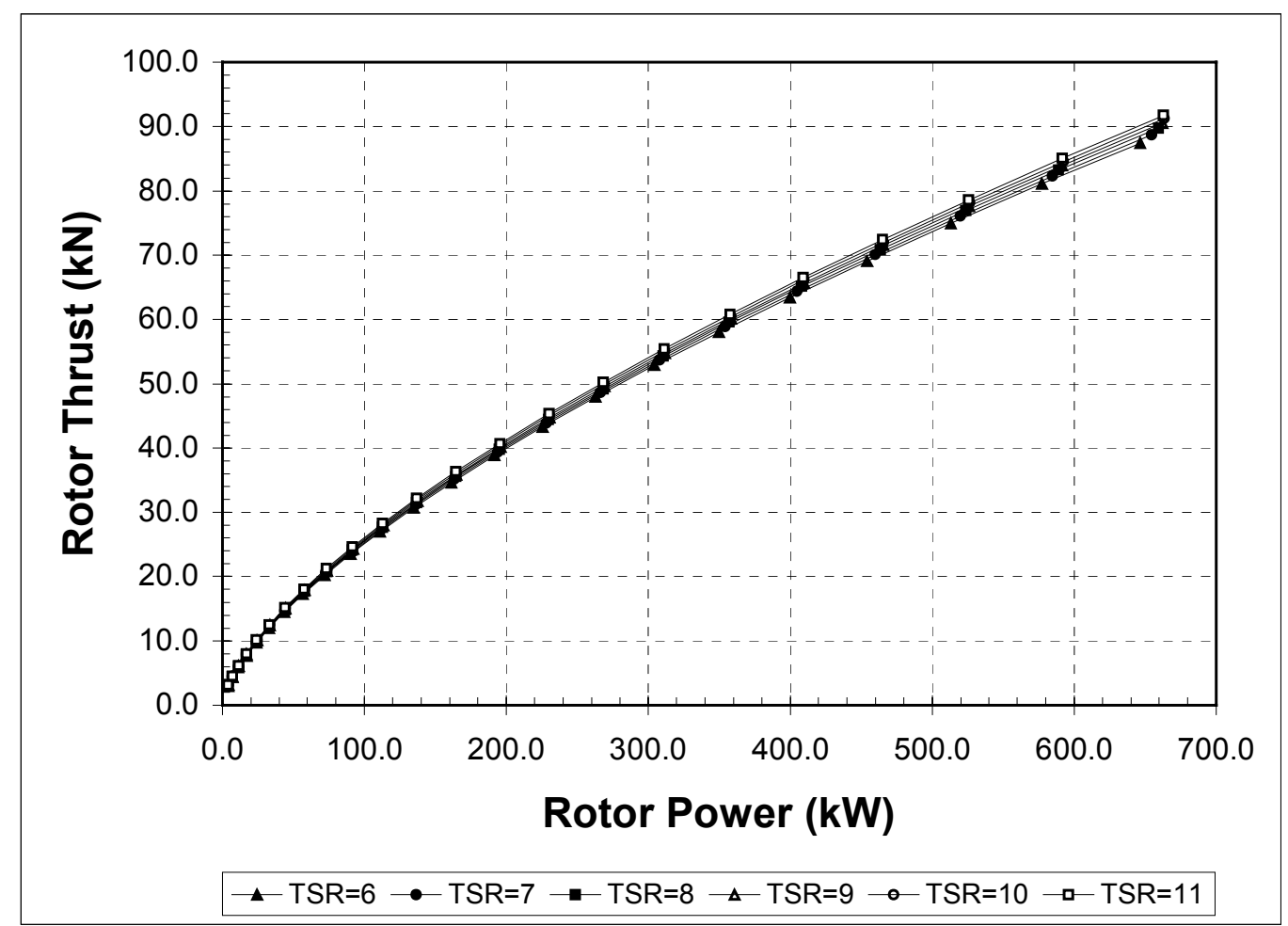

Figure 25. Thrust versus power for $\mathbf{S 8 1 8 / 8 2 5 / 8 2 6}$ blades at varying design TSR

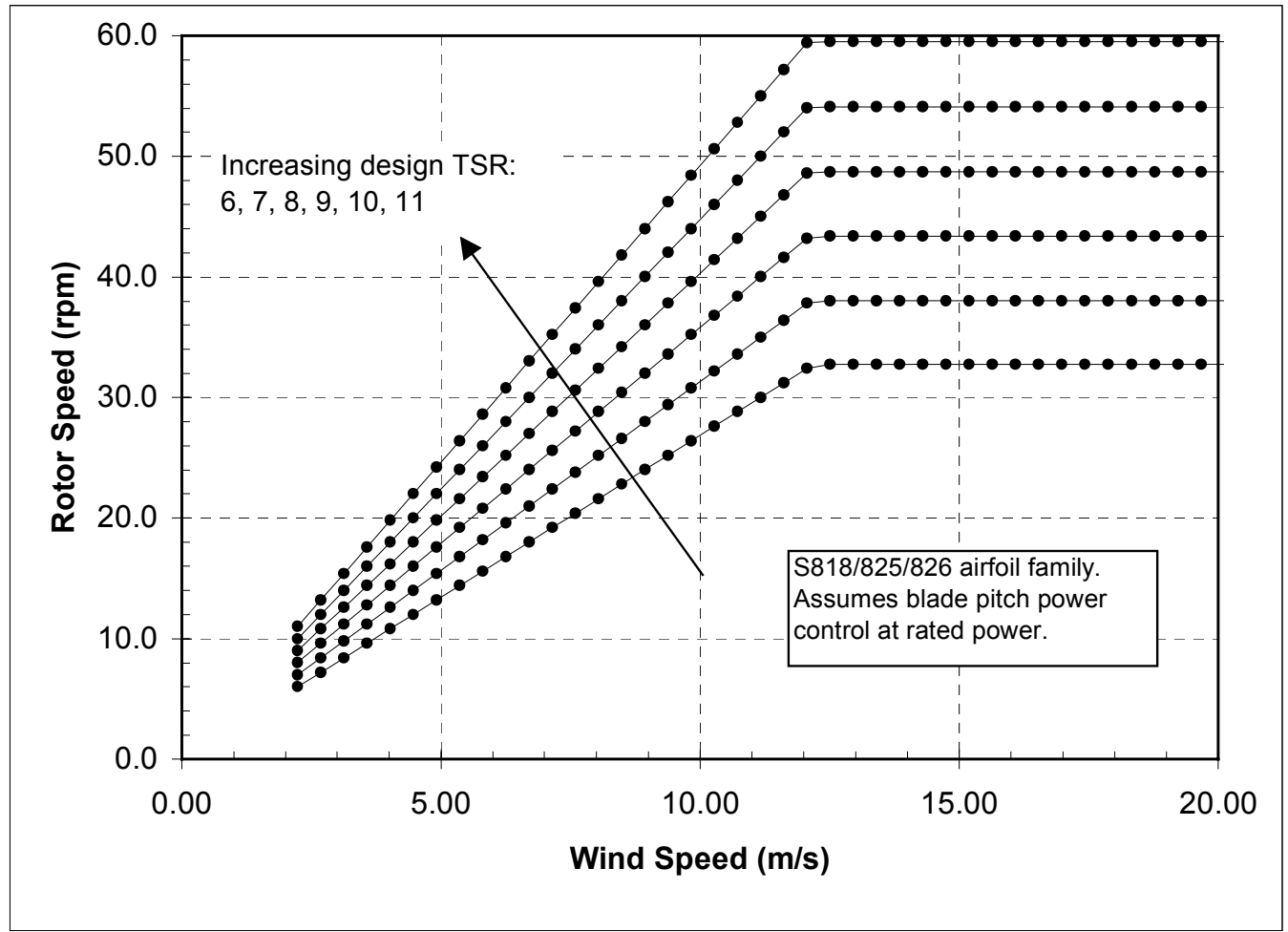

Figure 26. RPM Schedule for optimal VS operation at varying design TSR 
Figure 27 shows $\mathrm{C}_{\mathrm{P}}$-TSR curves for near-optimal S818/825/826 rotors designed for TSR of 7 and 8 . The rotor designed for TSR $=7$ shows a greater penalty in $\mathrm{C}_{\mathrm{P}}$ for operating at TSRs below the design point than does the TSR $=8$ rotor. The sensitivity of $\mathrm{C}_{\mathrm{P}}$ to operating at TSRs above the design values is roughly the same for both rotors. Figure 28 shows the near-optimal planforms for TSR $=7$ and 8 . In addition to the longer chord lengths, the TSR $=7$ blade is lightly more non-linear in the tip region than the $\mathrm{TSR}=8$ blade.

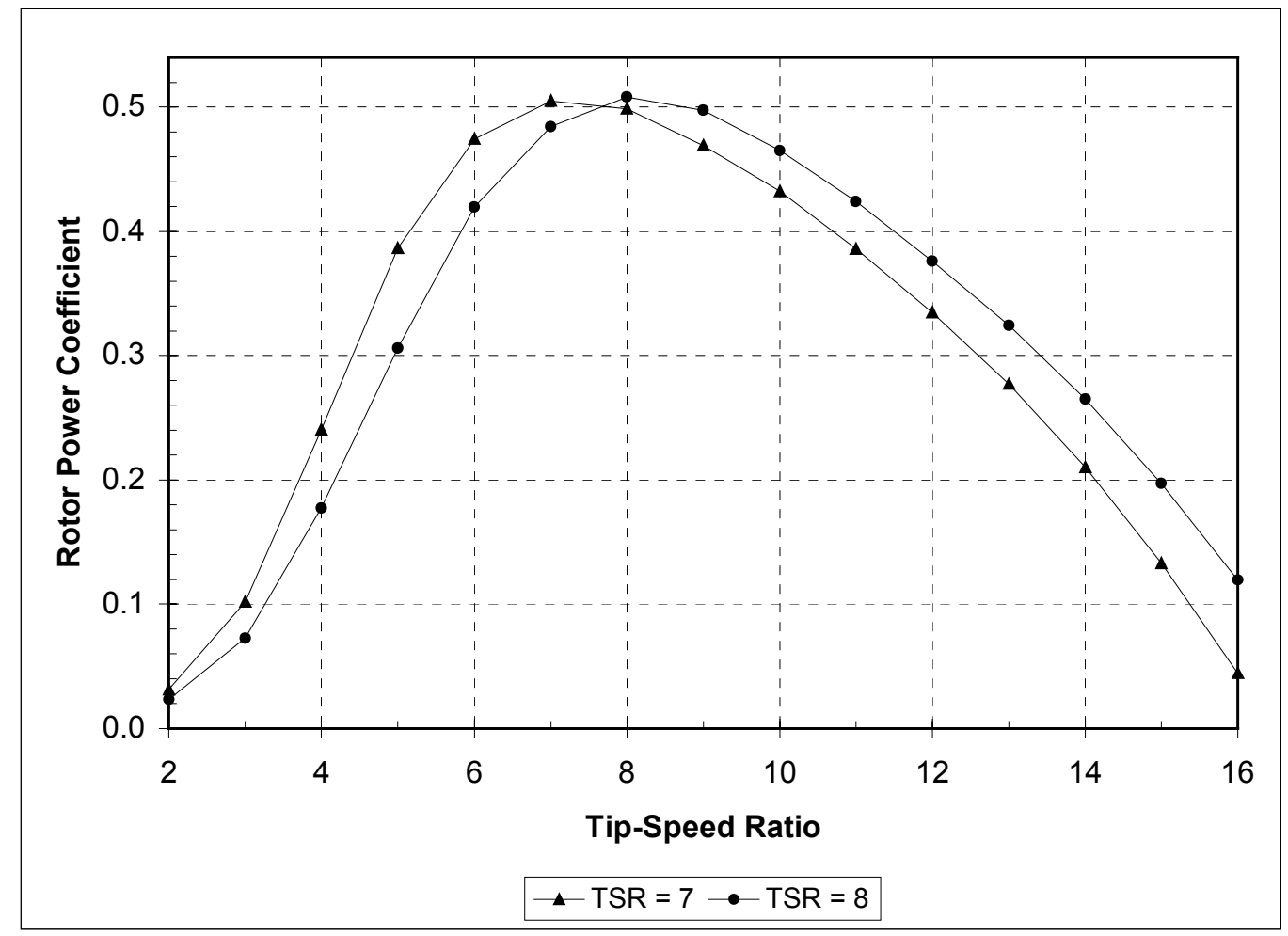

Figure 27. $C_{P}-T S R$ curves for near-optimal $\$ 818 / 825 / 826$ blades

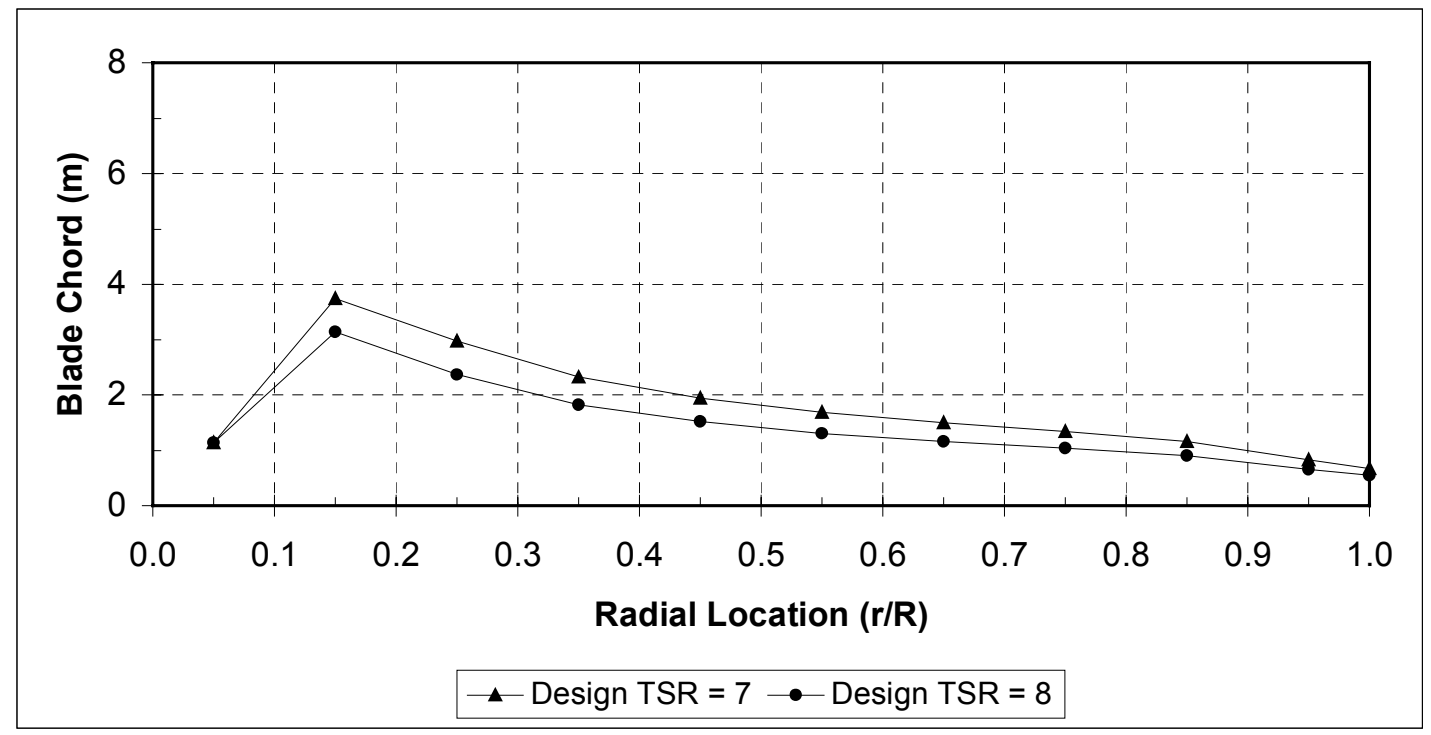

Figure 28. Planforms for near-optimal S818/825/826 blades 


\section{Detailed Aerodynamic Design}

The designs of the previous sections have used fairly ideal inputs with minimal constraints on the resulting designs. While this approach is suitable for trade-off and sensitivity studies, additional details and constraints must be considered during detailed aerodynamic design. The following sections present some aspects of the detailed design for a blade using the S818/825/826 airfoil family at design TSR $=8$.

\subsection{Effect of Varying Lift Distributions}

As shown in Section 4.2.2, the power performance optimum with respect to $C_{L, 75 \% R}$ can be very flat. The designer may, therefore, consider the implications of designing for a $C_{L, 75 \% R}$ that varies from the peak $\mathrm{C}_{\mathrm{Pmax}}$ value. Table 9 presents a summary of the $\mathrm{C}_{\mathrm{L}, 75 \% \mathrm{R}}$ effects on power performance, planform, and the associated peak root flap bending. As seen in the table, within the range of 1.05 to 1.25 , the effect of $\mathrm{C}_{\mathrm{L}, 75 \% \mathrm{R}}$ on power performance is essentially negligible. Blades designed for higher $\mathrm{C}_{\mathrm{L}}$ have a more slender planform and lower peak bending loads, roughly $4 \%-5 \%$ decrease per 0.05 of lift coefficient. As was seen in earlier design studies, the steady rotor thrust/power is invariant with $\mathrm{C}_{\mathrm{L}, 75 \% \mathrm{R}}$, with the increase in local lift offset by the smaller chord (result not shown).

Table 9. Summary Effects of Varying CL,75\%R for S818/825/826 Blade at Design TSR =8

\begin{tabular}{|c|c|c|c|c|c|c|c|}
\hline $\mathbf{C}_{\mathbf{L}, 75 \% \mathbf{R}}$ & $\begin{array}{c}\mathbf{A E P} \\
(\mathbf{M W h} / \mathbf{y})\end{array}$ & $\begin{array}{c}\Delta \mathbf{A E P} \text { w.r.t. } \\
\mathbf{T S R}=\mathbf{8}(\mathbf{\%})\end{array}$ & $\mathbf{C}_{\mathbf{P m a x}}$ & $\begin{array}{c}\Delta \mathbf{C}_{\mathbf{P} \max } \mathbf{w . r . t .} \\
\mathbf{C}_{\mathbf{L}, 75 \% \mathbf{R}}=\mathbf{1 . 1 5}\end{array}$ & $\begin{array}{c}\text { Chord at 75\% } \\
\mathbf{R}(\mathbf{c m})\end{array}$ & $\begin{array}{c}\mathbf{R F B}_{\max } \\
(\mathbf{k N}-\mathbf{m})\end{array}$ & $\begin{array}{c}\Delta \mathbf{R F B}_{\max } \mathbf{w . r . t .} \\
\mathbf{C}_{\mathbf{L}, 75 \% \mathbf{R}}=\mathbf{1 . 1 5}\end{array}$ \\
\hline 1.05 & 966 & 0 & 0.5074 & $-0.12 \%$ & 114.3 & 1,381 & $+8.7 \%$ \\
\hline 1.10 & 966 & 0 & 0.5079 & $-0.02 \%$ & 109.1 & 1,323 & $+4.2 \%$ \\
\hline 1.15 & 966 & - & 0.5080 & - & 104.2 & 1,270 & - \\
\hline 1.20 & 965 & +0.10 & 0.5076 & $-0.08 \%$ & 100.0 & 1,221 & $-3.8 \%$ \\
\hline 1.25 & 962 & +0.42 & 0.5063 & $-0.33 \%$ & 96.0 & 1,176 & $-7.2 \%$ \\
\hline 1.30 & 956 & +1.01 & 0.5040 & $-0.79 \%$ & 92.3 & 1,126 & $-11.3 \%$ \\
\hline
\end{tabular}

* System AEP calculated for wind speeds $\leq 12 \mathrm{~m} / \mathrm{s}$

Figure 29 shows $C_{P}$-TSR curves for $C_{L, 75 \% R}$ values ranging from 1.1 to 1.3. As seen in the figure, the $C_{P}$ curves become more narrow with increased $\mathrm{C}_{\mathrm{L}, 75 \% \mathrm{R}}$. Thus, designing for a high lift distribution can result in a more slender blade with a minimal penalty in peak power performance, but the resulting rotor may be more sensitive to off-design operation. 


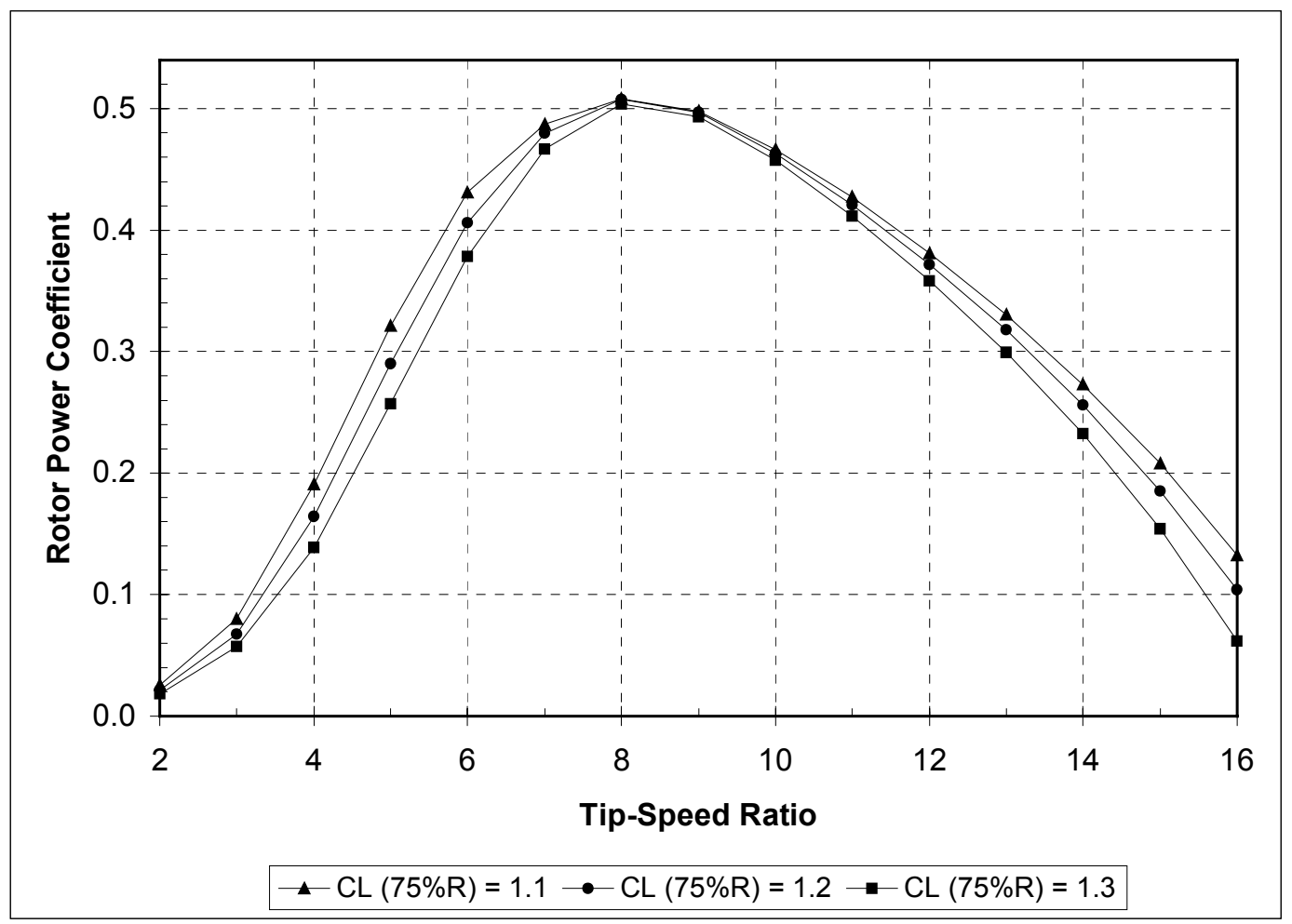

Figure 29. Effect of varying $C_{L, 75 \% R}$ on $C_{P}-T S R$ curve

\subsection{Performance Losses Due to Imposed Design Details}

The previous design studies have all assumed a lifting airfoil shape extended all the way to the blade root and have had no restrictions imposed on the allowable chord and twist distributions. However, for considerations of cost, weight, and/or structural efficiency, it is usual for the designer to impose some constraints on these items. Common constraints and imposed design features include a transition to a non-lifting root section (i.e., circular root), imposed linear taper of planform, and constrained twist schedule.

Figures 30 and 31 show the planform and twist distribution, respectively, for the near-optimal blade as determined by PROPID for the S818/825/826 airfoil family at design TSR $=8$. The figures also show an imposed linear taper and a truncated twist schedule that have been used for analysis and an evaluation of the resulting loss in power performance. The taper shown in Figure 30 was developed by trial-and-error to find a linear fit to the original PROPID planform that resulted in minimal loss of power performance. The truncated twist schedule of Figure 31 is an arbitrary deviation from the twist calculated by PROPID. 


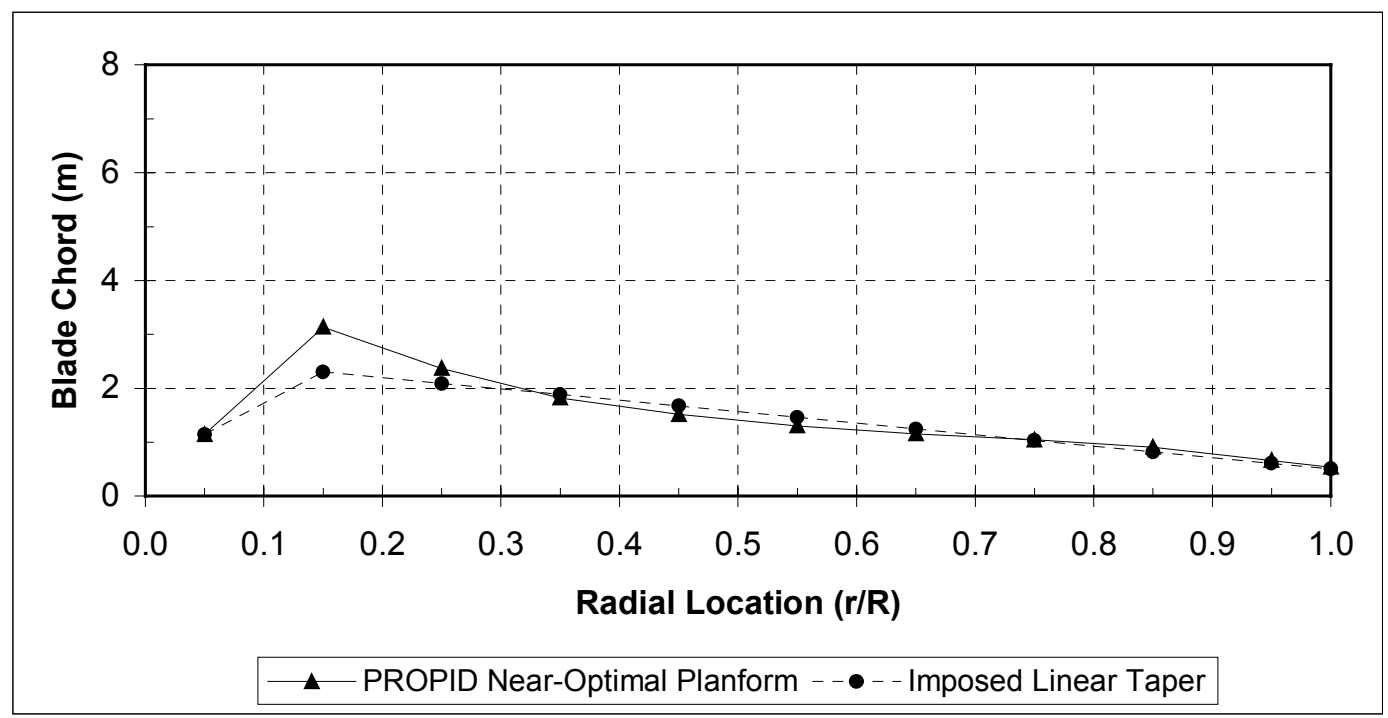

Figure 30. Imposed linear taper for $\mathbf{S 8 1 8 / 8 2 5 / 8 2 6}$ blade

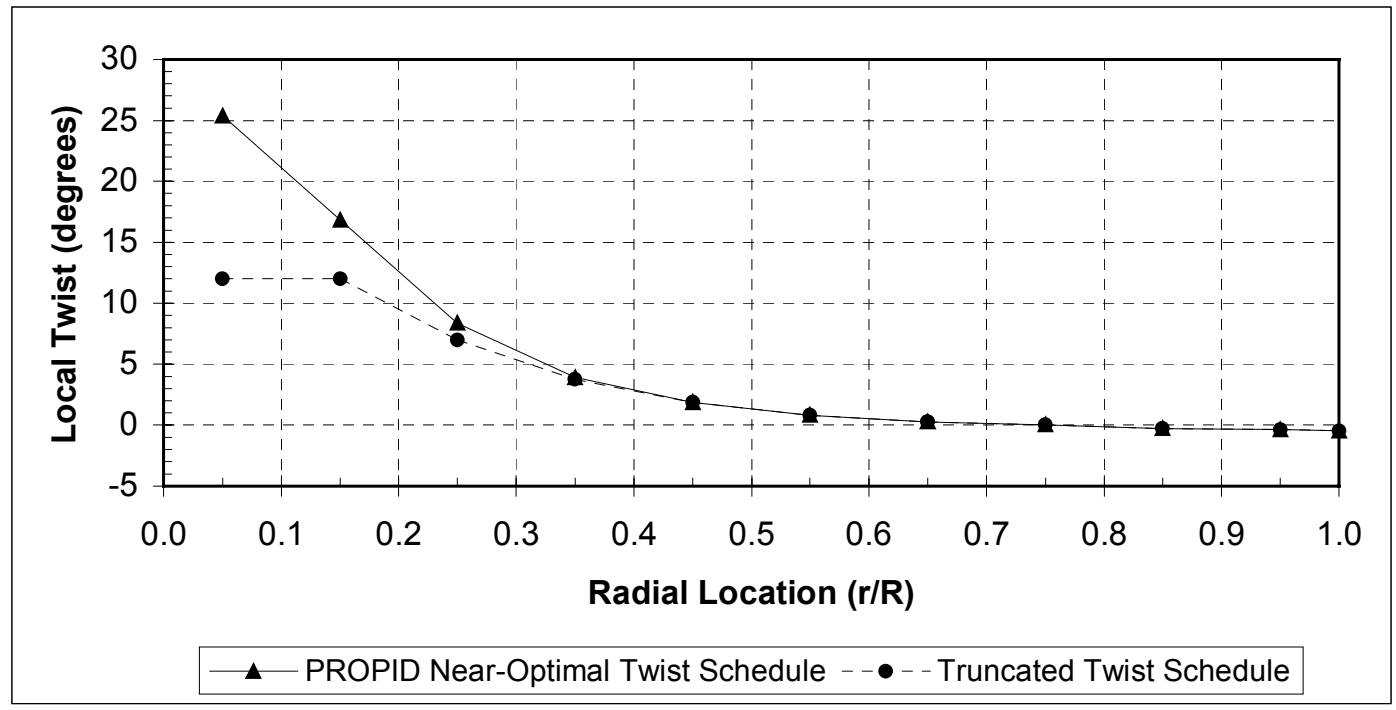

Figure 31. Truncated twist schedule for $\$ 818 / 825 / 826$ blade

Table 10 summarizes the effects on power performance of the imposed linear planform and truncated twist schedule shown in Figures 30 and 31, as well as the effect of including the transition to a non-lifting root in the analysis. Note that each intermediate entry in Table 10 considers the isolated effect of a single design detail, and the final entry is the cumulative effect of all three details. The effect of including a non-lifting root in the analysis is seen to be negligible, and the effect of truncating the twist schedule is also small. The effect of imposing a linear taper, however, is a non-trivial $1.3 \%$ loss in performance. An analysis of this loss was performed, and it was determined that although the changes appear very subtle in Figure 30, over half of the performance loss $(0.7 \%)$ was due to the altered chords outboard of $75 \%$ span. This underscores the importance this region, and the care that must be given to design details near the blade tip. Note also that all of the AEP sensitivities shown above were calculated for wind speeds $\leq 12 \mathrm{~m} / \mathrm{s}$, and the incremental effects would be smaller if calculated over a full range of operational wind speeds. 
Table 10. Effect of Design Details on S818/825/826 Blade

\begin{tabular}{|c|c|c|c|}
\hline Case & $\mathbf{A E P}^{*}(\mathbf{M W h} / \mathbf{y})$ & $\mathbf{C}_{\mathbf{P m a x}}$ & $\mathbf{\Delta C}_{\mathbf{P m a x}}(\mathbf{\%})$ \\
\hline Baseline & 966.3 & 0.5080 & - \\
\hline Linear planform & 953.7 & 0.5013 & -1.32 \\
\hline Truncated twist & 963.7 & 0.5067 & -0.26 \\
\hline Non-lifting root & 965.5 & 0.5076 & -0.08 \\
\hline All details above & 951.9 & 0.5007 & -1.44 \\
\hline
\end{tabular}

*AEP calculated for wind speeds $\leq 12 \mathrm{~m} / \mathrm{s}$

\subsection{Comparison of Power Performance with ART-1 and ART-2A Rotors}

Table 11 gives a tabular description of the S818/825/826 blade geometry with the design details (linear taper and truncated twist distribution) as indicated in Figures 30 and 31. An analysis of this blade has been used to compare with the calculated power performance of the ART-1 and ART-2A rotors. The AEP calculations for these comparisons are shown in Table 12. Because the calculated ART-1 power curve does not reach rated power until $13.5 \mathrm{~m} / \mathrm{s}$ (due to the lower efficiency of the airfoils), all the comparative AEP calculations have been made inclusive of this wind speed. Note also that the rotor power curves (rather than the system power) have been used in the AEP comparisons of this section.

Table 11. Blade Geometry for S818/825/826 with Aerodynamic Design Details

\begin{tabular}{|c|c|c|c|c|}
\hline $\begin{array}{c}\text { Station } \\
(\mathbf{r} / \mathbf{R})\end{array}$ & Section Shape & $\begin{array}{c}\text { Radial } \\
\text { Location }(\mathbf{m})\end{array}$ & $\begin{array}{c}\text { Chord } \\
\text { Length (m) }\end{array}$ & $\begin{array}{c}\text { Twist } \\
\text { (degrees) }\end{array}$ \\
\hline 0.065 & WWG-600 root & 1.38 & 1.143 & 12.00 \\
\hline 0.15 & Transition to S818 & 3.20 & 3.139 & 12.00 \\
\hline 0.25 & Transition to S818 & 5.33 & 2.374 & 7.00 \\
\hline 0.35 & S818 & 7.47 & 1.819 & 3.75 \\
\hline 0.45 & Hybrid S818/S825 & 9.60 & 1.515 & 1.86 \\
\hline 0.55 & Hybrid S818/ S825 & 11.73 & 1.309 & 0.83 \\
\hline 0.65 & Hybrid S818/S825 & 13.87 & 1.160 & 0.27 \\
\hline 0.75 & S825 & 16.00 & 1.044 & 0.00 \\
\hline 0.85 & Hybrid S825/S826 & 18.14 & 0.909 & -0.28 \\
\hline 0.95 & S826 & 20.27 & 0.665 & -0.40 \\
\hline 1.00 & S826 & 21.34 & 0.543 & -0.46 \\
\hline
\end{tabular}


Table 12. AEP Calculations for ART Rotor Power Curves

\begin{tabular}{|c|c|c|c|c|c|c|c|c|c|c|c|c|}
\hline \multirow{2}{*}{$\begin{array}{c}\text { WS } \\
\text { Bin } \\
(\mathrm{m} / \mathrm{s})\end{array}$} & \multirow{2}{*}{$\begin{array}{c}\text { Hours } \\
\text { Per } \\
\text { Year }\end{array}$} & \multicolumn{2}{|c|}{ ART-1 } & \multicolumn{3}{|c|}{ ART-2A } & \multicolumn{3}{|c|}{ ART-2B (variable speed) } & \multicolumn{3}{|c|}{ ART-2B (fixed-speed oper.) } \\
\hline & & $\begin{array}{l}P_{\text {Rotor }} \\
(\mathrm{kW})\end{array}$ & $\begin{array}{c}\mathrm{E}_{\text {Rotor }} \\
(\mathrm{kWh})\end{array}$ & $\begin{array}{l}P_{\text {Rotor }} \\
(\mathrm{kW})\end{array}$ & $\begin{array}{c}\mathrm{E}_{\text {Rotor }} \\
(\mathrm{kWh})\end{array}$ & $\begin{array}{l}\text { Var. } \\
(\%)\end{array}$ & $\begin{array}{l}P_{\text {Rotor }} \\
(\mathrm{kW})\end{array}$ & $\begin{array}{c}\mathrm{E}_{\text {Rotor }} \\
(\mathrm{kWh})\end{array}$ & $\begin{array}{l}\text { Var. } \\
(\%)\end{array}$ & $\begin{array}{l}P_{\text {Rotor }} \\
(\mathrm{kW})\end{array}$ & $\begin{array}{c}\mathrm{E}_{\text {Rotor }} \\
(\mathrm{kWh})\end{array}$ & $\begin{array}{l}\text { Var. } \\
(\%)\end{array}$ \\
\hline 3.0 & 386.5 & 0.0 & 0 & 8.5 & 3,287 & $\mathrm{~N} / \mathrm{A}$ & 10.0 & 3,864 & $\mathrm{~N} / \mathrm{A}$ & 0.0 & 0 & $\mathrm{~N} / \mathrm{A}$ \\
\hline 3.5 & 407.0 & 0.0 & 0 & 13.5 & 5,496 & $\mathrm{~N} / \mathrm{A}$ & 15.8 & 6,433 & $\mathrm{~N} / \mathrm{A}$ & 0.0 & 0 & N/A \\
\hline 4.0 & 420.0 & 0.0 & 0 & 20.2 & 8,465 & N/A & 23.5 & 9,877 & $\mathrm{~N} / \mathrm{A}$ & 0.0 & 0 & N/A \\
\hline 4.5 & 426.1 & 0.0 & 0 & 28.7 & 12,229 & N/A & 33.5 & 14,294 & $\mathrm{~N} / \mathrm{A}$ & 0.0 & 0 & N/A \\
\hline 5.0 & 426.2 & 0.0 & 0 & 39.4 & 16,780 & N/A & 46.2 & 19,677 & N/A & 0.0 & 0 & $\mathrm{~N} / \mathrm{A}$ \\
\hline 5.5 & 421.1 & 7.6 & 3,185 & 52.4 & 22,066 & 592.8 & 61.5 & 25,919 & 713.8 & 3.9 & 1,661 & -47.8 \\
\hline 6.0 & 411.5 & 27.3 & 11,238 & 68.0 & 27,994 & 149.1 & 80.0 & 32,909 & 192.8 & 24.6 & 10,106 & -10.1 \\
\hline 6.5 & 398.1 & 49.8 & 19,818 & 86.5 & 34,436 & 73.8 & 101.7 & 40,491 & 104.3 & 48.6 & 19,369 & -2.3 \\
\hline 7.0 & 381.7 & 75.2 & 28,690 & 108.0 & 41,237 & 43.7 & 127.0 & 48,478 & 69.0 & 76.8 & 29,330 & 2.2 \\
\hline 7.5 & 362.9 & 104.3 & 37,835 & 132.9 & 48,221 & 27.5 & 156.1 & 56,664 & 49.8 & 109.8 & 39,856 & 5.3 \\
\hline 8.0 & 342.4 & 137.0 & 46,919 & 161.3 & 55,205 & 17.7 & 189.4 & 64,836 & 38.2 & 148.3 & 50,772 & 8.2 \\
\hline 8.5 & 320.6 & 173.9 & 55,753 & 193.4 & 62,004 & 11.2 & 227.1 & 72,794 & 30.6 & 192.4 & 61,670 & 10.6 \\
\hline 9.0 & 298.1 & 215.2 & 64,139 & 229.6 & 68,441 & 6.7 & 269.8 & 80,429 & 25.4 & 241.6 & 72,004 & 12.3 \\
\hline 9.5 & 275.4 & 260.9 & 71,845 & 270.0 & 74,353 & 3.5 & 317.4 & 87,408 & 21.7 & 296.3 & 81,575 & 13.5 \\
\hline 10.0 & 252.7 & 309.6 & 78,253 & 314.9 & 79,600 & 1.7 & 370.3 & 93,580 & 19.6 & 356.5 & 90,096 & 15.1 \\
\hline 10.5 & 230.6 & 360.2 & 83,065 & 364.6 & 84,067 & 1.2 & 428.5 & 98,810 & 19.0 & 421.5 & 97,189 & 17.0 \\
\hline 11.0 & 209.1 & 413.3 & 86,428 & 419.2 & 87,666 & 1.4 & 492.5 & 102,996 & 19.2 & 490.9 & 102,672 & 18.8 \\
\hline 11.5 & 188.6 & 466.9 & 88,054 & 476.1 & 89,797 & 2.0 & 562.5 & 106,094 & 20.5 & 563.0 & 106,180 & 20.6 \\
\hline 12.0 & 169.2 & 522.5 & 88,387 & 535.6 & 90,602 & 2.5 & 638.9 & 108,076 & 22.3 & 636.1 & 107,608 & 21.7 \\
\hline 12.5 & 150.9 & 580.6 & 87,621 & 597.9 & 90,246 & 3.0 & 666.4 & 100,573 & 14.8 & 666.3 & 100,555 & 14.8 \\
\hline 13.0 & 134.0 & 641.3 & 85,907 & 667.0 & 89,349 & 4.0 & 667.0 & 89,349 & 4.0 & 667.0 & 89,349 & 4.0 \\
\hline 13.5 & 118.3 & 667.0 & 78,904 & 667.0 & 78,904 & 0.0 & 667.0 & 78,904 & 0.0 & 667.0 & 78,904 & 0.0 \\
\hline \multicolumn{3}{|c|}{ AEP Total (MWh): } & 1,016 & & 1,170 & & & 1,342 & & & 1,139 & \\
\hline \multicolumn{3}{|c|}{ Var. from ART-1 (\%): } & & & 15.2 & & & 32.1 & & & 12.1 & \\
\hline
\end{tabular}

The calculated power curves for the ART-1, ART-2A (ART-1 with variable-speed operation) and ART-2B rotors are shown in Figure 32. For the ART-2A turbine, variable speed operation results in an increase of power output at low wind speeds, but at moderate-to-high wind speeds the ART-2A and ART-1 power curves converge. As a result, the annual energy for ART-2A exceeds the ART-1 by $15.2 \%$. The ART-2B power output exceeds ART-1 at all wind speeds, with a resulting AEP increase of $32.1 \%$.

Figure 33 shows a comparison of the calculated ART-1 power curve with the ART-2B blades operated at a fixed speed of $42 \mathrm{rpm}$. Near cut-in, the ART-2B rotor at fixed speed produces slightly less power than the baseline ART-1 rotor, but at moderate-to-high wind speeds the ART-2B blade significantly outperforms the ART-1. The net result is a $12.1 \%$ increase over the baseline rotor.

It should be noted that the AEP gains due to variable-speed operation have been calculated on the basis of increased rotor power. The increments in system AEP would be dependent on the relative efficiencies of the variable-speed and fixed-speed drive trains under consideration and could, in principle, be either higher or lower than the values presented herein. 


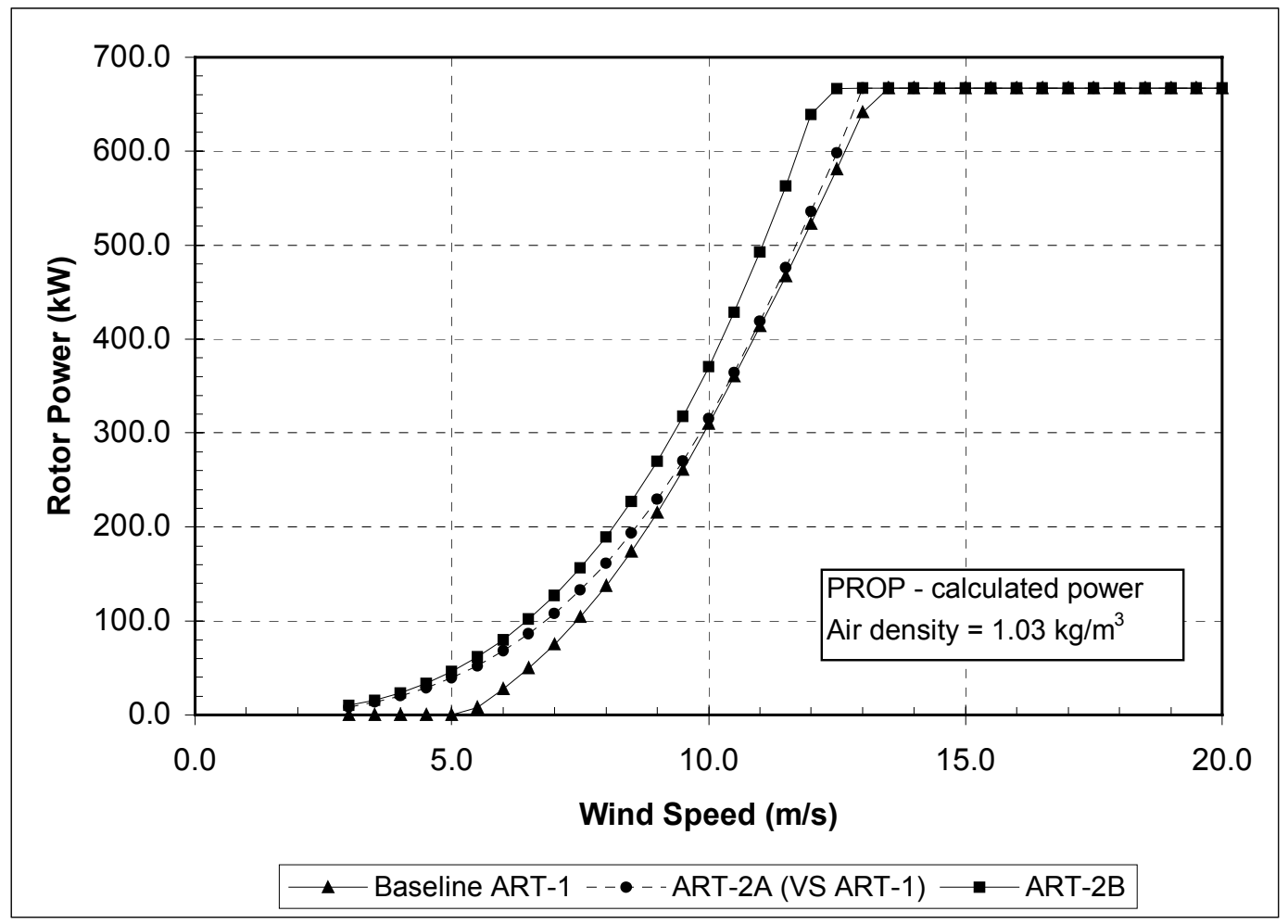

Figure 32. Calculated ART power curves

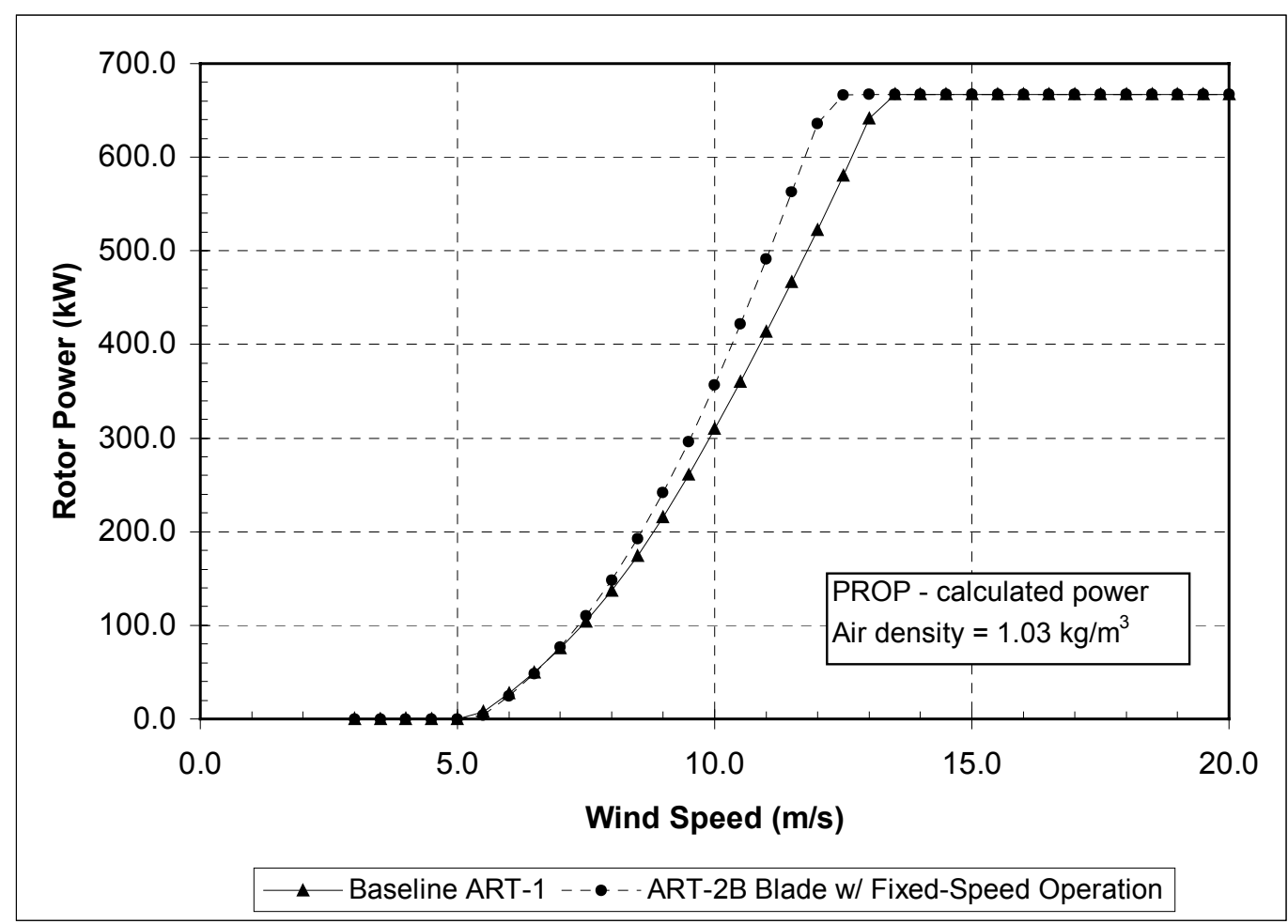

Figure 33. ART-2B rotor at fixed-speed operation 


\section{Conclusions}

In support of the ongoing research efforts of the NREL Advanced Research Program, an aerodynamic design has been performed for the ART-2B rotor blades. The ART-2B blade was designed to reflect the state-of-the-art in aerodynamic performance. As such, the aerodynamic design objectives were given first priority in this process, with structural design aspects considered as secondary.

The aerodynamic designs for the ART-2B rotor blades were performed for optimal variable-speed, variable-pitch operation with peak rotor power coefficients as high as possible. Studies were performed to investigate various airfoil families, design tip-speed ratios, and other design considerations. Specifically, the design studies included:

- An evaluation of three NREL S-series airfoil families

- S818/825/826

- $\mathrm{S} 818 / 827 / 828$

- $\quad \mathrm{S} 815 / 809 / 810$.

- For the S818/825/826 airfoil family, a sweep of design tip-speed ratios was conducted.

- For the S818/825/826 airfoil family at design TSR =8, detailed aerodynamic design aspects were considered, including an evaluation of performance losses due to imposed design details.

For each airfoil design considered, a near-optimal blade geometry was determined, with calculated annual energy production used as the primary figure of merit.

A final detailed design is presented, using the S818/825/826 airfoil family at a design TSR of 8 , and including an imposed linearly-tapering planform and a truncated twist distribution. This final design was evaluated for power performance and compared with other ART turbines. For wind speeds less than or equal to $13.5 \mathrm{~m} / \mathrm{s}$, the calculated AEP for the ART-2B rotor exceeds the baseline ART-1 turbine by $32.1 \%$.

Structural efficiency (strength, cost, and weight) have been addressed qualitatively through consideration of the resulting blade dimensions. For selected cases, the effect of design variations on operating rotor thrust and peak (50-year) blade bending loads has been evaluated. For the designs under consideration, the rotor power per unit thrust was found to be largely invariant. However, the designs showed significant variations in rotor solidity and the associated peak bending loads (as based on a dragdominated load case).

The "final" S818/825/826 rotor presented herein is the result of an aerodynamic design process with limited structural considerations. The next steps in a detailed design process would include:

- Consideration of cost of energy implications for both candidate rotor geometries and net energy capture (i.e., efficiency) for variable-speed operation

- Preliminary structural design

- selection of materials, basic internal structure, and shell design

- preliminary development of basic shell thickness distribution, calculations of weight, and stiffness

- Additional smoothing of geometry

- chord, twist, thickness, and airfoil blending along blade

- evaluation of derivatives to eliminated discontinuities

- analysis of resulting geometries for power performance, iteration as desired

- Detailed structural design, root design, lay-up schedule, ply drops, and other details. 


\section{References}

1. Tangler, J.L.; Somers, D.M. (1995). "NREL Airfoil Families for HAWTs". Presented at the American Wind Energy Association Windpower '95 Conference.

2. Eppler, R.; Somers, D.M. (1980). A Computer Program for the Design and Analysis of Low-Speed Airfoils. NASA TM-80210. National Aeronautics and Space Administration.

3. Somers, D.M. (January 1997). Design and Experimental Results for the S809 Airfoil. NREL/SR440-6918.Golden, CO: National Renewable Energy Laboratory.

4. Somers, D.M.; Tangler, J.L. (2000). "Wind Tunnel Tests for Two Airfoils for Wind Turbines Operating at High Reynolds Numbers", Presented at the AIAA Wind Energy Meeting, NREL/CP500-27891.

5. Selig, M.S.; Tangler, J.L. (1994) “A Multipoint Inverse Design Method for Horizontal Axis Wind Turbines”, Presented at the AWEA Windpower '94 Conference. NREL/CP-500-16336. Golden, Co: National Renewable Energy Laboratory.

6. International Electrotechnical Commission. (1998). Wind Turbine Generator Systems: Power Performance Measurement Techniques. International Standard 1400-12.

7. International Electrotechnical Commission. (1999). IEC 61400-1: Wind turbine generator systems - Part 1: Safety Requirements, $2^{\text {nd }}$ Edition. International Standard 1400-1.

8. Somers, D.M. (January 1999). Design and Experimental Results for the S814 Airfoil, NREL/SR440-6918. Golden, CO: National Renewable Energy Laboratory.

9. Giguere. P. (August 1999) PROPID seminar. National Wind Technology Center, Golden, CO.

10. Giguere, P.; Selig, M.S. (1996) "Desirable Airfoil Characteristics for Large Variable-Speed Horizontal Axis Wind Turbines". Presented at the AWEA Windpower '96 Conference. NREL/CP500-22297. Golden, CO: National Renewable Energy Laboratory. 


\section{Appendix A}

\section{Summary of Archived Electronic Files}


The primary electronic files used for this design study have been archived and written to a compact disc (CD) titled "ART2B Blade." This CD contains an electronic version of the present report, all spreadsheet files that were used to generate the figures contained in the report, an executable copy of the PROPID code used for the design studies, and an archive of the major input and output files. The PROPID output files all have two varying digits prior to the ".dat" extension. These digits follow the output file naming convention of PROPID, as indicated in Table A-1. Note that not all files shown in Table A-1 were written as output and/or saved for each design case (input file) run. Also note that although scientific units have been exclusively used in the body of this report, the PROPID calculations (and the output files) have used units of feet, pounds, and miles per hour, respectively, for length, force, and wind speeds. Table A-2 provides a description of the CD directory structure, file naming conventions and information contained within.

Table A-1. Naming Convention for PROPID Output Files

\begin{tabular}{|c|l|}
\hline $\begin{array}{c}\text { PROPID Output File } \\
\text { Number } \\
\text { \#\#.dat" }\end{array}$ & \multicolumn{1}{c|}{ Data Contained } \\
\hline 21 & $\begin{array}{l}\text { PROPID “dump" file containing converged blade design for run } \\
\text { (chord, twist, pitch, airfoils, design point used) }\end{array}$ \\
\hline 39 & rpm versus wind speed (mph) for variable speed operation \\
\hline 40 & $\begin{array}{l}\text { Rotor power (kW) versus wind speed (mph) for variable speed } \\
\text { operation }\end{array}$ \\
\hline 45 & Rotor power coefficient (Cp) versus tip-speed ratio \\
\hline 50 & Rotor thrust coefficient at varying TSR \\
\hline 51 & $\begin{array}{l}\text { Rotor thrust (pounds) versus wind speed (mph) variable speed } \\
\text { operation }\end{array}$ \\
\hline 95 & Local blade chord (feet) versus radius (feet) \\
\hline 99 & Local blade twist (degrees) versus radius (feet) \\
\hline
\end{tabular}


Table A-2. Archive of Blade Design Study Electronic Media (page 1 of 2)

\begin{tabular}{|c|c|c|}
\hline Sub-Directory & Filenames & Content \\
\hline (none) & ART-2B Blade Design Final.doc & Electronic version of current report \\
\hline “" & ART-2B propid blade results.xls & Spreadsheet containing PROPID design and analysis data, charts for reporting \\
\hline “6 & AEP 1.xls & Calculation of hours for Wiebull wind distribution, used for final AEP calculation \\
\hline “" & sfoils 1.xls & Spreadsheet containing profiles and aerodynamic properties of S-series airfoils \\
\hline “6 & Cl dist example.xls & Spreadsheet containing example of shifting / rotation for target $C_{L}$ distributions \\
\hline “" & propid34.exe & Executable version of PROPID code used in design studies \\
\hline aerodata & intuitive & Files containing aerodynamic properties of airfoils, to be read by PROPID \\
\hline S815_809_810 & 15_09_10_01.in & $\begin{array}{l}\text { Input file for near-optimal design of } \mathrm{S} 815 / 809 / 810 \text { blade at } \mathrm{TSR}_{\text {design }}=8 \text {, used to } \\
\text { shift } \mathrm{C}_{\mathrm{L}, 75 \% \mathrm{R}} \text { and evaluate results }\end{array}$ \\
\hline " & f590_\#\#.dat & $\begin{array}{l}\text { Output files for design of } S 815 / 809 / 810 \text { blade with } C_{L, 75 \% R}=0.65 \text {. The digits in } \\
\text { the \#\# place indicating the content of the output file as indicated on previous page }\end{array}$ \\
\hline S818_825_826 & 18_25_26_01.in & $\begin{array}{l}\text { Input file for near-optimal design of S818/825/826 blade at } \mathrm{TSR}_{\text {design }}=8 \text {, used to } \\
\text { shift } C_{L, 75 \% R} \text { and evaluate results }\end{array}$ \\
\hline 6 & 18_25_26_07.in & $\begin{array}{l}\text { Input file for near-optimal design of } S 818 / 825 / 826 \text { blade, used to rotate lift } \\
\text { distribution clockwise with respect to } C_{L, 75 \% R}=1.15 \text { and evaluate results }\end{array}$ \\
\hline “" & 18_25_26_08.in & $\begin{array}{l}\text { Input file for near-optimal design of } S 818 / 825 / 826 \text { blade, used to rotate lift } \\
\text { distribution counter-clockwise with respect to } C_{L, 75 \% R}=1.15 \text { and evaluate results }\end{array}$ \\
\hline " & f856_\#\#_\#\#.dat & 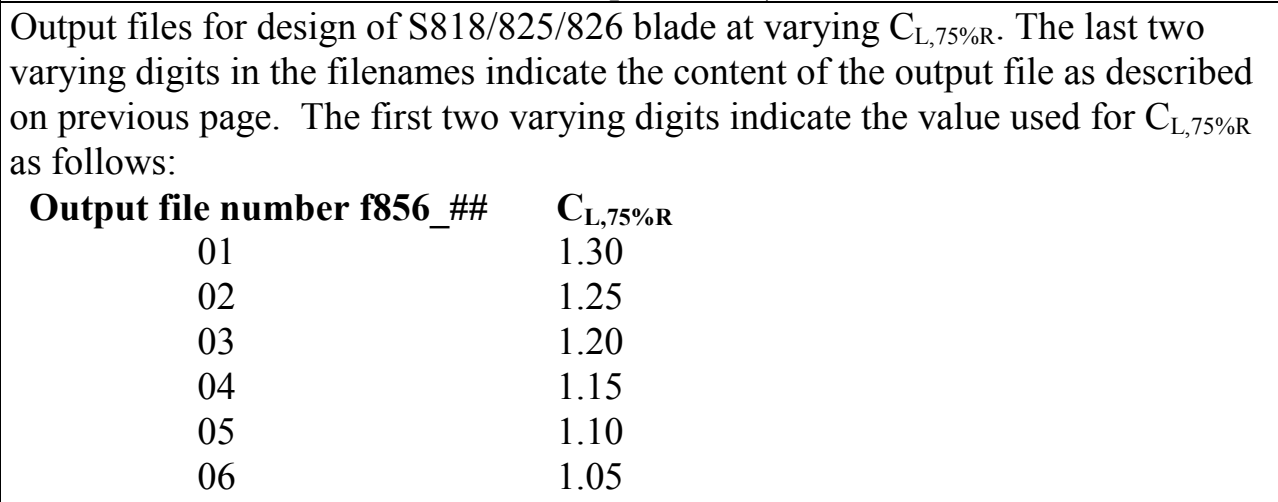 \\
\hline
\end{tabular}


Table A-2. Archive of Blade Design Study Electronic Media (page 2 of 2)

\begin{tabular}{|c|c|c|}
\hline Sub-Directory & Filenames & Content \\
\hline \multirow[t]{2}{*}{ S818_827_828 } & 18_27_28_01.in & $\begin{array}{l}\text { Input file for near-optimal design of } \mathrm{S} 818 / 827 / 828 \text { blade at } \mathrm{TSR}_{\text {design }}=8 \text {, used to } \\
\text { shift } \mathrm{C}_{\mathrm{L}, 75 \% \mathrm{R}} \text { and evaluate results }\end{array}$ \\
\hline & F878_\#\#.dat & $\begin{array}{l}\text { Output files for design of } S 818 / 827 / 828 \text { blade with } \mathrm{C}_{\mathrm{L}, 75 \% \mathrm{R}}=0.75 \text { (The digits in } \\
\text { the \#\# place indicating the content of the output file as indicated on previous } \\
\text { page.) }\end{array}$ \\
\hline \multirow[t]{2}{*}{ Smooth 818_825_826 } & \multirow[t]{2}{*}{ Smooth_856_\#\#.in } & $\begin{array}{l}\text { Input files for investigation of design details on S818/825/826 blade. Varying } \\
\text { digits in input files denote the parameters changed as follows: }\end{array}$ \\
\hline & & $\begin{array}{cl}\text { Input file number smooth_856_\#\# } & \text { Parameter Changed } \\
01 & \text { Baseline blade } \\
02 & \text { Linear planform } \\
03 & \text { Truncated twist } \\
04 & \text { Non-lifting root } \\
05 & \text { All details above } \\
06 & \text { Same, with analysis at fixed speed }\end{array}$ \\
\hline " & Smooth_856_\#\#_\#\#.dat & $\begin{array}{l}\text { Output files for investigation of design details on S } 818 / 825 / 826 \text { blade. First } \\
\text { varying digits denote the parameters under consideration as shown in the table } \\
\text { above (files only saved for } 05 \text { and } 06 \text { ). Last two varying digits denote information } \\
\text { contained in each file. }\end{array}$ \\
\hline TSR_818_825_826 & 18_25_26_TSR\#\#.in & $\begin{array}{l}\text { Input file for investigation of } S 818 / 825 / 826 \text { blades designed with } C_{L, 75 \% R}=1.15 \\
\text { and varying design TSR. Last two (varying) digits denote the } \mathrm{TSR}_{\mathrm{design}}\end{array}$ \\
\hline "6 & tsr\#\#_\#\#.dat & $\begin{array}{l}\text { Output files for above investigation of design TSR First two varying digits denote } \\
\text { the design TSR, and the last two denote the output content }\end{array}$ \\
\hline Wind Tunnel S825 & wind_tunnel_dsgn_856.in & $\begin{array}{l}\text { Input file for near-optimal design of } \mathrm{S} 818 / 825 / 826 \text { blade at } \mathrm{TSR}_{\text {design }}=8 \text {, using } \\
\text { wind tunnel measured data for the } \mathrm{S} 825 \text { airfoil and Eppler data for the } 818 \text { and } 826\end{array}$ \\
\hline “ & wind tunnel_desgn_\#\#.dat & Output files for above case, \#\# denotes data contained in file \\
\hline 6 & wind_tunnel_anal_856.in & $\begin{array}{l}\text { Input file for analysis of S818/825/826 blade where measured S825 data is used in } \\
\text { analysis, but design was completed using Eppler data for all three airfoils }\end{array}$ \\
\hline "6 & wind_tunnel_anal_\#\#.dat & Output files for above case, \#\# denotes data contained in file \\
\hline
\end{tabular}




\section{Appendix B}

\section{Example PROPID Input File for Rotor Design}




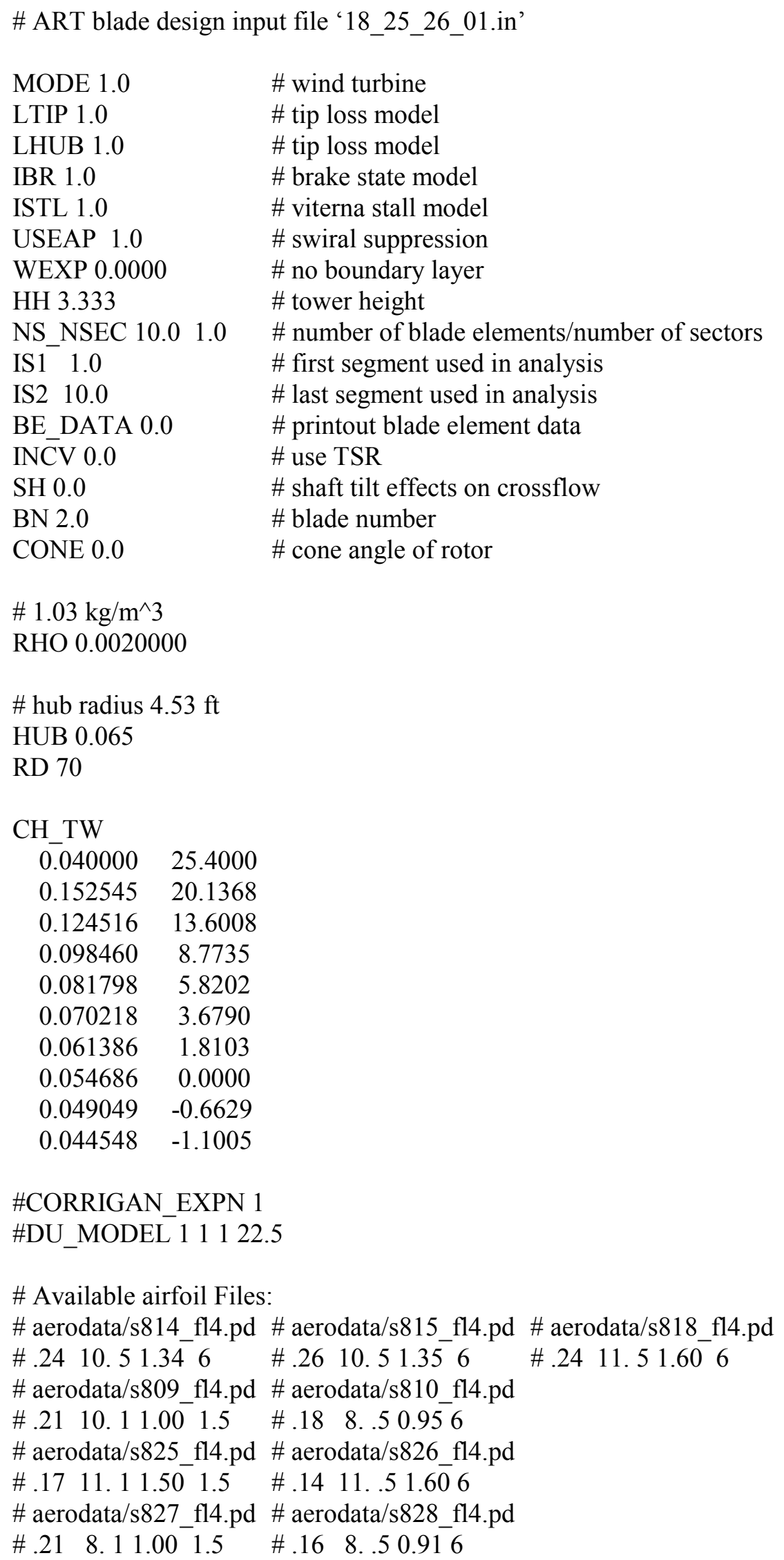




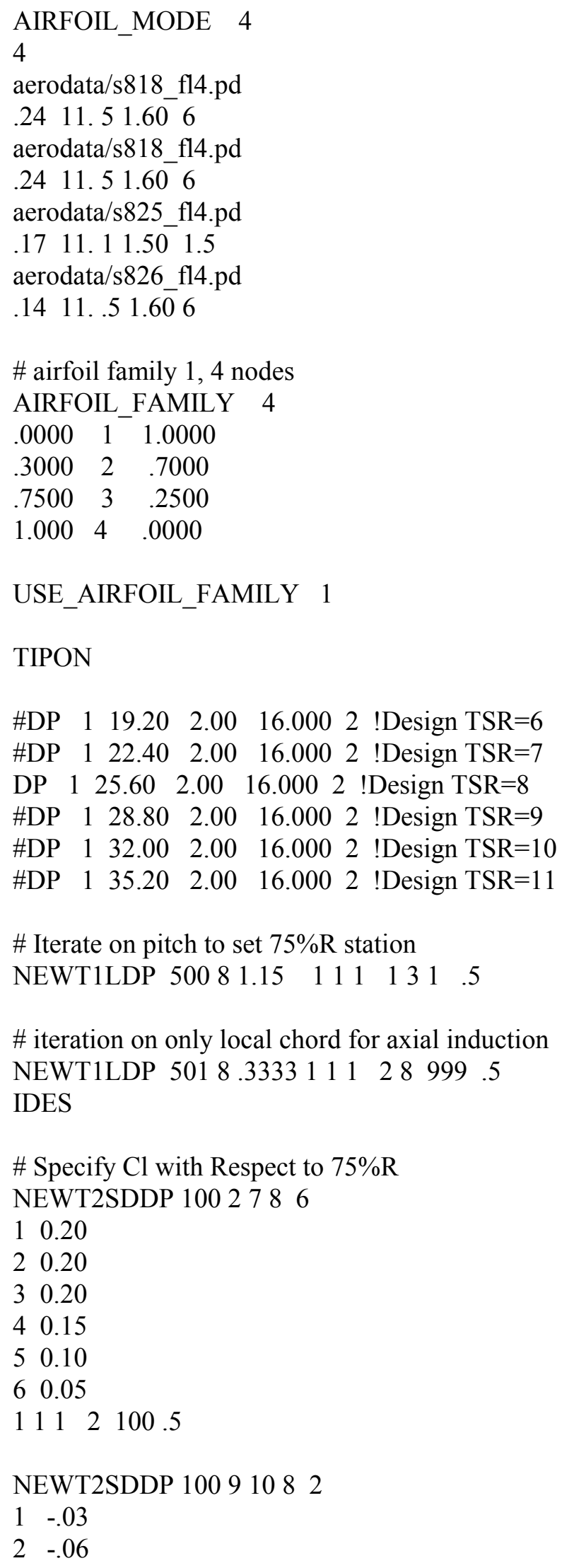

$\begin{array}{lll}2 & 0.20\end{array}$

$\begin{array}{lll}3 & 0.20\end{array}$

$\begin{array}{ll}4 & 0.15\end{array}$

$\begin{array}{ll}5 & 0.10\end{array}$

$\begin{array}{lll}6 & 0.05\end{array}$

$\begin{array}{llll}111 & 2 & 100.5\end{array}$

NEWT2SDDP 10091082

$1-.03$

$2-.06$ 
$\begin{array}{lll}111 & 2 & 100.5\end{array}$

IDES

\# Specify a with Respect to $75 \% \mathrm{R}$

NEWT2SDDP 1012786

10.00

$\begin{array}{lll}2 & 0.00\end{array}$

30.00

$\begin{array}{ll}4 & 0.00\end{array}$

$\begin{array}{ll}5 & 0.00\end{array}$

$\begin{array}{lll}6 & 0.00\end{array}$

$\begin{array}{llll}111 & 1 & 100.05\end{array}$

NEWT2SDDP 10191082

10.0

20.0

$\begin{array}{llll}111 & 1 & 100.05\end{array}$

IDES

\section{LCOL45}

VS MODE

PITCH DP 1

TSR_SWEEP 2161

WIND_SWEEP 161612

2D_SWEEP

WRITE_FILES 45

\# reset the print flags so that 45 is not written again

RPRINT

FIXPD 6671

VS MODE

PITCH DP 1

\#TSR_SWEEP 660

\#TSR SWEEP 770

TSR SWEEP 880

\#TSR_SWEEP 990

\#TSR_SWEEP 10100

\#TSR_SWEEP 11110

WIND_SWEEP $550 \quad 12$

2D_SWEEP

\# write out RPM vs WS, Pwr vs WS, and thrust vs WS

WRITE_FILES $39 \quad 40 \quad 51$

RKR_GAMMA 1.700 .892244 ! Weibull, shape factor $=1.7$

GAEP $16.7816 .78127 \quad 0.9 \quad ! 7.5 \mathrm{~m} / \mathrm{s}$ mean, $12 \mathrm{~m} / \mathrm{s}$ cutout, $90 \%$ effic.

PITCH DP 1

RPM_DP 1 
WIND_DP 1

1D SWEEP

\# write out ch(ft-ft), and tw(deg-ft)

WRITE FILES 9599

\# write out converged blade data

DUMP_PROPID 21

* 
Public reporting burden for this collection of information is estimated to average 1 hour per response, including the time for reviewing instructions, searching existing data sources,

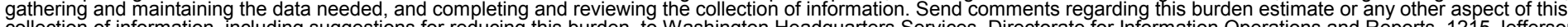
Davis Highway, Suite 1204, Arlington, VA 22202-4302, and to the Office of Management and Budget, Paperwork Reduction Project (0704-0188), Washington, DC 20503.

\begin{tabular}{|l|l|l|}
\hline 1. AGENCY USE ONLY (Leave blank) & $\begin{array}{c}\text { 2. REPORT DATE } \\
\text { August } 2000\end{array}$ & $\begin{array}{l}\text { 3. REPORT TYPE AND DATES COVERED } \\
\text { Subcontract Report }\end{array}$ \\
\hline
\end{tabular}

4. TITLE AND SUBTITLE
NREL Advanced Research Turbine (ART) Aerodynamic Design of ART-2B Rotor
Blades

NREL Advanced Research Turbine (ART) Aerodynamic Design of ART-2B Rotor

5. FUNDING NUMBERS

T: WE001510

C: VAM-8-18208-01

6. $\operatorname{AUTHOR}(\mathrm{S})$

Dayton A. Griffin

7. PERFORMING ORGANIZATION NAME(S) AND ADDRESS(ES)

8. PERFORMING ORGANIZATION REPORT NUMBER

Global Energy Concepts, LLC

9. SPONSORING/MONITORING AGENCY NAME(S) AND ADDRESS(ES)

National Renewable Energy Laboratory

1617 Cole Blvd.

Golden, CO 80401-3393

10. SPONSORING/MONITORING AGENCY REPORT NUMBER

NREL/SR-500-28473

11. SUPPLEMENTARY NOTES

NREL Technical Monitor: Alan Laxson

12a. DISTRIBUTION/AVAILABILITY STATEMENT

National Technical Information Service

12b. DISTRIBUTION CODE

U.S. Department of Commerce

5285 Port Royal Road

Springfield, VA 22161

13. ABSTRACT (Maximum 200 words)

The National Renewable Energy Laboratory (NREL) installed two Advanced Research Turbines (ART) at the National Wind Technology Center near Boulder, Colorado, to use as full-scale test beds for ongoing research efforts, including three-dimensional blade aerodynamics and the effects of various control methods on turbine loads and performance. The Westinghouse WWG-0600 was selected as a baseline configuration for the ART turbines. The first turbine, ART-1, is currently operational and has been used to collect a baseline set of performance and loads data. A second turbine, ART-2A, incorporates several major modifications and may be upgraded further to a configuration designated aRT-2B. Possible features of the ART-2B turbine include a multi-degree of freedom hum and newly designed rotor blades. Global energy concepts, L.L.C. provided engineering support to NREL in designing the components for the ART-2B turbine. This document provides a summary of work performed by GEC on the aerodynamic design of ART-2B rotor blades.

14. SUBJECT TERMS

15. NUMBER OF PAGES

wind energy, advanced research turbines, wind turbine blade aerodynamics, design

16. PRICE CODE

17. SECURITY CLASSIFICATION OF REPORT Unclassified
18. SECURITY CLASSIFICATION OF THIS PAGE Unclassified
19. SECURITY CLASSIFICATION OF ABSTRACT Unclassified
20. LIMITATION OF ABSTRACT

UL

NSN 7540-01-280-5500

Standard Form 298 (Rev. 2-89) Prescribed by ANSI Std. Z39-18 